\title{
Beyond Telecommuting: A New Paradigm for the Effect of Telecommunications on Travel
}

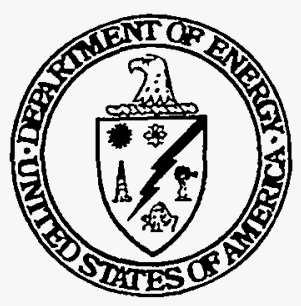

September 1994

\section{U.S. DEPARTMENT OF ENERGY Office of Energy Research Office of Scientific Computing Washington, DC 20585}




\section{DISCLAIMER}

This report was prepared as an account of work sponsored by an agency of the United States Government. Neither the United States Government nor any agency thereof, nor any of their employees, make any warranty, express or implied, or assumes any legal liability or responsibility for the accuracy, completeness, or usefulness of any information, apparatus, product, or process disclosed, or represents that its use would not infringe privately owned rights. Reference herein to any specific commercial product, process, or service by trade name, trademark, manufacturer, or otherwise does not necessarily constitute or imply its endorsement, recommendation, or favoring by the United States Government or any agency thereof. The views and opinions of authors expressed herein do not necessarily state or reflect those of the United States Government or any agency thereof. 


\section{DISCLAIMER}

Portions of this document may be illegible in electronic image products. Images are produced from the best available original document. 


\title{
Beyond Telecommuting: A New Paradigm For the Effect of Telecommunications on Travel
}

\author{
John S. Niles
}

Global Telematics 

$\ldots$ 


\section{FOREWORD}

"One little realized impact of telecommunications on settlements has been to increase mobility greatly."

Jean Gottmann (1983)

"The substitution of telecommunications for travel is of minor importance because, even if it happens, it will be offset by the human desire to exercise mobility."

Ilan Salomon (1985)

"Had the telephone not been invented, the entire economy would be drastically different than it is today, and much of the transportation we are asked to envision would simply never have been generated."

Patricia Mokhtarian (1990)

"Very clearly, most information in the economy is embodied in material goods and in people, both of which can only be moved around on 'real' highways."

Mark Hepworth and Ken Ducatel (1992)

"All information technologies ... have expanded our ability to understand the world around us. But these technologies have also created distinctive patterns of distortion and have thus changed the way our minds receive, remember, and understand the world."

Al Gore (1992) 
. 


\section{EXECUTIVE SUMMARY}

Conventional wisdom holds that telecommunications is a natural substitute for transportation. Digital traffic on the fiber optic and wireless networks of the National Information Infrastructure (NII) can replace vehicle traffic on the streets and highways of the national transportation infrastructure. For example, telephone calls and videoconferencing can replace travel to meetings, and electronic-mail transmission of documents substitutes for postal delivery.

A leading example of travel substitution is telecommuting, which means using telecommunications to replace commuting between home and work. Telecommuting accounts for 7.6 million U.S. workers as of early 1993, up 15\% from 6.6 million in 1992. The U.S. Department of Transportation (USDOT) estimates that telecommuting by the year 2002 will reduce the annual total vehicle miles traveled (VMT) by just $1 \%$ below the level expected to be seen if there were no telecommuting. A follow-up study by the U.S. Department of Energy (USDOE) calculates that the reduction in mileage from telecommuting by 2002 is likely to be even less because of (1) commuters living further from work, and (2) other travelers taking the road space vacated by telecommuters. However, telecommuting is not the only way that telecommunications can act as a substitute for transportation. Other examples of telecommunications substituting for travel include:

- Sporting, entertainment, political, religious, and other live events broadcast to a dispersed audience, rather than requiring that the audience travel to the event.

- Observations from scattered sites collected via remote sensing and transmitted to a central point, rather than sending a human observer.

- People initiating travel to a needed destination only after using telecommunications to find that the trip will be necessary or productive.

- Service transactions carried out by electronic means that require less travel. Such transactions include payroll direct deposits instead of taking paychecks to the bank, and electronic income tax filings.

- Dedicated telecommunications applications that increase vehicle loads and save trips by consolidating freight loads and expanding traveler ridesharing.

- Interactive educational, shopping, and entertainment services, and more television channels with movies on demand, that may convince more consumers to stay home rather than traveling to the mall or theater.

\section{Beyond Telecommuting}

Telecommuting is only a small part of a large and expanding set of processes that govern how the National Information Infrastructure makes an impact on transportation. Present and future NII applications in health care, public education, government, and manufacturing offer opportunities for general societal benefits that are more significant than travel savings. 
- For example, an electronically-networked system of specialized national medical centers, regional hospitals, and smaller rural and neighborhood clinics can deliver appropriate levels of care (open-heart surgery, appendectomies, or immunizations) and personal attention at the appropriate location.

- In public education, local teaching and learning can be enhanced by telecommunications providing access to people and information in the next county or on the other side of the world. Telecommunications is also a key resource for extending learning environments into homes, offices, libraries, and community centers.

- Other government services from field inspections to forms processing are amenable to revision through applications of voice, data, and video telecommunications. These applications can be designed to improve quality and access, and reduce or avoid costs.

- Modern manufacturing processes increase the responsiveness of production to the immediate needs of purchasers. Raw materials and finished products are put into computer-coordinated shipments monitored by NII-enabled location tracking systems, reducing dependence on large inventories in warehouses and storerooms.

\section{From Substitution to Stimulation}

Because of the popularity and effectiveness of telecommuting as a work practice, telecommunications is becoming embedded primarily as a transportation substitute in the thought processes of transportation researchers and government planners. But a closer examination of the U.S. experience over the last few decades does not reveal a natural evolution of telecommunications substituting for travel. Both grow together, one feeding the other. Travel per household is rising, urban congestion is increasing, and latent demand for travel emerges clearly when new road capacity is opened up, even as the NII is expanding. This report provides additional, cautionary perspectives on the idea that telecommunications is a force for reducing the need to travel. As telecommunications volumes build independently of direct substitution for transportation, an opposite effect occurs, namely, travel stimulation. A number of distinct stimulation effects can be identified:

- Telecommunications causes economic growth, productivity improvement, and income growth at the individual, organizational, and societal level. More money means more travel.

- As the economy grows, the use of telecommunications expands the number and geographic scope of economic and social relationships in which people and organizations engage.

- Telecommunications permits geographic decentralization of residential settlement, and of organizational activity locations. Decentralization leads to higher travel consumption, because trip origins and destinations tend to be farther apart.

- Telecommunications enables rapid response systems that dispatch customized vehicle trips to meet personal and organizational needs. Examples of this are just-in-time logistics, home delivery of fast food, overnight package delivery, and temporary employment services. 
- New telecommunications functionality resulting from digital switching and fiber optics supports population growth and a wider span of economic activity in rural communities, leading to growth in travel.

- Telecommunications makes travel time more productive and more feasible for travelers; use of wireless mobile phones while traveling is the leading example.

- Telecommunications makes the transportation system work more effectively and efficiently. Examples of this are air traffic control, computerized airline reservation systems, and Intelligent Vehicle Highway Systems (IVHS).

\section{Effect of Improvements in the National Information Infrastructure}

The deployment of interactive, more functional, higher bandwidth communications into homes and rural areas will allow more telecommuting and other travel substitution practices. But at the same time a better telecommunications infrastructure will probably reinforce the dynamics that make telecommunications a travel stimulator as well. More powerful telecommunications will feed all of the ways listed above in which telecommunications expands the motivations to travel.

Other benefits of the NII are more important to the nation than travel savings: support of health care reform, efficient government, better education for our children, and rising manufacturing competitiveness. Telecommuting, in particular, is a very useful practice for stronger reasons than travel savings. It provides a work environment where workers can be more productive and closer to their families at the same time.

Whether the widespread deployment of more powerful, higher bandwidth telecommunications will lead advanced economies to show growing telecommunications usage per unit of economic output relative to transportation intensity depends significantly on changes in the price-performance of transportation. In the United States, for example, the cost of driving automobiles, based on fuel prices, vehicle prices, and taxation, is declining. This cost trend tends to work against trip substitution even while continual improvements in the price-performance of the NII supports substitution. An analytical, econometric determination of how telecommunications and transportation have been substituting for each other or complementing each other as economic inputs during the past few decades of NII expansion is an important follow-up research need coming out of this study.

\section{A New Policy Paradigm}

A dominant public policy paradigm today is that telecommunications yields telecommuting which yields travel savings. The wide impact of telecommunications on the economy and society in contrast to the limited travel impact of telecommuting suggests that a better paradigm is now needed: Telecommunications yields some travel savings through telecommuting and other travel substitution effects, but also sets up a countervailing mechanism of travel stimulation that needs to be more widely recognized and better understood. 
Governments must learn to coordinate public policy on telecommunications, transportation, land use, and capital facilities investment in light of the interactions described here. The overall challenge is to allocate resources and attention reasonably across the entire spectrum of public facility systems that provide support for the transactions and relationships comprising economic and social life. Such systems include the cables, circuits, services, and computers of the National Information Infrastructure; the roads and airports of the transportation system; and physical locations like schools, libraries, clinics, and meeting halls where people interact directly with other people.

\section{Recommendations for Government Policy}

A more explicit and complete inclusion of telecommunications in planning processes for improving the overall transportation system is a government responsibility deserving higher visibility at the state and metropolitan-area level and the encouragement of USDOE. Telecommuting and other telecommunications applications cut across both the supply and the demand sides of transportation, and are part of both the problem and the solution of state and metropolitan regions meeting the air quality and mobility goals mandated by the Federal Clean Air Act Amendments and the Intermodal Surface Transportation Efficiency Act.

Consideration of telecommunications would fit well into a least cost, integrated resource planning (IRP) framework that incorporates travel substitution, stimulation, and system management. IRP transfers ideas and methods that are now successfully used in electric energy planning to the transportation arena.

Also, government policy could focus on promoting and ensuring telecommunications-based alternatives to travel for the inevitable future periods when travel becomes difficult or expensive due to disruptions from special events, weather, disasters; or oil supply interruptions.

Although government policy intervention to accelerate the deployment of higher bandwidth and other more powerful telecommunications capabilities cannot be justified by the potential for travel savings alone, there are many other government roles in developing NII technology and applications that make productive use of tax dollars:

- Development and deployment of government processes that use the evolving NII to deliver more service for less money. Accessing government records from home and library computers is an example.

- Support of NII improvement in disadvantaged geographic areas and for socially-important applications that the market leaves behind despite the economic cost to society at large.

- Legislative and rule-making action to eliminate barriers to the deployment of NII-enabled services for health care, education, and government services generally.

In short, government leaders must take their vision for transportation changes in the information age beyond telecommuting to a much larger set of NII applications that comprehensively affect the movement and location patterns for both organizations and individuals. Basing public policy on a more complete understanding of the new information technologies and their patterns of use will 
reduce the costs and increase the benefits to our society and economy from the parallel infrastructures of transportation and information. 
, 


\section{CONTENTS}

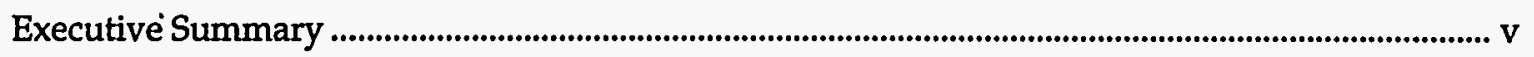

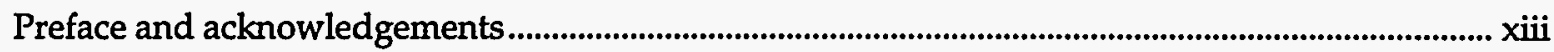

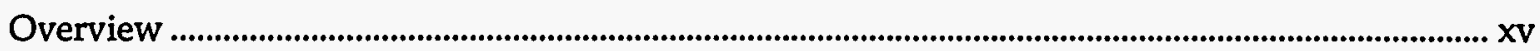

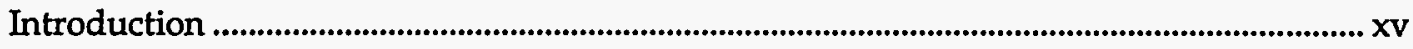

Beyond Telecommuting .............................................................................................................................. XV

Telecommunications as a Travel Substitute...................................................................................... xvii

From Substitution to Stimulation ............................................................................................................ xviii

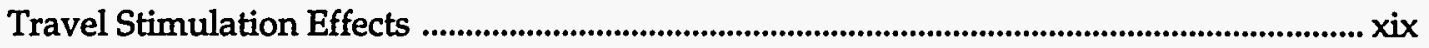

Telecommunications-Transportation Interaction Model ............................................................. xx

Effect of Improvements in the National Information Infrastructure..........................................xxi

The New Paradigm .................................................................................................................................................... xxii

Recommendations for Government Policy ...................................................................................... xxiii

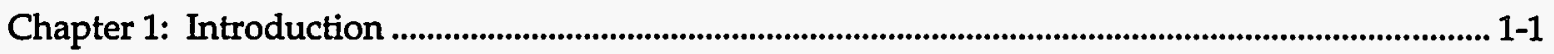

Beyond Telecommuting ............................................................................................................................ 1-3

From Telecommunications to Telematics......................................................................................... 1-5

Four Telephenomena Affecting Travel............................................................................................... 1-7

Goals of This Study ................................................................................................................................ 1-11

Chapter 2: Perspectives on Telecommunications and Transportation ................................................ 2-1

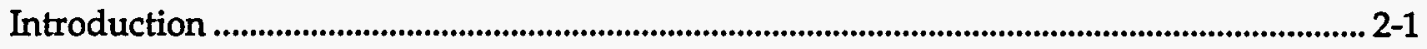

Comparing Telecommunications and Transportation ................................................................. 2-3

Substitution of Telecommunications for Transport ........................................................................ 2-5

Is Overall Travel Substitution Occurring?............................................................................................... 2-7

Model of Interactions Between Telecommunications and Transport ...................................... 2-11

Physical Proximity .......................................................................................................................................... 2-14

Expansion of Relationships ................................................................................................................ 2-16

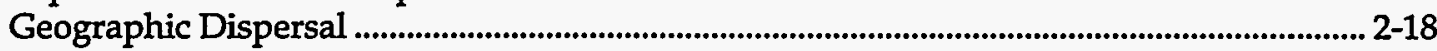

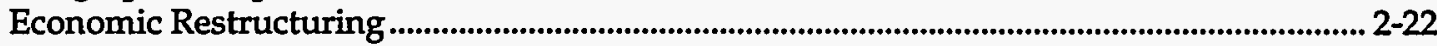

Telecommunications as a Force for Improving Transport ........................................................... 2-25

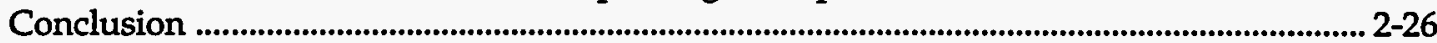

Chapter 3: Policy Analysis ............................................................................................................................. 3-1

Telecommunications Infrastructure Policy ....................................................................... 3-1

Cost of Transportation ................................................................................................................................ 3-4

How to Increase Telecommunications Substitution for Travel................................................... 3-6

Telecommunications Applications Beyond Telecommuting ..................................................... 3-10

Conclusion .................................................................................................................................................. 3-18

Chapter 4: Recommendations........................................................................................................................ 4-1

Research on Telecommunications-Transportation Interactions................................................ 4-1

Integrated Resource Planning Demonstrations................................................................................ 4-1

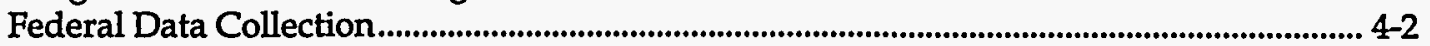

Federal Support of Research and Development......................................................................4-3

Robustness of Telecommunications ........................................................................................................ 4-3

Telecommunications Access to Service ................................................................................ 4-3 
Chapter 4, continued

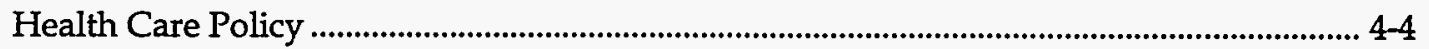

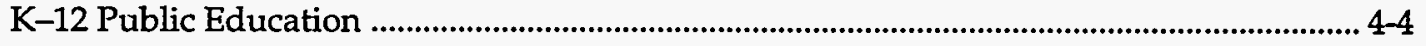

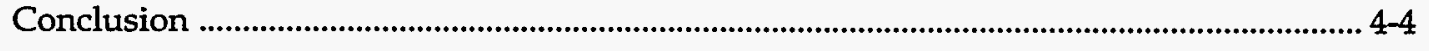

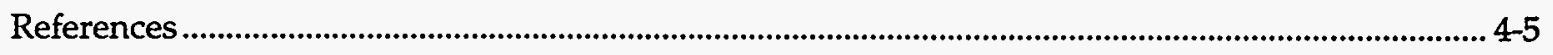




\section{PREFACE AND ACKNOWLEDGEMENTS}

The study reported in this document has been carried out by Global Telematics for the United States Department of Energy (USDOE) and the Lawrence Berkeley Laboratory (LBL). It was conducted in support of the development of the National Information Infrastructure (NII). A Federal document, The National Information Infrastructure: Agenda for Action (Information Infrastructure Task Force, 1993), describes the NII as "a seamless web of communications networks, computers, databases, and consumer electronics that will put vast amounts of information at users' fingertips." The Agenda implies that geographic distance to places formerly visited-schools, shopping centers, offices, libraries, cultural centers, and cinemas-will matter less when the NII is available for daily use. Many journeys that people make via modes of transportation, goes the argument, can be replaced by communication and information flows through the network. This implication in turn opens up questions and issues about the level of demand for transportation services as the NII develops. Will more use of telecommunications in personal and work life mean that people take fewer or shorter trips in transportation vehicles?

The future of transportation demand is of interest to the Department of Energy because a growing percentage of the nation's energy is consumed in the transportation sector, mostly by cars and trucks. In 1990, transportation accounted for $27 \%$ of total U.S. energy consumption (Exhibit P-1), almost three quarters of it going to highway uses. The share of petroleum consumed by transportation is also on the rise, having reached 65\% in 1991. Petroleum continues to be the dominant transportation fuel; natural gas, electricity, and other special fuels contribute very little today. A growing share of gasoline, approximately $50 \%$ now, is refined from oil imported into the U.S. from overseas.

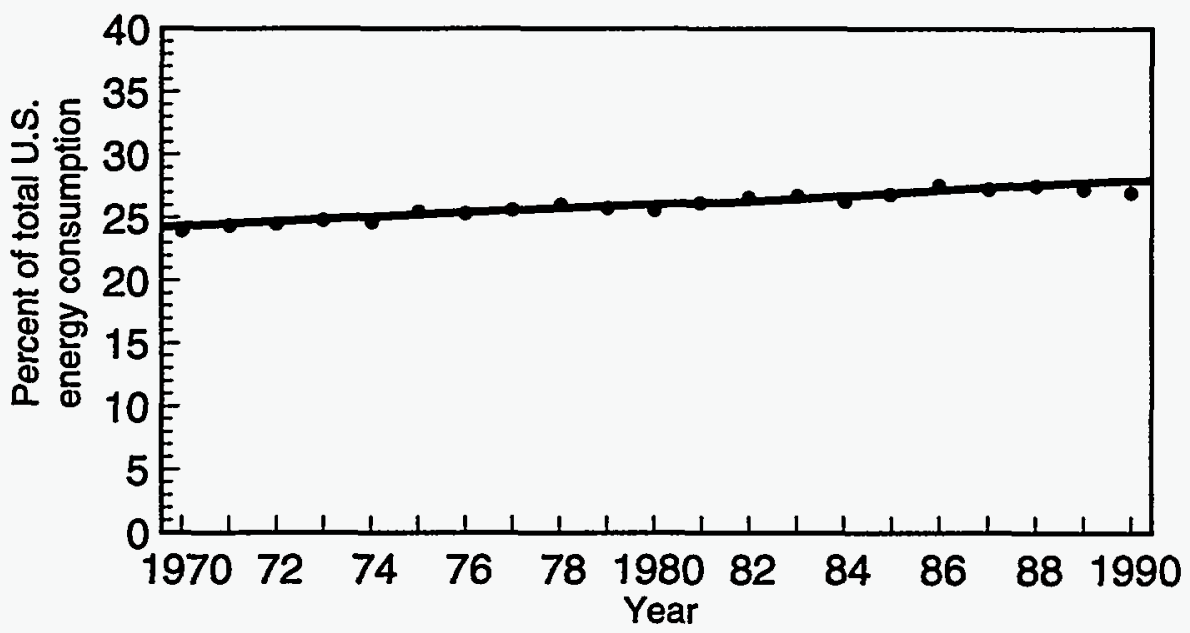

Ex P-1: A growing percentage of U.S. energy consumption goes to transportation. (Data source: U.S. Department of Energy.) 
This report is intended to contribute to an increased awareness of why transportation volumes are likely to continue growing even as telecommunications usage and associated economic and social benefits grow because of an expanding National Information Infrastructure.

This report is derived from an earlier study report by Global Telematics with the same title, dated August 21, 1993. That draft was part of the background research for a separate Department of Energy report on telecommuting to the U.S. Congress, titled Energy, Emissions, and Social Consequences of Telecommuting (USDOE, 1993).

The lead author of this manuscript is John Niles of Global Telematics. Other contributors managed by this firm are Dick Nelson, Transportation and Energy Analysis; Bill Gruber, Research \& Planning, Inc.; Tom Lehman, Tom Lehman \& Associates; Andy Dunau, Dunau Associates; Ed Parker, Parker Telecommunications; Monica Babine, Productivity Enhancement Consulting; and Mark Plackett, Telecommuting Products \& Services.

Substantial contributions to earlier drafts of this manuscript were also made by Ed Hillsman, Amy Wolfe, and Carl Petrich of Oak Ridge National Laboratory and by Robert Cowell of the University of Tennessee.

Global Telematics received helpful reactions to review drafts of this report from John Cavallini, Bob Aiken, Lew Fulton, and Dick Holt, USDOE; Stewart Loken and Ruth Steiner, Lawrence Berkeley Laboratory; Patricia Mokhtarian, University of California at Davis; Paul Toliver, Seattle Metro Transit; Karen Sy, Information Resource Management Associates; Ed Risse and Linda Risse, Synergy/Planning, Inc.; George Beard, State of Oregon; Frank Dillow, Nancy Williams, and Chris Jones, GTE; Mike Fitzgerald, State of Washington; Dale Sparks; Jack Collins, Northwest Small Cities Services; Julia Marsh, New Telecommunications Quarterly; Don Dillman, Washington State University; Pat Beaton, New Jersey Institute of Technology; Susan Hadden, University of Texas at Austin; Jane Fraser, Ohio State University; Joanne Pratt, Joanne H. Pratt Associates; Richard Harkness; Cynthia Fondriest, Strategic Transportation Initiatives, Inc.; and Jean Hanson and Karen Palmer, Resources for the Future.

The authors appreciate assistance in obtaining data from Lynda Trinh, Federal Highway Administration; Dongho Chang, Washington State Department of Transportation; Neil Kilgren, Puget Sound Regional Council; Stephen Roach, Morgan Stanley \& Co.; Stacy Davis, Oak Ridge National Laboratory; David Beal, Puget Sound Regional Transit Project; Chris Rau, US WEST Communications; Jerry Schneider, University of Washington; Rachel Parker, DRI/McGraw-Hill; Barbara Eversole and Patricia Harrington, Volpe National Transportation Systems Center; Michael Bagley, University of California, Davis; and Industry Analysis Division, Federal Communications Commission.

The contributions of all these people and others we may have omitted in error were interpreted and integrated by Global Telematics, which takes full and complete responsibility for the findings, conclusions, and recommendations presented in this report. Beyond Telecommuting, therefore, is the work of an independent private firm and does not represent a policy or position of any university, federal laboratory, or government agency. 


\section{OVERVIEW}

\section{Introduction}

Conventional wisdom about social and economic behavior holds that the use of telecommunications is a natural substitute for transportation. For example, telephone calls can replace travel to meetings, and facsimile or electronic-mail transmission of documents substitutes for courier or postal delivery. The moving of information can replace the moving of people and goods. Vehicle traffic on the national transportation infrastructure can be replaced by digital traffic on what is now called the National Information Infrastructure (NII).

A leading example is telecommuting. This means using telecommunications to replace commuting between home and work. Telecommuting is an optional way of expanding employees' work locations in those circumstances where it yields both improved organizational performance and employee satisfaction. Telecommuting accounts for 7.6 million U.S. workers as of early 1993, up 15\% from the 6.6 million counted in 1992 . The growth of telecommuting has been strong for the past five years. No one has identified any reasons to suggest that this growth will abate in the foreseeable future.

The U.S. Department of Transportation (USDOT) estimates that telecommuting by the year 2002 will reduce the annual total vehicle miles traveled (VMT) by $0.7-1.4 \%$ below the level expected to be seen if there were no telecommuting. A follow-up study by the U.S. Department of Energy (USDOE) found reasons why the reduction in mileage from telecommuting is likely to be even less. Nevertheless, the USDOT forecast of the travel reduction from telecommuting implies a total ongoing savings after ten years that is less than the $1.8 \%$ average annual growth in driving forecast by USDOE. This relatively small impact is explained by these factors: telecommuters are a minority of workers; telecommuting is usually a part-time practice that does not occur on the majority of work days; telecommuting is normally a temporary practice that depends on personal and employer circumstances; and commuting is a minority and decreasing share of the many purposes of surface travel even during peak rush hour periods.

\section{Beyond Telecommuting}

Telecommuting is an appealing and productive work practice that managers in both the private and public sectors are exploring and implementing. Telecommuting has organizational and personal benefits that are so positive that the travel savings that occur are frosting on an already tasty cake. That the travel savings are small when measured against the whole transportation picture in a modern economy does not mean that telecommuting is unworthy of pursuit. On the contrary, telecommuting works so well for many organizations that it would be important to implement it even if the result were increased employee commuting mileage. Still, telecommuting is only a small part of a large and 
expanding set of teleprocesses that govern how the National Information Infrastructure makes an impact on transportation.

Teleprocesses are all of the new work techniques and arrangements of organizations and individuals that voice, data, and video telecommunications allow. Such processes include telework, which affects the location of workers in ways that may go beyond telecommuting. As Exhibit O-1 illustrates, telecommuting is just a fraction of telework. Teleprocesses also include teleservices, which affect the locations of customers of both product and service organizations.

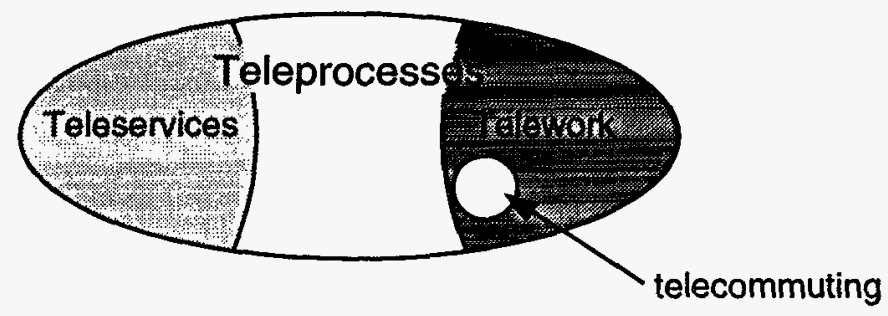

Ex O-1: Types of teleprocesses. (Source: Global Telematics.)

Telework and teleservices encompass present and future applications of the NII in the manufacturing, health care, $\mathrm{K}-12$ education, and government sectors of the economy. The opportunities for general societal benefits in each of these sectors, as well as in other sectors by extension and generalization, are more significant than travel savings.

For example, an electronically networked system of specialized national medical centers, regional hospitals, and smaller rural and neighborhood clinics can deliver appropriate levels of care (open-heart surgery, appendectomies, or immunizations) and personal attention at the appropriate location. In each place, appropriately trained medical professionals are all teleworkers. They are supported by teleprocess access to patient medical histories and by teleservices that expand local medical know-how on symptoms, treatments, and outcomes.

For public education, the tradition of widely dispersed community schools and face-to-face interaction for socialization and learning will continue, but local teaching and learning can be enhanced by teleservices providing access to people and information in the next county or on the other side of the world. Teleservices are also key resources for extending learning environments into homes, offices, libraries, and community centers.

Other government services and processes, from field inspections to forms processing, are amenable to revision through applications of voice, data, and video telecommunications. These applications can be designed to improve quality and access and can reduce or avoid costs. Sometimes agencies can use information technology to deliver information-based services, such as access to filed records, in a matter of minutes instead of hours or days and by telephone rather than in person. As other examples, remote air quality monitors and utility meters can be queried by phone, geographic databases can be checked from the field, reports can be written and transmitted to computer files from the field, and surveillance of unstaffed facilities can be maintained from miles away via remote video. 
Modern manufacturing teleprocesses increase the responsiveness of production to the immediate needs of purchasers by putting more raw materials and finished products into computer-coordinated shipments with locationtracking systems, rather than depending on large inventories in warehouses and storerooms. The agile, just-in-time methods of manufacturing are beginning to be adopted in the service sectors of the economy as well.

Improving the availability and performance of telecommunications leads to gains in organizational performance and overall economic development. These gains from enhancing the NII do not necessarily lead to simultaneous reductions in travel.

\section{Telecommunications as a Travel Substitute}

The travel substitution characteristics of telecommunications continue to be acclaimed. Some policy mavens declare that telecommunications can be thought of as "information transportation." Instead of moving people and paper in vehicles riding on heavy, costly infrastructure, the information in people's heads, desks, briefcases, and computer files is transmitted at the speed of light through cables and the air. Indeed, telecommuting is not the only way that telecommunications can act as a substitute for transportation. Other examples beyond telecommuting include the following:

- Telecommunications allows sporting, entertainment, political, religious, and other events to be broadcast to a dispersed audience instead of requiring that the audience travel to the event in order to see and hear it.

- Telecommunications enables observations from scattered sites to be collected and transmitted to a central point via remote sensing rather than by a human observer. One example is gas, electric, and water meters' being monitored by data telecommunications rather than by a meter reader who visits the premises.

- The NII enables people to initiate travel to a needed destination only after using telecommunications to find that the trip will be necessary or productive. Examples include phoning for the estimated time of arrival of a plane or train before going to meet an arriving passenger, being informed by an organizational superior that attendance at a meeting is not required, and checking with a store to see if an item is in stock before driving in Saturday traffic to the mall.

- Telecommunications allows consumers to make purchases by telephone or on-line catalog instead of traveling to store locations. Besides reducing travel requirements for shoppers, purchased items bypass so-called middlemen in the transportation-intensive process of wholesale and retail distribution and move more directly to end-user locations.

- The NII allows service transactions and events to be carried out in ways that require no travel or less travel. Such transactions include use of payroll direct deposits instead of taking paychecks to the bank, filing income tax electronically rather than mailing tax returns, and going to neighborhood electronic kiosks rather than traveling downtown.

- Telecommunications is a basic technology for expanding the opportunities in both personal travel and goods movement to combine trips. Two people can call each other to arrange to share rides in one vehicle rather than drive separately to a meeting. Voice and data 
communications in the freight industry allows coordination of shipments and higher vehicle load factors.

- The NII can potentially lead to some household activity patterns that consume lower levels of transportation than the alternatives. In other words, interactive computer services and greater numbers of television channels in homes may make staying home in the evening more attractive than going out.

Telecommunications as a transportation substitute is becoming embedded in the thinking of transportation researchers and government planners. Many erroneously use the words "telecommunications" and "telecommuting" interchangeably. Specialists restrict the word "telecommuting" to mean those employees and employee-like contract workers who do not commute between home and an office on some of their work days. The term has been expanded by journalists and politicians, however, to refer to any work-related practice involving telecommunications that seemingly cuts down on travel, such as operating a home-based business, receiving classroom instruction by videoconferencing, or sending medical $x$-rays to a clinic across town by wire rather than by envelope and messenger.

This report provides additional, cautionary perspectives on the idea that telecommunications is exclusively a force for reducing the need to travel. We explore how applications of telecommunications can act as a trip substitute and simultaneously as a travel stimulant.

\section{From Substitution to Stimulation}

Telecommunications substitution for transportation that works well typically evolves into a growth in telecommunications volume that explodes beyond what transportation is capable of providing. Faxing may begin as a substitute for use of couriers, postal mail, and overnight express, but then fax volumes build beyond what these physical delivery mechanisms could ever handle. As fax becomes less expensive per page, its usage diffuses throughout society and becomes universal. Substitution of fax for document transport is no longer an operative concept, and fax usage is largely uncoupled from physical document transportation. Fax communications by then has a momentum of its own. Similarly, the vast majority of voice telephone calls can no longer be construed as substitutes for travel, nor can ten million people watching a soccer game on television translate into a reduction of ten million person-trips to the stadium.

Furthermore, as telecommunications volumes build independently of direct substitution for transportation, there begins to be an opposite effect, namely, travel stimulation. The expanding millions watching soccer on TV provide a growing pool of people who begin to consider going to the stadium occasionally. Intensive telephone, video, and fax interchanges between people who barely know each other creates desire for follow-up face-to-face meetings. A number of distinct stimulation effects can be identified. 
Our research has brought out the following list of travel stimulation mechanisms of telecommunications:

- The NII causes economic growth, productivity improvement, and income growth at the individual, organizational, and societal levels. Extensive databases and powerful computer-based econometric techniques have recently allowed this causation to begin to be empirically demonstrated. More money means more travel.

- As the economy grows, the NII expands the number and geographic scope of economic and social relationships in which people and organizations engage. Electronic mail and toll-free telephone numbers are examples of relationship-expanding communications technologies that generate travel in addition to telecommunications volume.

- Telecommunications makes people aware of additional general audience events and opportunities that are reached through travel, such as political rallies, professional conferences, entertainment events, and shopping opportunities.

- Telecommunications permits geographic decentralization of residential settlement and of organizational activity locations. Decentralization leads to higher travel consumption, because trip origins and destinations tend to be farther apart.

- The NII speeds up the pace of economic activity, as futurist Alvin Toffler writes in his book Powershift. He describes how wealthier nations simply operate at higher speeds than less developed countries. The same idea is expressed by business consultants in the phrase "time-based competition." The acceleration of commerce tends to generate customized, single-purpose trips that leave immediately and go by single-occupancy vehicles and small trucks.

- Telecommunications enables rapid response systems that dispatch customized vehicles to meet personal and organizational needs. Several examples of this are just-in-time logistics, home delivery of fast food, overnight package delivery, and temporary employment services.

- Telecommunications enables a wide variety of new last-minute information flows that generate personal travel through attractive invitations and compulsory orders to attend.

- New telecommunications functionality resulting from digital switching and fiber optics supports the urbanization of rural communities together with associated growth in economic activity. This pattern typically causes more local automobile traffic and a flow of visitors using transportation from distant locations.

- Telecommunications makes travel time more productive and more feasible for travelers; use of wireless mobile phones while traveling is the leading example.

- The NII makes the transportation system work more effectively and efficiently. Examples of this are air traffic control, computerized airline reservation systems, and Intelligent Vehicle Highway Systems (IVHS, also called smart highways). 


\section{Telecommunications-Transportation Interaction Model}

Based on the two lists just presented, what we are seeing in telecommunications, therefore, are trip substitution opportunities arising simultaneously with travel demand growth.

The figure below is a graphic that illustrates our model of the interaction effects between transportation and telecommunications in any country. The graphic is a mathematical construction of plausible economic effects unrelated to any specific empirical data. It is intended to illustrate generic structural relationships. This graphic is derived from a similar one shown by researcher Ilan Salomon.

The assumption made here is that transactions are a common metric for measuring both telecommunications and transportation. Exhibit O-2 shows overall transaction volumes mapped as annual quantities in the vertical bars. The bars are divided into four sections, the lower two of which are travel transactions. The upper two sections in each bar are telecommunications transactions.

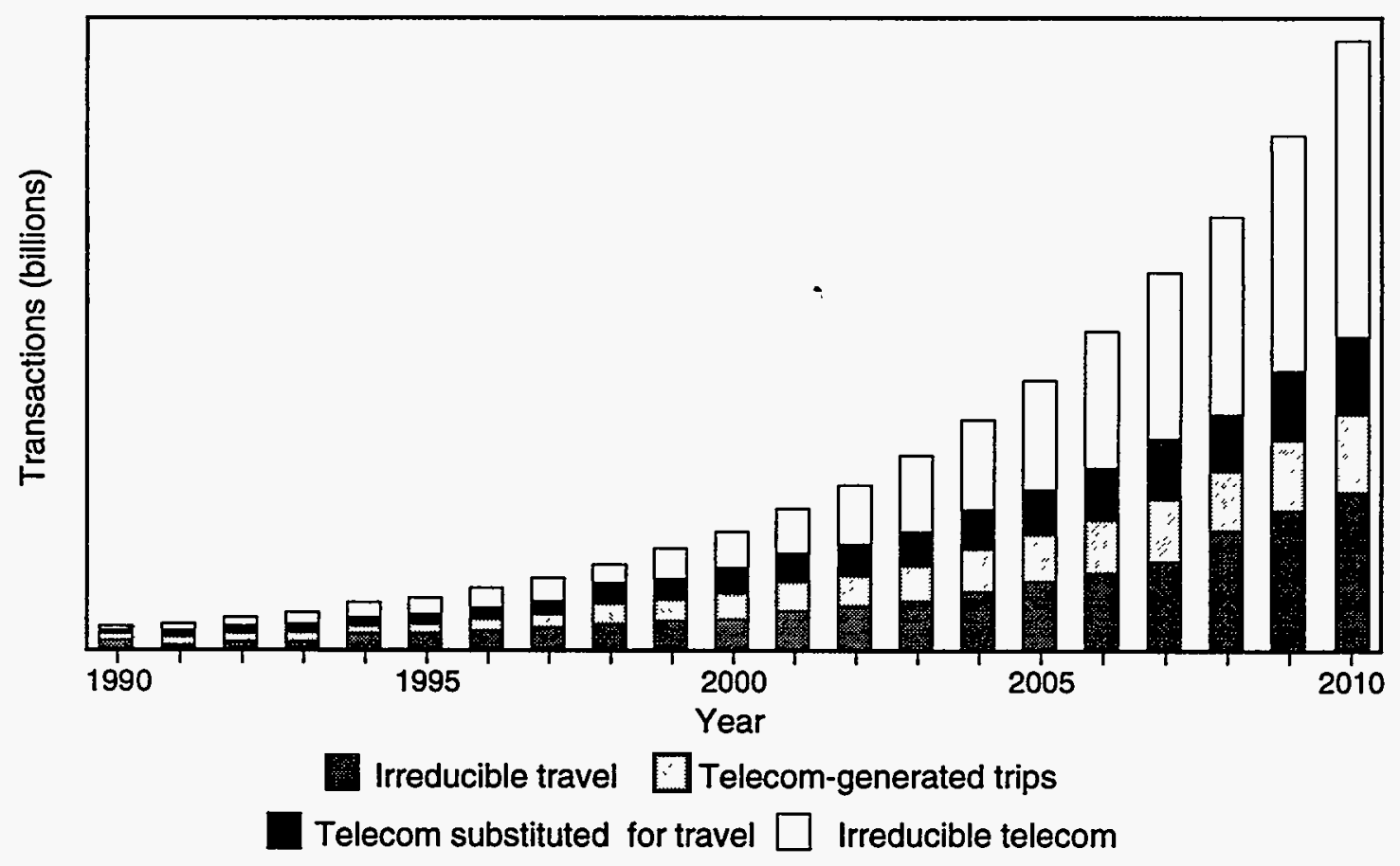

Ex O-2: Simulation of interaction between transportation and telecommunications. (Source: Global Telematics.)

The telecommunications transactions are made up of some that are a substitution for travel and other telecommunications transactions that bear no relationship to travel. Similarly, the transportation transactions are made up of those that are stimulated by telecommunications, for one of the reasons on the list previously presented, and those that are not. 
This model highlights two key points about transportationtelecommunications interactions: first, that telecommunications is both a substitute for travel and a stimulant and, second, that the net overall effect of telecommunications on transport, whether a net substitute or net stimulant, depends on whether list one or list two given above is dominant. If telecommunications substitution events add up to more travel miles saved than miles generated by telecommunications-induced stimulation, then there is net substitution. If the reverse is true, then there is net stimulation of travel by telecommunications.

In the figure, trip-replacing telecommunications transactions are set equal to trip transactions that are stimulated by telecommunications. Thus, the effect of telecommunications on transportation volumes is shown as neutral. This neutrality is an arbitrary assumption, however, made in the absence of data that measure both kinds of transactions in an entire economic region.

Whether the effects in the earlier list of travel substitutions outweigh the effects in this last list of travel stimulants is still an open question. Certainly, percapita travel demand is showing very strong growth in advanced and developing economies. Travel growth occurs even as telecommunications volumes grow. Growth in travel is of course influenced by current policies and prices affecting transportation. When travel on the usual routes becomes impossible, such as when bridges and roads were made impassable in the October 1989 and January 1994 California earthquakes, telecommunications usage and telecommuting soar until the roads are restored; but, in the case of San Francisco at least, some new telecommuters continued the practice part time even after conditions returned to normal.

An analytical econometric determination of how telecommunications and transportation have been balancing out as economic inputs in normal (nonearthquake) economic circumstances to date is an important research need. The scale of analysis could range from that of a metropolitan region to a nationwide scale to cross-national comparisons. The functionality of the NII has been improving and traffic congestion has been worsening for a quarter century now. We should therefore expect to see by now a trend toward travel substitution emerging in economic input-output tables, if the conventional wisdom on telecommunications holds true as commercial and social interactions evolve. Careful measurement is needed.

\section{Effect of Improvements in the National Information Infrastructure}

Will wider deployment of telecommunications or qualitative improvements in the National Information Infrastructure reduce the need for travel? Some public policy analysts have argued that government regulatory changes to accelerate the deployment of switched broadband telecommunications to residential premises, small businesses, and community service facilities such as schools and libraries would boost the use of telecommuting and other travelsubstituting applications of the NII.

The argument for explicitly modifying public policy to push deployment of broadband for travel substitution derives from the idea that higher bandwidth and the associated higher cost-effectiveness of applications would accelerate trip substitution; but do currently available telecommunications functions that are usable on existing high-speed communications networks make remote access as 
good as "being there," thus making travel less necessary? Experiments with these communications technologies and functions to date do not provide any hint of this result; in fact, the opposite is shown. For example, a detailed evaluation of a long-term, complex, continuous video connection between two Xerox Corporation laboratories in different states concluded that the arrangement was not an adequate substitute for face-to-face experience.

Broadband telecommunications enlarges the universe of choices for remote access to information and interaction. Broadband provides higher speed, higher volumes, and higher image resolution in information flows; but as broadband NII lets teleprocesses become more like "being there," the value of using travel will tend to increase. The opportunity to focus human attention exclusively on face-to-face presence, sensate experience, and physical interaction at meetings, places, and events will be a "scarce good" and thus more valuable, as a principle of economic supply and demand. Lunch with the boss, a teacher, or a good customer will usually be worth more than a videoconference with that person.

Could broadband offer new, unforeseen services that in some manner provide people with a compelling reason to travel less frequently? The evidence to date on the compelling things that people do now, such as eating, sleeping, having various kinds of fun, engaging in addictive behaviors, and so on, is that people invariably like to do them in a variety of different locations. Tens of thousands of drunk driving deaths every year illustrate that people like to move around even when they most definitely should not.

The deployment of interactive, more functional, higher bandwidth communications into homes will surely allow more practice of telecommuting, if that is what company managers and their employees continue to find works best. Growing telecommuting is the trend in the United States, but at the same time having a better NII available sooner will not automatically alter the dynamics that make telecommunications a travel stimulator. (As described earlier, these dynamics include new relationships and transactions that cover a wider area, economic growth, suburbanization, transportation improvement, and just-intime logistics.) Simply accelerating the deployment of high-speed and more functional, interactive telecommunications services into more end-user locations does not transform the economy toward lower transportation intensity. Rather, more powerful telecommunications will feed all of the ways in which telecommunications expands the motivations to travel.

Whether the widespread deployment of a more powerful, higher bandwidth NII will lead advanced economies to show higher telecommunications intensity and lower transportation intensity also depends on changes in the price-performance of transportation. In the United States, for example, the cost of driving automobiles, based on fuel prices, vehicle prices, and taxation, is declining. Travel delays caused by increasing traffic congestion in urban regions can be considered an additional cost of transportation, but these costs are only felt by a portion of the population.

\section{The New Paradigm}

The wider impact of the National Information Infrastructure on the economy and society in contrast to the limited travel impact of telecommuting suggests that a new public policy paradigm is needed. The present dominant paradigm is that telecommunications yields telecommuting, which yields travel 
savings. A new and better paradigm is that telecommunications yields some travel savings through telecommuting and other travel substitution effects but that it also sets up a countervailing mechanism of travel stimulation that needs to be more widely recognized and better understood. Furthermore, other benefits of teleprocesses are even more important to the nation than travel savings: support of health care reform, efficient government, better education for our children, and rising manufacturing competitiveness. Telecommuting remains a very useful teleprocess, providing an optional work environment where workers can be more productive and closer to their children at the same time.

The U.S. experience of the last few decades does not reveal a natural evolution of the NII substituting for travel. Both grow together, one feeding the other. Travel per household is rising, urban congestion is increasing, and latent demand for travel emerges clearly when new road capacity is opened up, even as the information age expands.

To change to a different developmental path from that followed in the past, governments must learn to coordinate public policy on telecommunications, transportation, land use, and capital facilities investment in light of the interactions described here. The overall challenge is to allocate resources and attention reasonably across the entire spectrum of public facility systems that provide support for the transactions and relationships comprising economic and social life. Such systems include the cables and computers of the National Information Infrastructure; the roads and airports of the transportation system; and physical locations like schools, libraries, clinics, and meeting halls where people interact directly with other people.

\section{Recommendations for Government Policy}

One important government strategy deserves higher visibility at the state and metropolitan-area levels and the encouragement of USDOE: A more explicit inclusion of telecommunications in planning processes for improving the overall transportation system. Telecommuting and other NII applications, if considered as part of a broad set of supply and demand determinants and solutions, could assist state and metropolitan regions in meeting the air quality and mobility goals mandated by federal legislation (the Clean Air Act Amendments and the Intermodal Surface Transportation Efficiency Act). This new consideration would fit well into a least-cost, integrated resource planning (IRP) framework. Integrated resource planning would be a transfer to the transportation arena of ideas and methods that are now successfully used in electric energy planning.

Also, government policy could focus on promoting and ensuring telecommunications-based alternatives to travel for the inevitable future periods when travel becomes difficult or expensive because of disruptions from special events, weather, disasters, or oil supply interruptions. The USDOE should have a special role in planning for this last eventuality.

Those in charge of coordinating transportation and telecommunications policy need to work on developing more understanding about telecommunications-transportation interactions and on disseminating this understanding to professional and political leadership. Then, this knowledge needs to be joined with politically acceptable public transportation goals in a policy-making process aimed at specific transportation outcomes, such as reducing peak-period traffic volumes. 
Targeting of effort based upon a more thorough understanding of the relationship between telecommunications and transportation is an important requirement for decision makers in both the telecommunications and transportation sectors. Without this understanding and focus, the deployment of more capable NII is likely to exacerbate present trends of worsening traffic congestion, even while other benefits occur.

Government policy intervention to accelerate the deployment of higher bandwidth and other more powerful telecommunications capabilities cannot be justified by the potential for travel savings alone. Still, there are many other government roles in NII technology and applications that lead to productive uses of limited resources. These include

- Development and deployment of government teleprocesses that deliver more service for less money and make use of existing and pending NII capabilities.

- Support of infrastructure improvement in disadvantaged geographic areas and for socially important applications that the market leaves behind despite the economic cost to society at large.

- Legislative and rule-making action to eliminate barriers to the deployment of teleservices for health care, education, and general government teleservices.

Teleprocesses can be designed and implemented in effective support of basic reform initiatives in each of the service areas named. These reform efforts typically emphasize targeting and improving services that assist and empower disadvantaged Americans. In this regard, teleservices can help, if designed with equity in mind.

Specific follow-up recommendations of this study include

- Research on telecommunications-transportation interactions: The USDOE and USDOT should support research that quantifies, through statistical analysis of economic data, the impact of NII spending on transportation consumption per unit of economic output. This research should be designed to verify whether the relationship is one of net substitution of telecommunications for transportation or one of net stimulation.

- Integrated resource planning demonstrations: The USDOE should take action to initiate demonstration projects by state government planning agencies and metropolitan planning organizations that translate existing, proven energy planning techniques into an integrated resource planning (IRP) methodology applicable to metropolitan area surface transportation.

- Federal data collection: Federal data collection should encompass measurement of economic activity conducted in locations outside of traditional, fixed employment locations reached by the traditional hometo-work commute. These other locations include homes, vehicles, and variable customer locations. Federal data collection also needs to focus on travel behavior outside of commuting, which accounts for a majority of trips, energy consumption, and emissions.

- Federal support of research and development: The Federal government should support policy-focused research on the social and economic consequences, opportunities, and costs resulting from NII-stimulated 
flexibility in the use of time and space. The determinants and dynamics of patterns of activity, land use, and travel are not well understood.

- Robustness of telecommunications: The Federal Communications Commission and state regulators should continue to emphasize robust telecommunications capabilities that can continue operations after major natural disasters, accidents, system malfunctions, and acts of sabotage in either telecommunications or transportation systems. Providing an alternative to disruptions in transportation is a compelling government motivation for pursuing telecommunications as a substitute for transportation.

- Telecommunications access to service: Federal, state, and local government agencies should focus on investments in the design, development, and implementation of those teleprocesses that reengineer service delivery for the following benefits: agency cost savings and avoidance, customer and taxpayer satisfaction, service delivery effectiveness and coverage, and reduced travel generation for both customers and employees. An important source of funding for teleprocess initiatives would be redirection from budgets that cover the planning, design, development, and construction of government-owned and -supported public works infrastructure and buildings.

- Health care policy: Federal health care program regulations that require office visits as a condition of payment for a physician's services should be reviewed in light of a new tele-health model that suggests that best practice is achieved when appropriate care is provided at the appropriate location.

- K-12 public education: The US Department of Labor and the US Department of Education should work jointly to accelerate the financial investments needed in $\mathrm{K}-12$ public education to pay for the new technology, instructional materials, and teacher preparation that allow schools to motivate and enable children to learn skills that better prepare them for a lifetime in an economy that is continually restructuring itself around the NII.

In short, government leaders must shift their focus beyond telecommuting to a much larger set of teleprocesses that are increasingly changing the patterns of activity and location for both organizations and individuals. Only through a growing understanding of the new information technologies and their patterns of use will this nation discover ways to minimize the costs and increase the benefits to our society and economy from the parallel growth of transportation and telecommunications. 


\section{Chapter 1}

\section{INTRODUCTION}

Telecommuting is the most widely recognized trip-saving application of telecommunications. Telecommuting usually means office-based employees using telecommunications to work at their homes or at a nearby alternative office for a few days each week instead of commuting a longer distance to work.

State-government-sponsored studies of telecommuting in California (Kitamura, 1990; Handy and Mokhtarian, 1993) and Washington State (Heifetz, 1992; Kunkle, 1992; Quaid and Lagerberg, 1992) have found that telecommuting produces an overall net reduction in all household driving, a net energy benefit even with some small additional energy use at the telecommuting site, and a generally positive performance and satisfaction result for both workers and their employers.

Early concerns that telecommuting might lead to offsetting increases in transportation, either by other family members who have an extra car available on telecommuting days or by telecommuters who quit early on Friday to take longer weekend recreational trips, have not been borne out by the California and Washington State studies. Travel diaries from households where workers begin to telecommute show reduced commuting and fewer household trips overall than those from nontelecommuting households.

These are tentative findings, however, constrained by the limited time that most telecommuting study projects have been active. In the long term, telecommuting could affect people's decisions about where to live. If an employee only goes to work at the office one or two days per week, she might be willing to have a two-hour commute so she can live in beautiful countryside. No longitudinal studies that could detect this pattern have been done yet.

Also, the studies from Washington State and California did not address the overall impact of information technology on travel behavior beyond the effects of telecommuting.

The 1993 USDOT National Telecommuting Study, Transportation Implications of Telecommuting (USDOT, 1993, p. ix), forecasts that telecommuting in the early 21st century is likely to grow to where it reduces vehicle miles traveled (VMT) in the range of 18 to 35 billion miles per year. Consequently, with telecommuting, VMT will be at most $1.4 \%$ below where it might otherwise be without telecommuting. This reduction stands in contrast to USDOT's forecast of $2.5 \%$ annual VMT growth (USDOT, 1993a) or the U.S. Department of Energy's forecast of $1.8 \%$ annual VMT growth through the year 2000 (USDOE, 1993). The USDOT characterized telecommuting as having "significant transportationrelated public benefits" (USDOT, 1993, p. v), even though these numbers show that the travel reductions predicted for telecommuting are likely to be overwhelmed by growth in travel volumes. Exhibit 1-1 presents a graphical depiction of forecast travel growth over the next ten years with no consideration of telecommuting. The small dot just below the forecast trend line is where VMT 
would be in the year 2002 if the USDOT high estimate for telecommuting were to materialize.

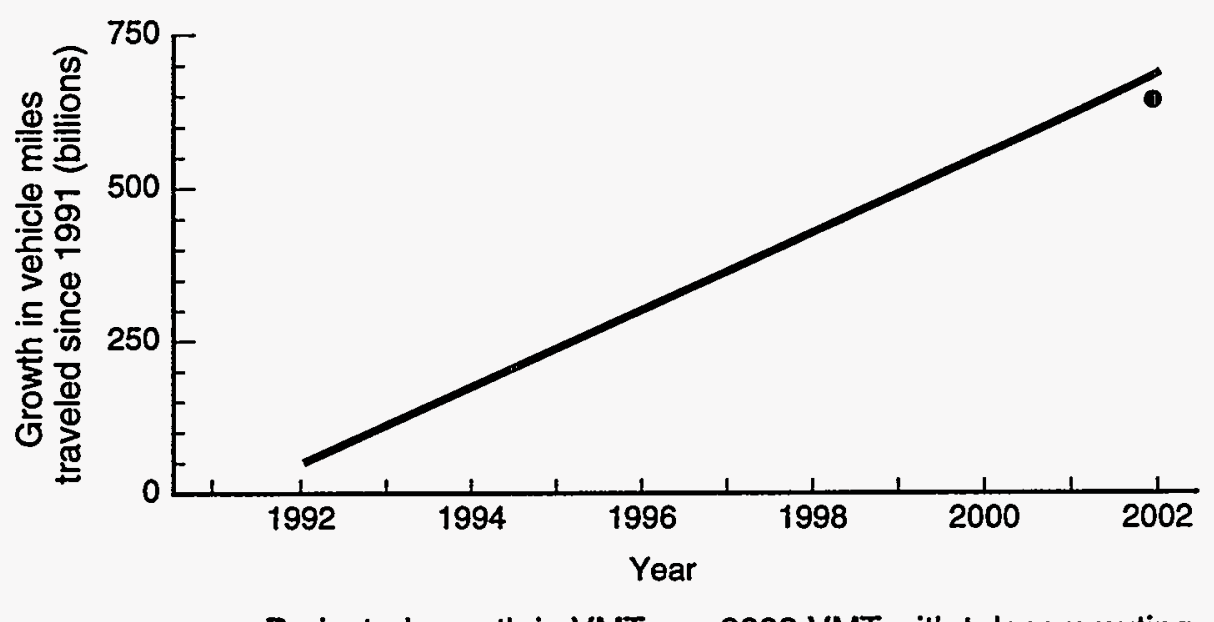

Ex 1-1: Cumulative growth in vehicle mileage overwhelms telecommuting savings. (Data source: U.S. Department of Transportation.)

A follow-up study from the United States Department of Energy, Energy, Emissions, and Social Consequences of Telecommuting, found three indirect effects of telecommuting that, on balance, make the direct VMT reduction impacts forecast by USDOT even less likely. These indirect effects are described by USDOE (USDOE, 1993, p. xi) as follows:

Improved Traffic Flow. Because of reduced congestion, the remaining vehicles on the highway will operate more efficiently. Better traffic flow and fewer stops and starts will reduce fuel use and emissions.

Latent Demand. People who previously avoided using their vehicles because traffic was too congested will start driving more because telecommuting has lessened this congestion. This will tend to offset the direct reductions in fuel use and emissions.

Increased Urban Sprawl. As close proximity to a central workplace diminishes in importance, telecommuters will feel free to live farther from urban centers. This geographic expansion of cities will lead to longer drives when these workers do use their vehicles, and it will require additional highway construction.

A report by Arthur D. Little (ADL), Can Telecommunications Help Solve America's Transportation Problems? (Boghani, 1991), examined the potential for telecommunications to displace transportation in applications other than telecommuting. The study created a mathematical model to show that four particular telecommunications applications, telecommuting, teleshopping, teleconferencing, and electronic data exchange, would yield $\$ 23$ billion in annual benefits if 10 to $20 \%$ of trips of certain types were eliminated. The ADL study implicitly assumes that such future trip substitution would not be overwhelmed by the dynamics of telecommunications-stimulated travel. Its estimates of transportation substitution were formulated from a previous study conducted in 
Europe in the early 1980s. The actual growth of travel since then, simultaneous with the ramp up of telecommunications, provides a challenge to the ADL study's conclusions for the future. This challenge motivates the present researchers to look at historical data on travel and telecommunications in order to enlarge our understanding of the relationship between telecommunications and travel.

\section{Beyond Telecommuting}

An issue raised by the mathematical modeling of the ADL and USDOT telecommuting studies is the extent to which each model captures the full relationship of telecommunications and travel. Why is the number of vehicle miles traveled (VMT) growing so fast and urban traffic congestion increasing while telecommunications is growing in capability and use every day, and why does this occur while the number of telecommuters is growing in the short term at more than $10 \%$ annually (Exhibit 1-2)? One answer is that commuting represents a minority share of trip purposes, even in rush hours, as illustrated in Exhibit 1-3, and is growing smaller. Telecommuting can only do so much for vehicle miles traveled, as reflected in the conclusion of the USDOT report. Furthermore, telecommuting is not the only travel-related application or consequence of telecommunications. Telecommuting is embedded in a much larger span of telework, which in turn is only a portion of a larger complex of economic processes that are changing because of telecommunications.

Another issue is the extent to which telecommunications applications beyond telecommuting fail to provide substitution for travel overall. This could be because travel growth is mostly independent of telecommunications or because there are mechanisms whereby some travel is stimulated by telecommunications. These are mechanisms that we investigate in this study.

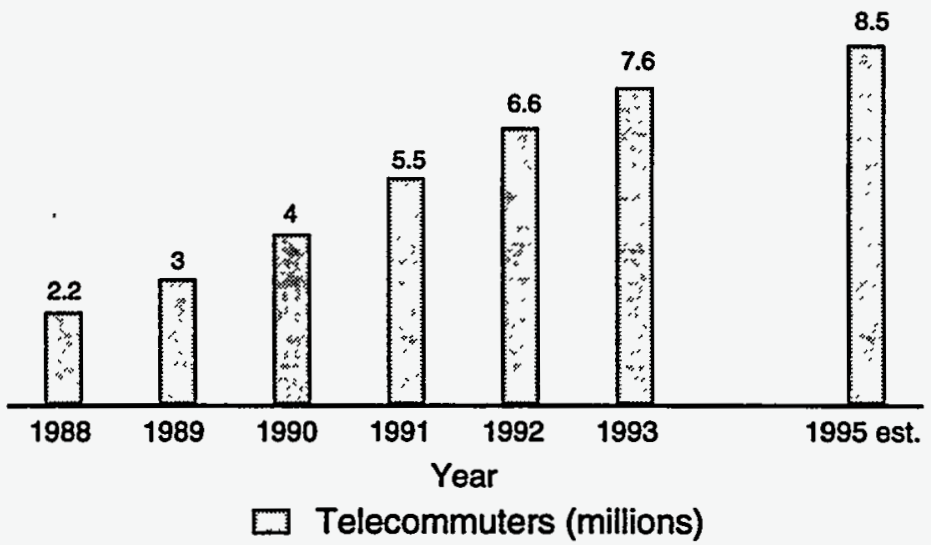

Ex 1-2: The number of work-at-home telecommuters is increasing. (Data source: Link Resources.) 


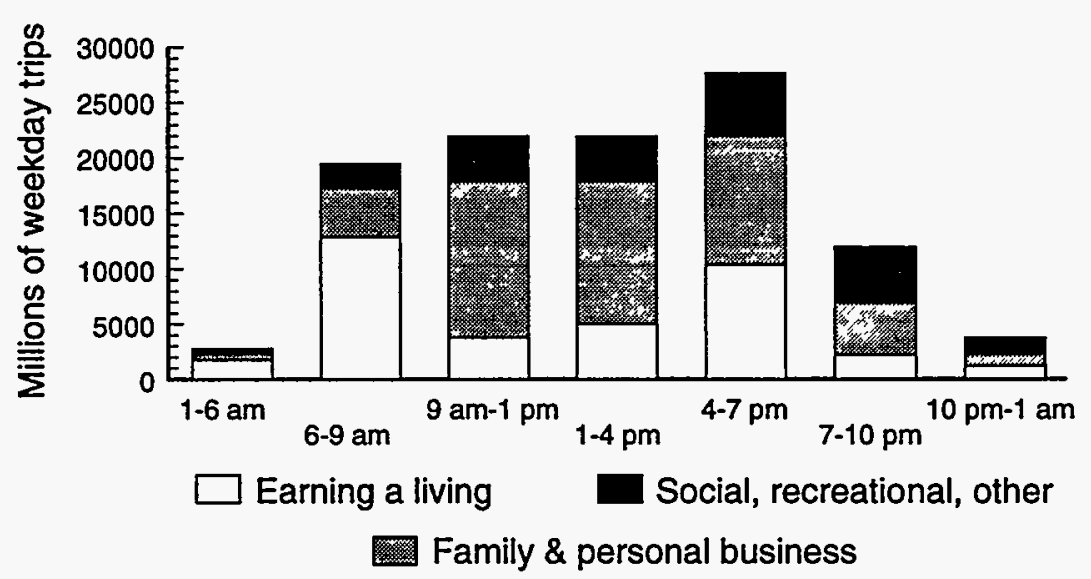

Ex 1-3: Most weekday trips after 9:00 a.m. are not commuting. (Data source: Nationwide Personal Transportation Survey.)

In an extensive body of published work that extends back to the early 1980s, Ilan Salomon has consistently argued against the conventional wisdom that telecommunications is a substitute for transportation. He notes in one study (Salomon, 1990), "There is, at present, very little evidence to support the substitution [of telecommunications for transportation] hypothesis." He writes in another paper (Salomon, 1987), "The findings [from an empirical study of telecommunications' impact on regional inequalities] suggest that reduced telecommunications costs do not have a major impact on changing the relative weights of location factors. The interplay of demand, supply and government intervention indicates that the disadvantage of distance will persist in the information era." The basic thrust of his work is that there is much more to be learned about how travel and telecommunications interact.

Patricia Mokhtarian (1990) of the University of California at Davis provides an initial framing for much of what is covered in this present study. Her work describes numerous ways in which telecommunications affects the demand for, and supply of, transportation, and vice versa. Many of them are elaborated upon in this study.

Rather than building up from the ultimately small phenomenon of telecommuting as a travel substitute, we take a top-down look at the U.S. economy and paint a larger picture of how telecommunications and transportation are working together both as substitutes and as complements. This present report focuses on and explores the apparent contradiction between the growing ability of telecommunications to substitute for trips through telecommuting and its effect in shaping a society in which travel per capita continues to increase year by year (Exhibit 1-4). 


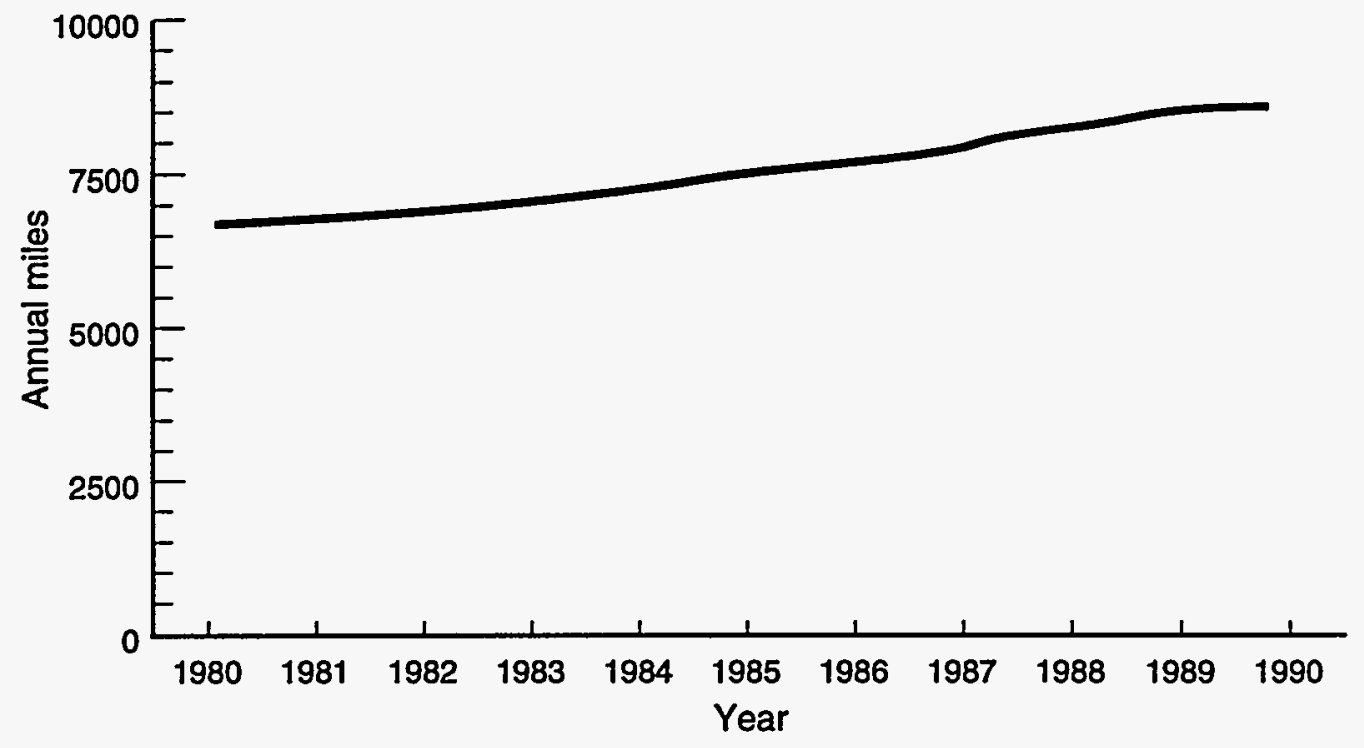

Ex 1-4: Motor vehicle miles per capita are growing. (Data source: Motor Vehicle Manufacturers Association.)

\section{From Telecommunications to Telematics}

Telecommunications and computers have now merged. New terminology like "telematics" or "National Information Infrastructure (NII)" can best describe the marriage, although we will continue to use "telecommunications" in this report. Computers are attached to networks and embedded within them. Examples of telecommunications as telematics are cellular mobile telephones, automatic teller machines, airline reservation systems, electronic cash registers that update inventory data and order replacement stock, and handheld computers that transmit and receive wireless messages. Virtually all switched telecommunications is telematics, since modern telephone switches are in fact special-purpose computers.

At the same time that telecommunications revolutionizes information flows, it also changes how people and goods move. Urban highway flows, commercial aviation, overnight package delivery, trucking, railroads, and international shipping are increasingly managed through computers and telecommunications that guide shipments, people, and vehicles.

The changes caused by new applications of telecommunications and transportation are just beginning:

- Office work becomes possible anywhere people are able to live or travel as equipment becomes smaller and telecommunications reaches everywhere.

- Warehouses shrink in number as customers phone their orders directly to factories and computers maintain inventories of goods while in shipment. 
- Heart defibrillators, fetal monitors, and other instruments attached to residential telephones allow medical personnel to monitor and continuously treat patients in their homes.

- Increasing numbers of adult learners across the nation dial into computer networks with their home computers or receive broadcasts to get college instruction.

- Government managers have new options for letting the public obtain services, including kiosks in shopping malls, computer bulletin boards, and automated audio response services from any touch-tone telephone.

Exhibit 1-5 is an outline of the telecommunications technologies that most directly impact travel and location of activity, based on a review of a Lawrence Berkeley Laboratory survey of information technology (Loken, 1993). As Pratt has noted, the ability of these new tools of work to bridge distance and to be easily moved around is causing an unprecedented proportion of work to be conducted at nontraditional sites, both remote and mobile (Pratt, 1993). Travel generation is intrinsic to this trend of new and impermanent activity locations.

Ex 1-5: Elements of telecommunications that relate to travel and activity location.

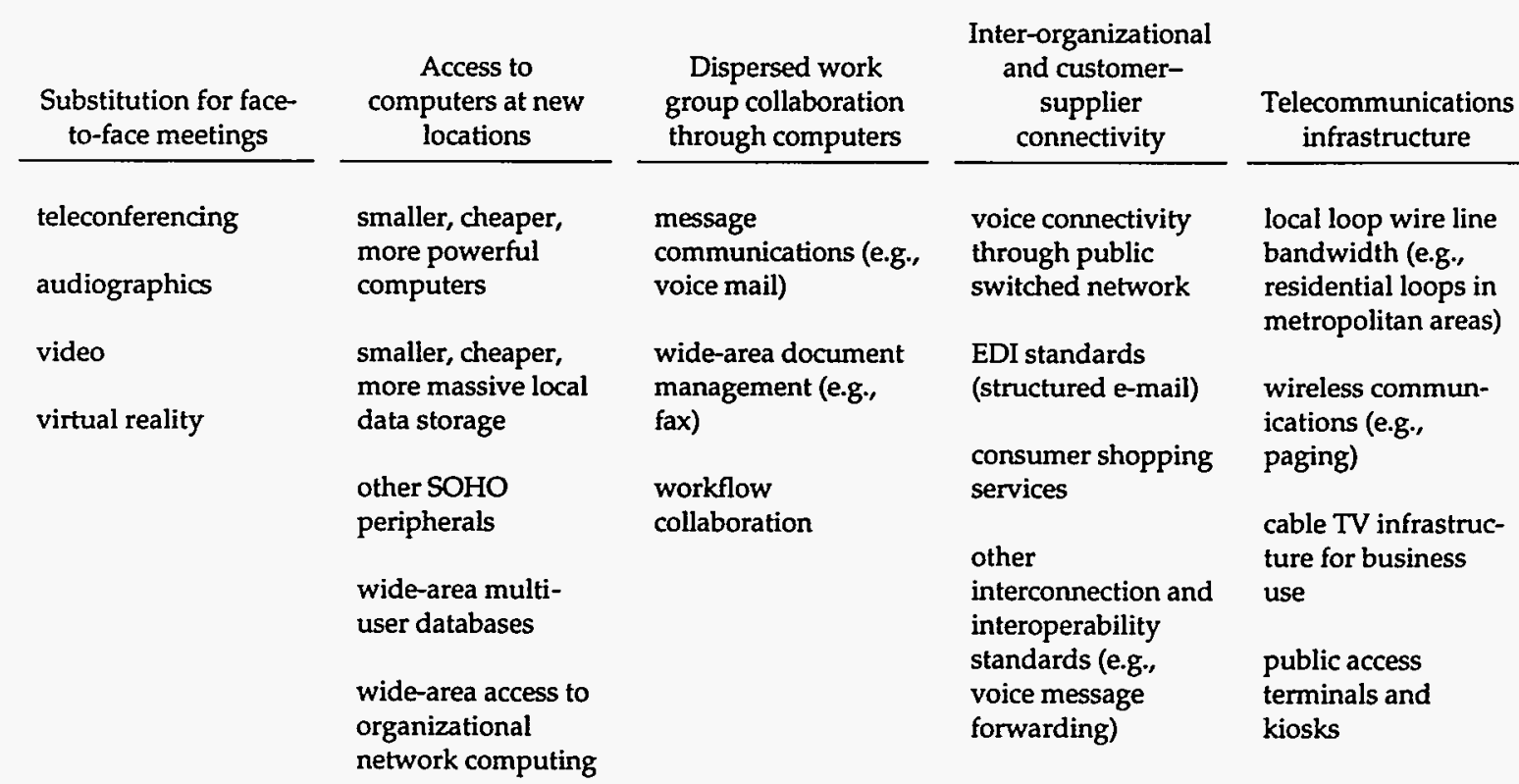

Abbreviations: SOHO, small office, home office; EDI, electronic data interchange. 


\section{Four Telephenomena Affecting Travel}

This study goes beyond telecommuting. The report considers the complete range of impacts of telecommunications on transportation of people and goods. This extends us into a range of telephenomena including telework, teleservices, teleprocess, and telestructure. These concepts are defined as follows:

Telework means telecommunications-enabled rearrangements of where workers are located. Telecommuting, employees working at home instead of in their usual office, is a small part of telework. Mobile sales forces and suburban data processing facilities are more prevalent examples of telework.

The assumed base case for employment is that of a worker who lives in a residential unit and commutes daily to a separate work facility. Variations in this pattern that represent different types of telework are shown in Exhibit 1-6. Those who are optimistic about telecommunications as a substitute for travel focus on the pattern of working at home and close to home. Pessimists would focus on the mobile and flexible work patterns that allow working in a variety of remote and portable locations.

The private research firm LINK Resources annually conducts a private telephone survey of several thousand U.S. households to estimate the number of home workers. In 1993, they counted 41.1 million, including persons working in home-based businesses and regular office employees doing after-hours work, as well as telecommuters working at home. Telecommuting accounted for 7.6 million workers as of early 1993, up 15\% from the 6.6 million counted in 1992. This number, which includes some contract workers not counted in the USDOT study (USDOT, 1993), is about 6\% of the U.S. labor force (Miller, 1993).

The growth of telecommuting, as measured by LINK Resources (USDOT, 1993, p. 1), has been strong for the past five years. No one has identified any reasons to suggest that this growth will abate in the foreseeable future. Several factors are at work: First and foremost, telecommuting is a technique that works. Telecommuting is an optional way of expanding employees' work locations in those circumstances where it yields both improved organizational performance and employee satisfaction. The need for more information workers, the workers who have jobs that are most adaptable to telecommuting, will continue. Computers are becoming smaller, more portable, and more powerful, offering new ways of connecting to corporate and public networks from any location via wireless communications or the ordinary public telephone network. New software is becoming available to support collaborative work by people who are separated by distance but have network access to share forms, documents, data files, and other work products.

Strong employment growth in small companies also supports the telecommuting trend, since these companies are more enthusiastic users of flexible arrangements than are larger companies. Further, there is no reason to think that there is an immediate top end on worker demand for telecommuting or on the need for employers to respond affirmatively. One contributing factor is that flexible locational arrangements are considered desirable by workers. Another is the looming shortage of skilled workers over the next ten to twenty years as the effect of the birth dearth following the baby boom years works its way through the economy. 
Ex 1-6: Telework variations.

Typical home telecommuter: Employee regularly stays at home and works, usually no more than two days per week.

Full-time home telecommuter: Employee routinely works from an at-home office or workstation within the same metropolitan area as the normal office and travels only once per week or less frequently to the normal office.

Telecenter/branch telecommuter: Employee works for reasons of convenience and travel-saving at a different facility provided by the employer but retains a desk in the normal office.

Telecenter/branch workers: People who are reassigned to working regularly and routinely from a remote telecenter or branch office somewhere else in the metropolitan area, their normal office being eliminated, downsized, or shared.

Virtual office worker: Employees who are provided with home or portable office equipment and have their normal office taken away because they spend the vast majority (typically $80 \%$ or more) of their work time in the field.

Long-distance telecommuters: People who would have a company office with the rest of their work group if they lived nearby but instead are allowed to work from a distant residential location because their employer wishes to retain them. They may report to a more convenient branch office, work from a home office, or do both.

Mobile professionals: People who usually have a normal office to which they officially report to work but who are able to work continuously with location independence because of extensive travel requirements inherent in job responsibilities. Includes traveling sales people, field auditors, trainers, and maintenance technicians.

Independent homeworkers: Self-employed people or business owners who could have an office outside of the home but who choose not to and instead work routinely from an office at home. Also called "lone eagles" (Burgess, 1992).

Remote regional field workers: Employees assigned to cover a geographic area that is remote from the main office of their supervisor, so they are required to work from home, a branch office, a rented office, or some combination.

Decentralized work groups: All of the employees in a work group are reassigned to another employer-provided facility in a different part of the metropolitan area from the normal office.

Remote branch/back office: Rather than expand the staff and space at the normal office, the employer establishes a new office in a remote location. The employer transfers existing employees to live and work in the new location or else hires new people who already live nearby.

Teleservices means telecommunications-enabled rearrangements of the locations wherè services are delivered to customers. Distance learning, automatic teller machines, and lawyers reached through " 900 " numbers are examples of teleservices. A teleservice classification by means of access is presented in Exhibit 1-7. 
Ex 1-7: Teleservices classified by means of access.

Through generic network attachments

videotex (e.g., Compuserve)

remote banking

home shopping channels

audiotex telephone services

(e.g., dial-up newspaper

classified ads)

"900" number telephone services
Through specialized terminals

airline reservation terminals

ticket-dispensing machines in airports

automatic teller machines

medical supply companies'

ordering terminals in

drugstores

indoor kiosks

fetal monitoring in the home
Through telecommunicationsenabled environments

distance learning in schools

videoconferencing

electronic, remote monitoring and servicing of machines

Teleservices are significant in the overall metropolitan traffic problem because they have a growing impact on non-work personal travel, which includes shopping and other consumer behavior. As illustrated by Exhibit 1-8, nonwork travel miles are showing more growth than are work miles.

Teleprocesses encompass telecommunications-enabled marketing, production, logistics, financing, and administrative processes of organizations

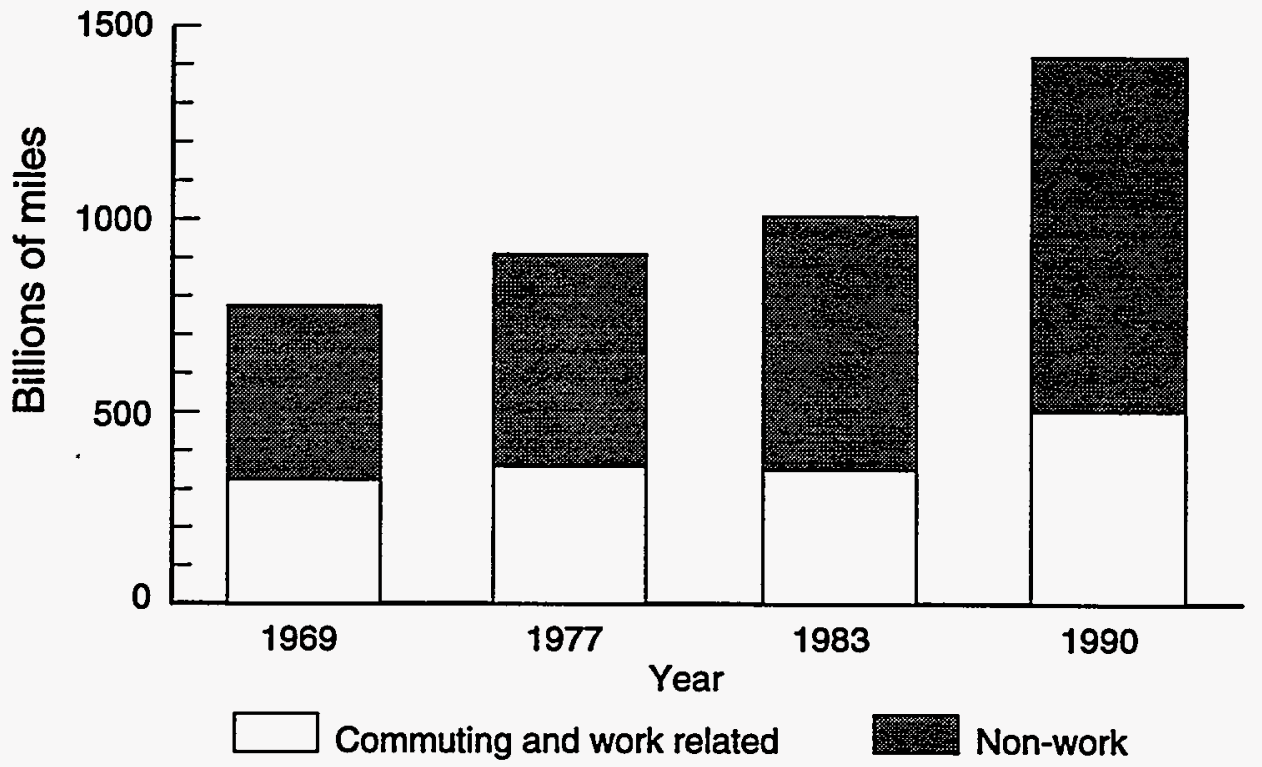

Ex 1-8: Non-work travel miles are growing faster than work miles. (Data source: Nationwide Personal Transportation Survey.) 
and of multiple organizations. Work group collaboration through groupware, electronic data interchange (EDI), and computerized inventory management are examples of teleprocesses.

Each teleprocess generates customer, worker, and supplier travel. Telework is teleprocesses from a worker location point of view, whereas teleservice means teleprocesses from a customer location point of view. Telework and teleservice are parts of teleprocess, but they are not the only parts. For example, telelogistics refers to the influence of telecommunications on the procurement, transportation, and maintenance of materiel, such as raw materials and finished goods. The relationship between teleprocesses, telework, and teleservices is shown in Exhibit $1-9$.

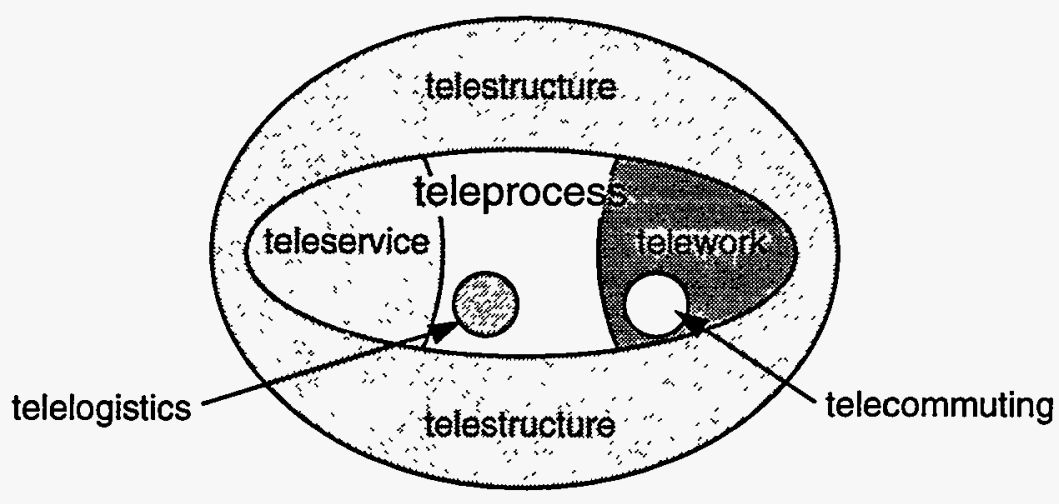

Ex 1-9: Telephenomena. (Source: Global Telematics.)

Teleprocesses are an important new pattern of resource allocation that provides people, organizations, and the American economy with more flexibility in where, when, and how work is done. Flexibility is largely driven by the surging strength and innovativeness of relatively small U.S. firms, although older, larger companies are increasingly implementing new teleprocesses as well.

Teleprocesses take place in government as well as business, and they apply to the production of both goods and services. Teleprocesses are usually implemented to increase the performance of the organization that uses them. For example, they are used to increase sales, cut costs, enhance service quality, or improve customer satisfaction.

An example of a teleprocess is computerized inventory management in retail stores, in which a central computer monitors the product stock levels in each individual store. The computer watches what is bought, as recorded by bar code scanners at the cash register, and orders new stock as needed. The system provides the basis for constantly introducing new products to replace existing ones that fall into the bottom half of sales performance at a store. This lets each neighborhood store meet the unique needs of its customers.

Some teleprocesses are not directly related to the location of workers and customers. Still, teleprocesses inherently have an impact on the location of workers and customers in operations subject to competitive threat, because the survival of such operations is determined by the effectiveness of their teleprocesses. 
Telestructure refers to telecommunications infrastructure and also to telecommunications-enabled infrastructure of all kinds. Smart buildings, computerized traffic control, and the national public switched telephone network are all parts of telestructure. The Federal Government has coined the term National Information Infrastructure (NII) to describe America's telestructure.

Telestructure is the enabling infrastructure for telework, teleservice, and teleprocess. It provides the environment in which teleprocesses work.

Teleprocesses and telestructure together make up telephenomena, as shown in Exhibit 1-9. Telephenomena, the applications and infrastructure of telecommunications combined with computers, are allowing massive structural change in how and where organizations set up operating processes, how and where people do their work, how and where services are delivered, and how and where infrastructure performance changes as a result of telecommunications advances. The emphasis in this study is on "where," although "where" has a close, complex relationship with "how."

\section{Goals of This Study}

Given this comprehensive picture of telecommunications, the purposes of this report are to

- Position telecommuting in the context of telecommunications and telephenomena, considered broadly.

- Incorporate transportation and telecommunications into a single, unified policy analysis framework, one that recognizes telecommunications as a complement to transportation as well as a substitute.

- Present research-based recommendations and options for improving policy to public officials, business executives, and general civic leadership, particularly in relation to the use of telecommunications to substitute for transportation. 


\section{Chapter 2}

\section{PERSPECTIVES ON TELECOMMUNICATIONS AND TRANSPORTATION}

Surface travel volume is made up of vehicle trips. Telecommunications volume is made up of electronic and optical information flows. Conventional wisdom holds that telecommunications is a force for reducing travel by moving information electromagnetically over cables and through the air instead of moving people and paper in vehicles. A main conclusion of this report is that this view is overly simplistic and contrary to observations from everyday life.

The usual methodology of studies supporting the travel substitution hypothesis is to define a limited set of telecommunications applications that indeed reduce travel, such as telecommuting. The studies then measure or assume the average result of a single substitution event, such as a day spent at home as a telecommuter or participation in a single teleconference. The travel substitution impact of a reasonably larger number of such events is then extrapolated by summing the effects of these individual events. The limitation of this methodology is that narrowing the focus to one class of event does not take into account the many other related telecommunications events and effects that stimulate trip making.

The following lists of trip elimination and trip stimulation mechanisms of telecommunications illustrate the complexity inherent in travel-telecommunications interactions.

The trip elimination effects of telecommunications tend to operate at the "micro" level of individual transactions and events.

- Telecommunications allows workers who would normally commute from home to a work location to telecommute from home or from a location closer to home.

- Telecommunications allows information to be sent in electronic form rather than in physical "document" form.

- Telecommunications enables humans to communicate remotely rather than travel to common meeting locations.

- Telecommunications allows sporting, entertainment, political, religious, and other events to be broadcast to a dispersed audience instead of having the audience travel to the event.

- Telecommunications enables observations from dispersed sites to be collected and transmitted to a central point via remote sensing rather than by a human observer. 
- Telecommunications enables the potential traveler to lay the foundation for more productive travel through remote negotiation, fact finding, or troubleshooting that sometimes makes a trip unnecessary. This communication replaces unconditional travel in anticipation of a need that has only a possibility of arising.

- Telecommunications allows consumers to make purchases without traveling to store locations. This permits the movement of goods to bypass the transportation-intensive process of wholesale and retail distribution.

- Teleconferencing, computer networks, electronic document flows, and remote sensing let organizational managers disperse and rearrange work sites in a way that can potentially reduce transportation of employees, customers, raw materials, or products. Still, net travel reduction is not necessarily a goal of management decisions to implement new teleservice and telework applications. Pursuing other goals, such as gaining market share or improving quality, may work to increase net trip making.

- Telecommunications allows service transactions and events to be carried out in ways that require no travel or less travel. Such transactions include using payroll direct deposits instead of taking paychecks to the bank, filing income tax returns electronically rather than mailing them, and going to neighborhood electronic kiosks rather than traveling downtown.

- Telecommunications leads to some household activity patterns that consume lower levels of transportation than the alternatives. In other words, interactive computer services and greater numbers of television channels in homes may make staying home in the evening more attractive than going out.

- Telecommunications allows automobile travelers to coordinate their journeys and share rides rather than travel in separate vehicles, thus reducing the number of vehicles on the road.

The trip generation mechanisms of telecommunications tend to operate at the long-term, "macro"-level of socioeconomic pattern changes.

- Telecommunications makes people aware of additional general-audience events and opportunities that are reached through travel, such as political rallies, professional conferences, entertainment events, and shopping opportunities.

- Telecommunications causes economic growth, productivity improvement, and income growth at the individual, organizational, and societal levels. Extensive databases and powerful computer-based econometric techniques have recently allowed this causation to begin to be empirically demonstrated, as described later.

- As the economy grows, telecommunications expands the number and geographic scope of economic and social relationships in which people and organizations engage. Electronic mail and toll-free telephone numbers are examples of relationship-expanding communications technologies that allow more rapid and farther reaching transactions and interactions. These relationships sometimes generate travel in addition to telecommunications volume. Such relationships include selling, buying, servicing, employment, memberships, friendships, and family. 
- Telecommunications permits geographic decentralization of residential settlement and of organizational activity locations. Decentralization leads to higher travel consumption, because trip origins and destinations tend to be farther apart.

- New telecommunications functionality resulting from digital switching and fiber optics supports the urbanization of rural communities together with associated growth in economic activity. This pattern typically causes more local automobile traffic and a flow of visitors using transportation from distant locations.

- Telecommunications speeds up the pace of economic activity. The same idea is expressed by business consultants in the phrase "time-based competition." The acceleration of commerce tends to generate customized, single-purpose trips that leave immediately and go by the fastest means. The quickest modes of door-to-door surface transportation in most metropolitan areas are single-occupancy vehicles and small trucks. These modes generate more traffic congestion than moving the same volumes in mass transit vehicles and large trucks.

- Telecommunications enables rapid response systems that dispatch customized vehicles to meet personal and organizational needs. Several examples of this are just-in-time logistics, home delivery of fast food, overnight package delivery, and temporary employment services.

- Telecommunications enables a wide variety of new last-minute information flows that generate personal travel through attractive invitations and compulsory orders to attend.

- Telecommunications makes travel time more productive and more feasible for travelers. Use of wireless mobile phones while traveling is the leading example. Wireless data communication between office computer networks and portable personal computers is a new capability being deployed to improve the productivity of business travelers.

- Telecommunications makes the transportation system work more effectively and efficiently. Examples of this are air traffic control, computerized airline reservation systems, and intelligent vehicle highway systems (IVHS, also called smart highways).

As these lists show, the availability and use of telecommunications eliminates trips and causes trips at the same time. The key question remains, "Is the availability and use of telecommunications a net generator or net eliminator of vehicle trips?" Given the two lists, the answer is inherently difficult to determine.

The definitive answer, a history that includes the growth of telecommuting and trip making over the past ten years, can only come from a statistical analysis of comprehensive economic data at the level of the entire economy. Such a follow-up research examination is the most important recommendation of this study.

\section{Comparing Telecommunications and Transportation}

Despite some similarities, transportation and telecommunications are fundamentally different. The key similarity is that both offer a means of achieving the interactions, transactions, and other relationships that make up 
human social and economic activity: conversations, meetings, teaching, helping, sharing, buying, selling, trading, and making agreements.

This similarity between telecommunications and transportation is very appealing and powerful. They are both means of connection. Not coincidentally, the cable pathways of telecommunications typically run next to roads and highways. The popular expression "information highway," used by journalists and government officials, captures the parallels between the two kinds of connective infrastructure.

Though "telecommunications may be thought of as the transportation of information" (Mokhtarian, 1990, p. 232), advanced telecommunications as applied in teleprocesses is in fact a much larger phenomenon than the movement of information. It includes storing, transforming, adding value to, filtering, and retrieving information as well. The richness of advanced telecommunications goes far beyond the simple transmission of an electromagnetic signal.

Telecommunications as "information transportation" semantically implies that information moved by means of telecommunications could have been moved in physical formats (such as documents or disks) via transportation. The phrase also implies that information that is being moved in transportation vehicles (for example, in the minds and briefcases of commuters on the freeway) could be moved just as well via telecommunications channels. There is some truth in both of these implications, of course, but not complete truth.

In fact, some telecommunications traffic does amount to information streams that were previously delivered by physical transportation. A worker faxes a report that used to go by messenger. A professional attends a mandatory meeting by teleconference rather than by driving across town. It is very clear, however, that the vast majority of telecommunications traffic would simply not happen if the information it carried in fact had to be delivered in transportation vehicles. A worker who makes twenty phone calls, sends five faxes, and sends or receives ten e-mail messages in a day is not replacing thirty-five personal journeys and document shipments that would otherwise have been made.

The second implication-that much physically transported information could alternatively be sent electromagnetically-is widely claimed in order to emphasize the opportunities for substitution of transportation by telecommunications. One can send a document through the Post Office or an overnight delivery service (transportation), or one can send a fax or an e-mail message (telecommunications). One can either visit another office to talk to someone (transportation) or make a phone call to take care of the same business (telecommunications). One can go out and buy the news as printed in a newspaper or magazine (transportation), or one can gain access to news services via television, touch-tone telephone, or computer modem (telecommunications). One drives to the store (transportation) or orders by phone (telecommunications).

The California State Department of Transportation defines mobility as "the movement of information as well as people and goods" (CalTrans, 1991). Pacific Bell, a regional telephone company serving California, presented a seminar in April, 1993 on "Telecommunications as Transportation" that used descriptors like "Pouring the Electronic Highway," "Information Transportation and the Changing Definition of Mobility," and "The Rubber Meets the Electronic Road" (Williams, 1993). These are innovative, pioneering ideas, but drawing a literal, physical analogy between telecommunications and transportation creates a danger of underestimating how much change is really possible. 
A comparison lies in the history of company managers learning how best to use computers and robots to improve productivity. Task automation was the first response. In automation, the work that people do is replaced step for step by an equivalent use of the computer. For example, a metal-cutting tool operated by a person is now operated by a robotic machine, or a form completed by a person with a pen is instead filled out by a person entering data on a keyboard.

Yet, over the past decade, managers have come to realize that work processes need to be changed much more fundamentally than by automation if substantial productivity gains are to be realized. The most effective teleprocesses are now understood to require careful analysis of functional requirements, a redesign of work flows, and the implementation of new activity patterns around the unique capabilities of telecommunications and computers. The overall process of improvement has begun to be called reengineering (Davenport, 1993). Instead of automating production lines, we can redesign both the manufacturing processes and the products to be manufactured so that one machine does the work of ten. Forms are eliminated by having computers capture data directly from customers. Looking at telecommunications merely as a new form of mobility is reminiscent of using computers and telecommunications for marginal automation improvements.

Francois Bar has consistently pointed out the fundamental differences between telecommunications and transportation. "... while telecommunications networks [in comparison with transportation networks] also decrease information transmission time and costs, their most dramatic impact results from the fundamental reorganization of work processes ..." (Bar, 1990, p. 33).

Thinking of telecommunications as "information highways" is also reminiscent of the earlier characterization of automobiles as "horseless carriages," or train locomotives as "iron horses." A highway mind-set in thinking about telecommunications both limits the imagination about what is possible and becomes a source of errors. For example, overdrawing an analogy between the National Information Infrastructure and the Interstate Highway System can lead to frustrating puzzles about the telecommunications equivalents of freeway exit ramps, local streets, parking lots, and driving skills, whatever those equivalents may be.

New teleprocesses require new paradigms. Solving difficult problems requires defining problems in new and better ways. Redefining transportation to include "information mobility" and defining telecommunications as "information transportation" are new but not sufficiently better.

\section{Substitution of Telecommunications for Transport}

As a matter of resultant outcome rather than initial intent, telecommunications frequently substitutes for transportation. People working in government, business, and other sectors can and do take actions to implement teleprocesses that yield substitutions of telecommunications for transportation. Yet, these teleprocesses typically do not start with the goal of reducing transportation use.

Travel elimination is a small part of the reason for increasing telecommunications intensity in government, health care, $\mathrm{K}-12$ education, and manufacturing. Organizations adopt telecommunications to improve the quality of service they provide their customers, to reduce the cost of activities, or to make 
themselves more effective. They may do so for one reason and then find others to be more important.

For example, a bank might provide automatic teller machines to reduce the cost of hiring more tellers, find that its customers like the convenience of withdrawing money at any hour of the day, and subsequently find that customers have become accustomed to the service and resist paying fees if the cost of the service later increases. Moreover, because one bank provides the service, others find it necessary to do so in order to compete. Transportation has nothing to do with the banks' decisions. Similarly, a government agency may decide to reengineer the way it handles documents, using optical character recognition to scan them, store them electronically, and move them more efficiently, in order to reduce its administrative costs or to improve the quality of service to its clients.

In many cases, telematics is used to enable activities that would not otherwise occur. For example, the use of live educational television broadcasts. and telephone links between students and broadcast studios makes it possible for small schools that cannot afford to hire teachers in all subject areas to offer a wider curriculum. Students could travel to another school for the course but probably would not do so for just one course. The choice is then between receiving instruction in a manner different from face-to-face interaction with a teacher and not receiving the instruction at all. Distance is indeed a factor in the decision to offer the course or to take it. The school and students, however, probably do not look at the decision as one of saving transportation but as one of having the course available.

Reducing transportation is sometimes the reason for a new teleprocess. A trucking company installing a vehicle location tracking system, then giving truck drivers wireless devices for receiving new dispatching orders, is a teleprocess that probably includes travel reduction as a goal.

Videoconferencing is sometimes justified on the basis of travel reductions. Exhibit 2-1 shows cost savings from specific cases of agency use in Washington State government.

Ex 2-1: Savings realized through use of video telecommunications.

\begin{tabular}{llll}
\hline Agency & Type of meeting & Participants & Savings \\
\hline $\begin{array}{l}\text { Utilities and } \\
\text { Transportation }\end{array}$ & public hearing & $\begin{array}{l}65-70 \text { Spokane } \\
\text { residents }\end{array}$ & $\begin{array}{l}\$ 1,543 \text { for staff } \\
\text { travel }\end{array}$ \\
$\begin{array}{lll}\text { Employment } \\
\begin{array}{l}\text { Security Dept. } \\
\text { policy briefing to }\end{array}\end{array}$ & $\begin{array}{l}\text { 25 regional } \\
\text { managers }\end{array}$ & $\$ 1,294$ for travel \\
$\begin{array}{l}\text { State Communangers } \\
\text { and Technical }\end{array}$ & $\begin{array}{l}\text { series of six } \\
\text { training sessions }\end{array}$ & $\begin{array}{l}100-150 \text { faculty } \\
\text { and admin. staff }\end{array}$ & $\begin{array}{l}\$ 12,000 \text { per } \\
\text { session for travel }\end{array}$ \\
\hline
\end{tabular}

Data Source: Washington State Department of Information Services, 1993.

Establishment of a telecommuting program may have travel reduction as an explicit goal, but it need not. An organization may seek other goals through 
telecommuting. A company that eliminates permanent offices for its sales force, equips each with a portable computer and telecommunications equipment, and raises the quota of daily sales calls in the field may very well increase the daily automobile mileage per worker while increasing its telecommunications use.

Peter Keen (1988) outlines in his book Competing in Time the various motivations for companies to set up new voice, data, and video telecommunications applications. These are shown in Exhibit 2-2. Transportation reduction is not on this list as a prime motivation, but it could be one result of implementing a new application.

\section{Ex 2-2: Business reasons for developing advanced telecommunications applications.}

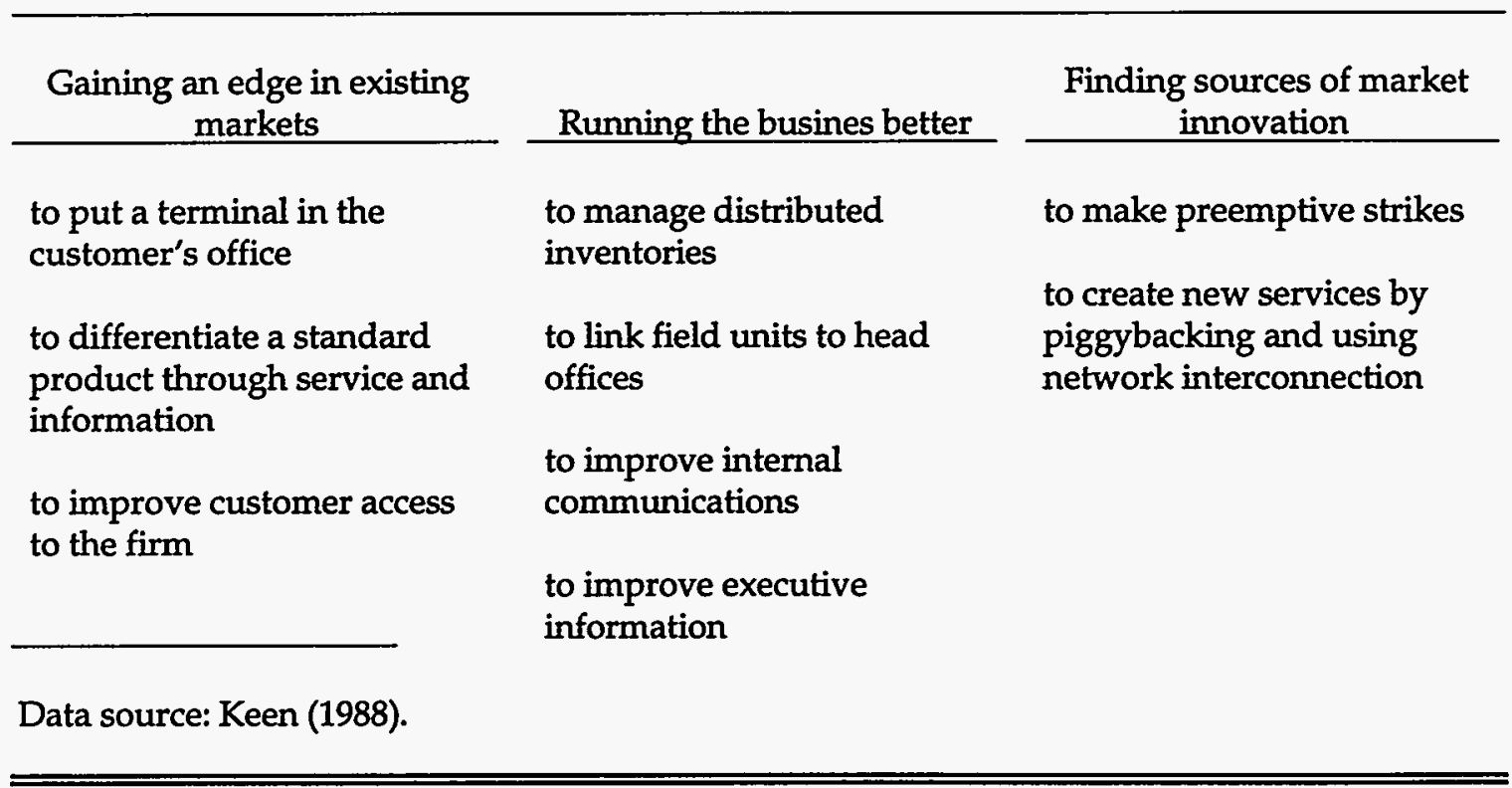

In general, organizations seek to achieve their production and service delivery missions by using facility, equipment, transportation, and telecommunications resources. These deployments yield new spatial, activity, and mobility patterns as a byproduct. Over time, these patterns include many ways in which telecommunications permits new methods of doing things that would formerly have required a trip.

\section{Is Overall Travel Substitution Occurring?}

Telecommunications and transportation both fulfill requirements for social and economic interactions, transactions, and other relationships, although in very different ways, as described earlier. There are millions of teleprocess events every day that amount to activities that could be done in alternative ways requiring more travel. Every telephone conversation, every data transmission, and every email message or fax represents a potential substitution of telecommunications for physical movement of people or paper. 
Telecommunications substitution for transportation is apparent on a small scale of analysis but is difficult to discover on a larger scale. Taken one by one, telecommunications transactions (faxes and teleconferences, for example) expand numbers of personal contacts and business trade areas. New relationships are established. More transactions and interactions occur. Even if $90 \%$ of the new interactions are done electronically, the remaining $10 \%$ involving personal visits or movement of physical matter via package shipment represents a net increase in travel.

Under present conditions of population growth, economic development, and public policy, the net result of human activity in the emerging information age has been a growing level of travel, as shown in Exhibit 2-3. Annual vehicle miles traveled (VMT) per household increased by $29 \%$ between 1983 and 1990, according to the Nationwide Personal Transportation Study, whereas the annual number of trips per household increased from 1,486 to 1,702, a gain of $15 \%$. For comparison, public switched telephone network minutes of use (MOU) are also shown. This measure is apparently growing at roughly the same rate as VMT, although a large but undetermined amount of telecommunications traffic over private telecommunications facilities is missed in the MOU measurement.

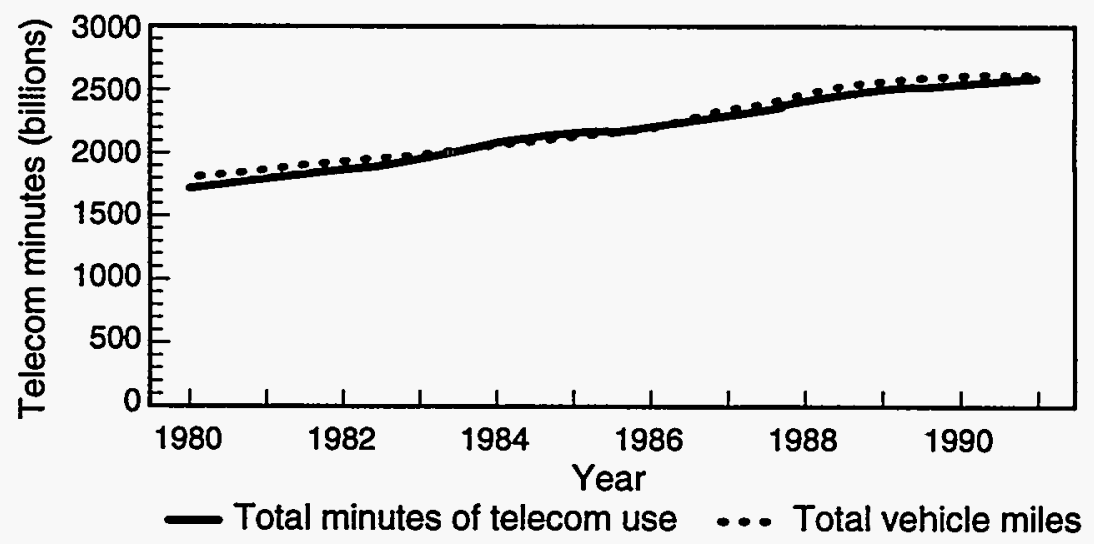

Ex 2-3: Same growth rate for telecom minutes and vehicle miles traveled. (Data sources: Federal Communications Commission and Motor Vehicle Manufacturers Association.)

Several recent, prominent studies of telecommunications substitution have been based on assumptions rather than on measurement. In a widely cited 1991 Arthur D. Little study of potential telecommunications impacts on transportation, substitution coefficients were derived from decade-old estimates made in Europe (Boghani, 1991, pp. 26, 30, 33). In the USDOT telecommuting study (1993), there similarly were no data or studies cited that actually measured historical travel substitution by telecommunications based on empirical data for a significant segment of the economy.

Some evidence for the prospect of telecommunications substituting for transportation lies in data provided to the State of Pennsylvania by DRI/McGraw-Hill from their proprietary databases describing the U.S. economy. DRI reports (Cronin, 1993) that the telecommunications intensity of the U.S. economy rose by $3.9 \%$ annually in the period 1965 to 1987 . This rate of increase in telecommunications intensity represents the telecommunications usage of 30 industries (including service industries) across 22 years. In 1965, the average 
industry used 27 cents' worth of telecommunications services to produce one hundred dollars' worth of output. In 1987, the comparable figure had risen to 62 cents per hundred dollars of output, more than a doubling. (All monetary figures are adjusted to current dollars.)

Over the same period, the use of transportation and warehousing services was falling from \$2.11 per hundred dollars of output in 1965 to $\$ 2.01$ in 1987 (Cronin, 1993a). This is a two tenths of $1 \%$ annual drop over more than two decades, during which time the price of petroleum energy was approximately doubling in constant dollars. Energy prices, therefore, were putting upward pressure on the economy's consumption of this input, which means that other economic factors must have been pushing transportation and warehousing services downward. These numbers are consistent with telecommunications substitution for transportation, although they are in no way a sufficient demonstration of such a relationship.

Selvanathan and Selvanathan (1994) analyzed transportation and communications statistics from Australia and the United Kingdom for the period 1960-1986. Using econometric tools, they concluded that communications demand was increasingly substituting for transportation demand in this period. Replication and extension of this work, with more interpretation of results for policy makers, is sorely needed.

There is no evidence that the movement of information in physical formats is slowing down because of telecommunications substitution. United States Post Office volumes are showing strong per-capita growth, as seen in Exhibit 2-4. Demand for overnight delivery services is growing at $20 \%$ annually (Burgess, 1990) even as the mix of shipped objects is changing. Fax delivery is cutting into physical document movement, but shipments of nonfaxable physical objects are growing in share. The movement of information through physical means is likely to remain an important component of the information age despite the availability of telecommunications. Physical information delivery includes such objects and events as full-color mail-order catalogs from retailers, CD-ROM disks holding 500 million characters of information, overnight package delivery, the rendezvous of a Hollywood movie print and a crowd of people at a cinema, wallet-sized smart cards with embedded microcomputer chips, and nationwide daily newspapers like the Wall Street Journal and USA Today.

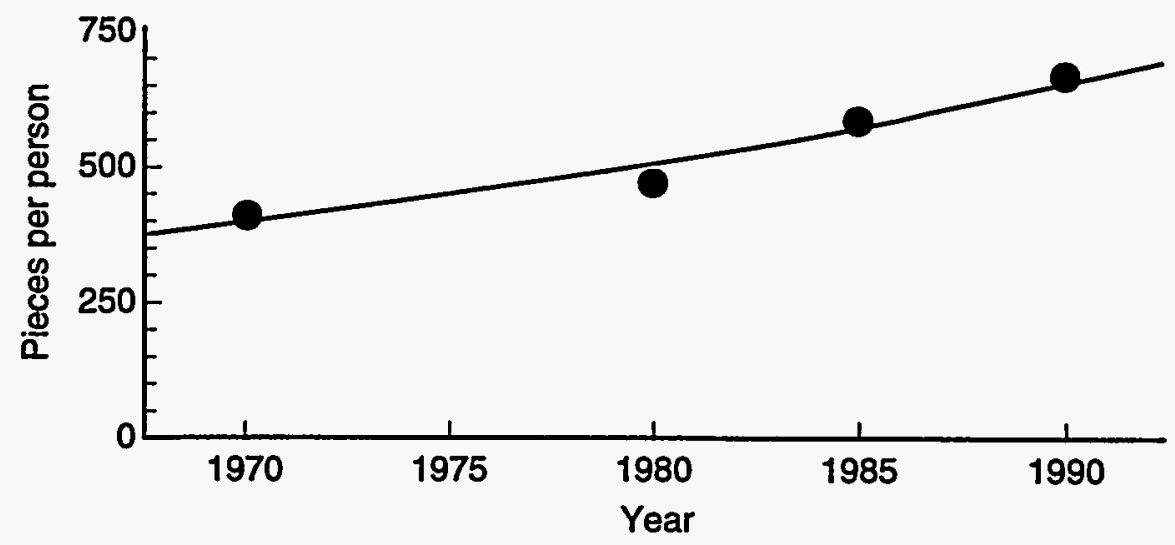

Ex 2-4: The volume of mail per capita is growing. (Data source: U.S. Postmaster General.) 
Surface transportation volumes seem to be pushing against the envelope of capacity more every year. For example, in the busiest metropolitan areas, traffic is closer every year to volume limits on freeways, and the resulting traffic congestion is growing worse (Exhibit 2-5). Despite opportunities to use telecommunications to reduce travel, people on average drive more every year.

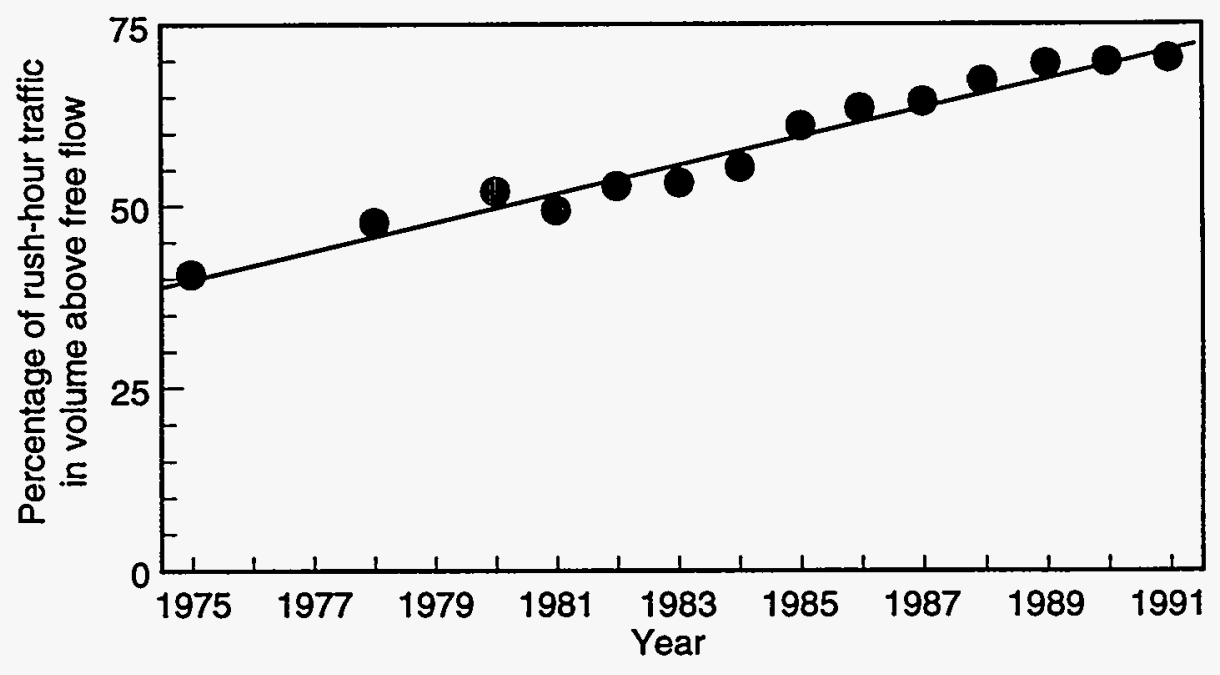

Ex 2-5: Urban freeway congestion is rising. (Data source: U.S. Federal Highway Administration.)

The phenomenon of latent travel demand is further support that transportation is a highly demanded service that will not be easily pulled down by the availability of telecommunications substitutes. Latent demand means use of roads that manifests only at times when free-flowing capacity is available. As an example of latent demand in a modern city that fully embraces the benefits of telecommunications, consider what happened in the Seattle metropolitan area when the new Interstate 90 freeway bridge opened up across Lake Washington in 1989: 40,000 new vehicle crossings per day materialized, a 60\% increase over traffic on the old bridge. This jump in traffic is dramatically illustrated in Exhibit $2-6$, on which an arrow shows the volume jump between 1988 and 1990. The new volume was not a net diversion from other routes nor from a mode shift. A comparison of the hourly average volumes on the new bridge before and after the bridge opening showed that increased traffic is maintained throughout the day.

Anthony Downs (1992) describes latent demand within rush-hour periods as a "triple convergence." He suggests that any free road space produced from marginal reductions in commuting (or from expansion of road capacity) is consumed quickly by three sources of ever-present demand: those traveling just outside of the peak time period who would shift back in, those driving on less optimal routes who would take advantage of lowered congestion on the most popular freeways, and those on slower public transit modes who would prefer driving if there were any more space on the road. Outside of commuting, latent demand induced by newly opened road capacity could include new vehicle trips by people who would not have otherwise made the trip or trips resulting from 


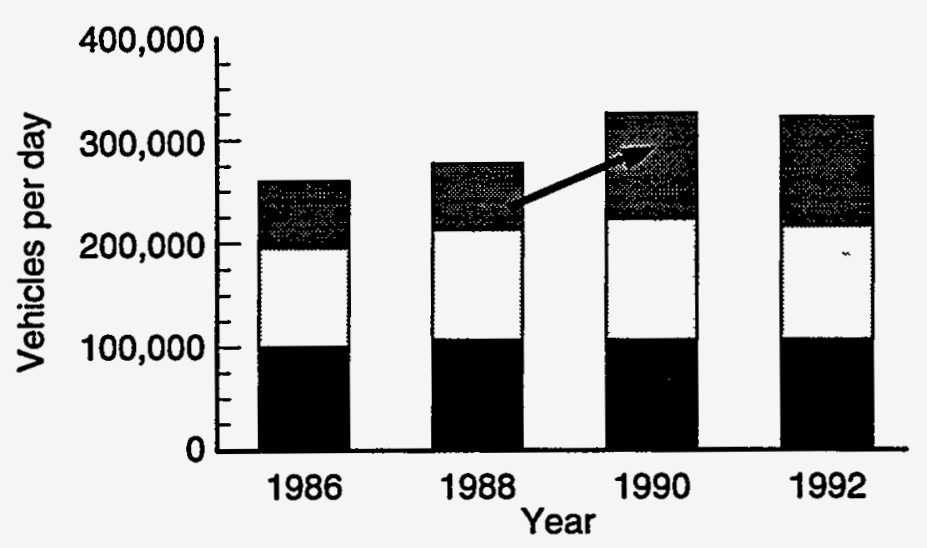

SR-520 (alternative) I-90

I-405 (alternative)

Ex 2-6: Latent travel demand illustrated when Seattle freeway bridge opened, 1989.

(Data source: Washington State Department of Transportation.)

drivers who select an alternate destination (i.e., shoppers who prefer a new mall over a downtown).

One analysis based on data from 339 cities estimates that, in the long run, each daily vehicle mile traveled that is removed from congested urban roads through telecommunications substitution will be $50 \%$ replaced by latent demand (USDOE, 1993, p. 91).

\section{Model of Interactions Between Telecommunications and Transport}

Exhibits 2-7 through 2-9 are a series of three graphics that illustrate the interaction effects between transportation and telecommunications. Each graphic in the series is a mathematical construction of arbitrary numbers and plausible economic effects unrelated to any empirical data. They are intended to illustrate generic structural relationships. These graphics are derived from a similar one shown by Salomon (1986).

Exhibit 2-7 illustrates the growth of telecommunications and transportation volumes with part of the telecommunications volume causing a trip reduction or substitution effect. Conventional wisdom and intuition yield this picture of how telecommunications and transportation interact with each other. In this model, transportation volumes are lower than they would have been if telecommunications were less used, because of the substitution effect. Note that both telecommunications and transportation are growing. 


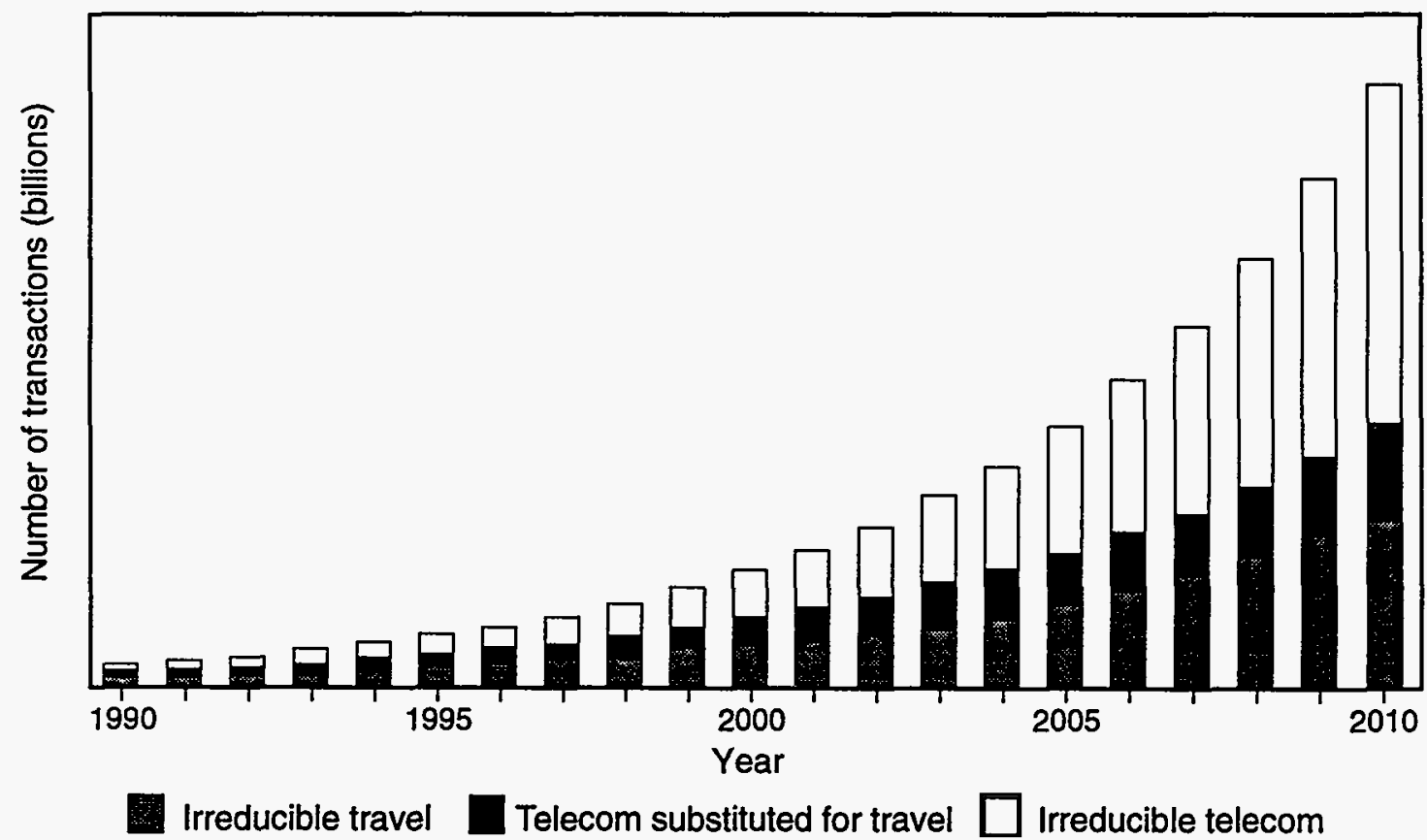

Ex 2-7: Simulation of telecommunications-transportation interactions (trip substitution only). (Source: Global Telematics.)

Exhibit 2-8 is just like Exhibit 2-7, with the addition of a trip-stimulation effect caused by telecommunications. The notion illustrated is that telecommunications may stimulate new trips, for a variety of reasons described in this report. In this exhibit, the trips that telecommunications stimulates are outnumbered by the trips that telecommunications replaces, so the effect of telecommunications is still one of net substitution. In this model, again, transportation volumes are lower than they would have been if telecommunications were less used, because the trip substitution effect outweighs the trip stimulation effect.

But what if trip stimulation by telecommunications were a stronger effect than trip substitution? This is the case illustrated by Exhibit 2-9. It is the same as Exhibit 2-8, except that trip stimulation is shown as having a greater effect than trip substitution, and the net effect of telecommunications on transportation is one of trip stimulation.

The key issue is the size of the substitution effect compared to the size of the stimulation effect. If substitution is greater than stimulation, then there is net substitution. If the reverse is true, then there is net stimulation of travel by telecommunications. Salomon (1985) suggests that the reality of the interaction between the two modes is simultaneous substitution and stimulation, the sum of both effects being net stimulation. 


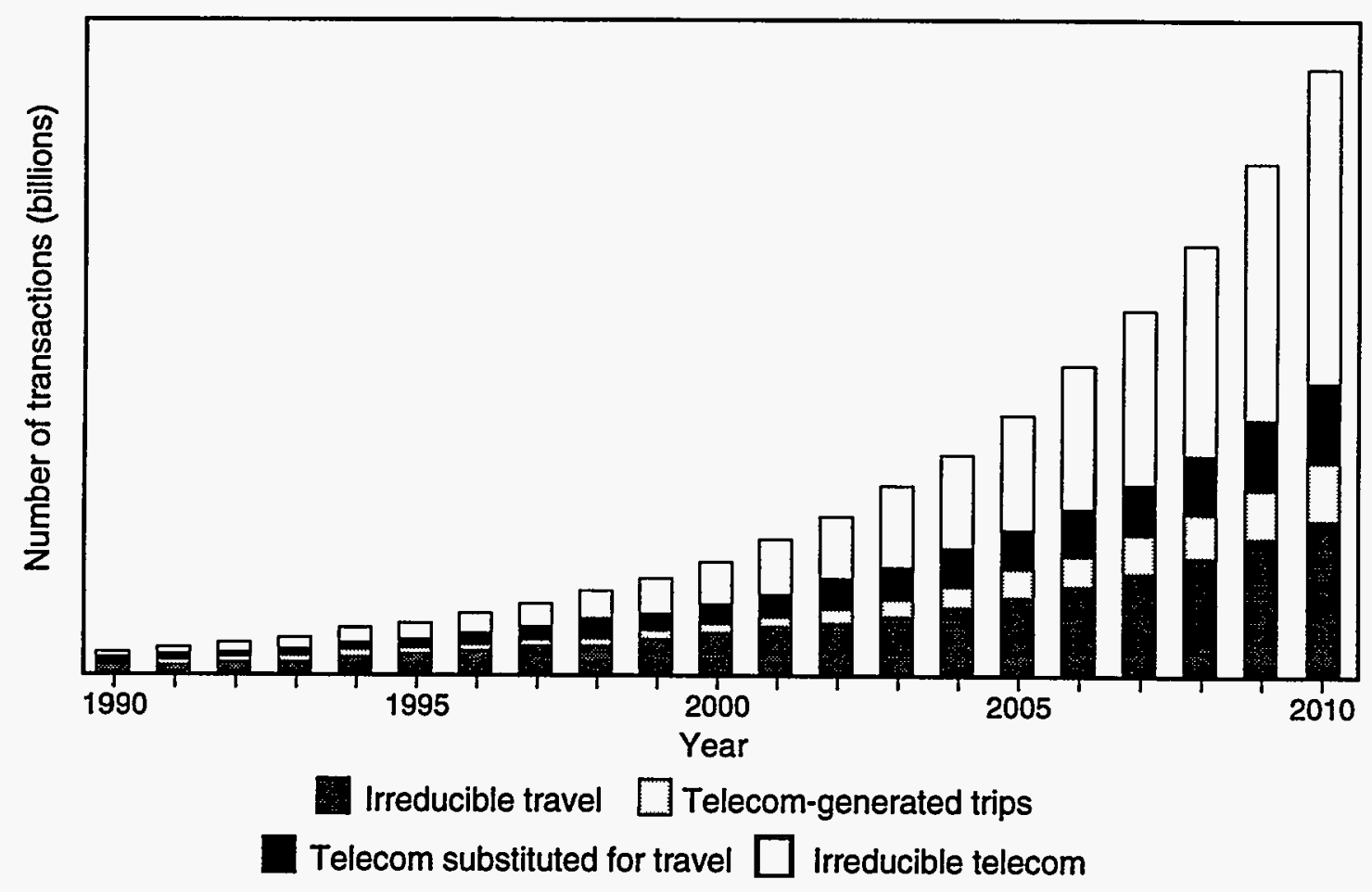

Ex 2-8: Simulation of telecommunications-transportation interactions (trip substitution greater than trip stimulation). (Source: Global Telematics.)

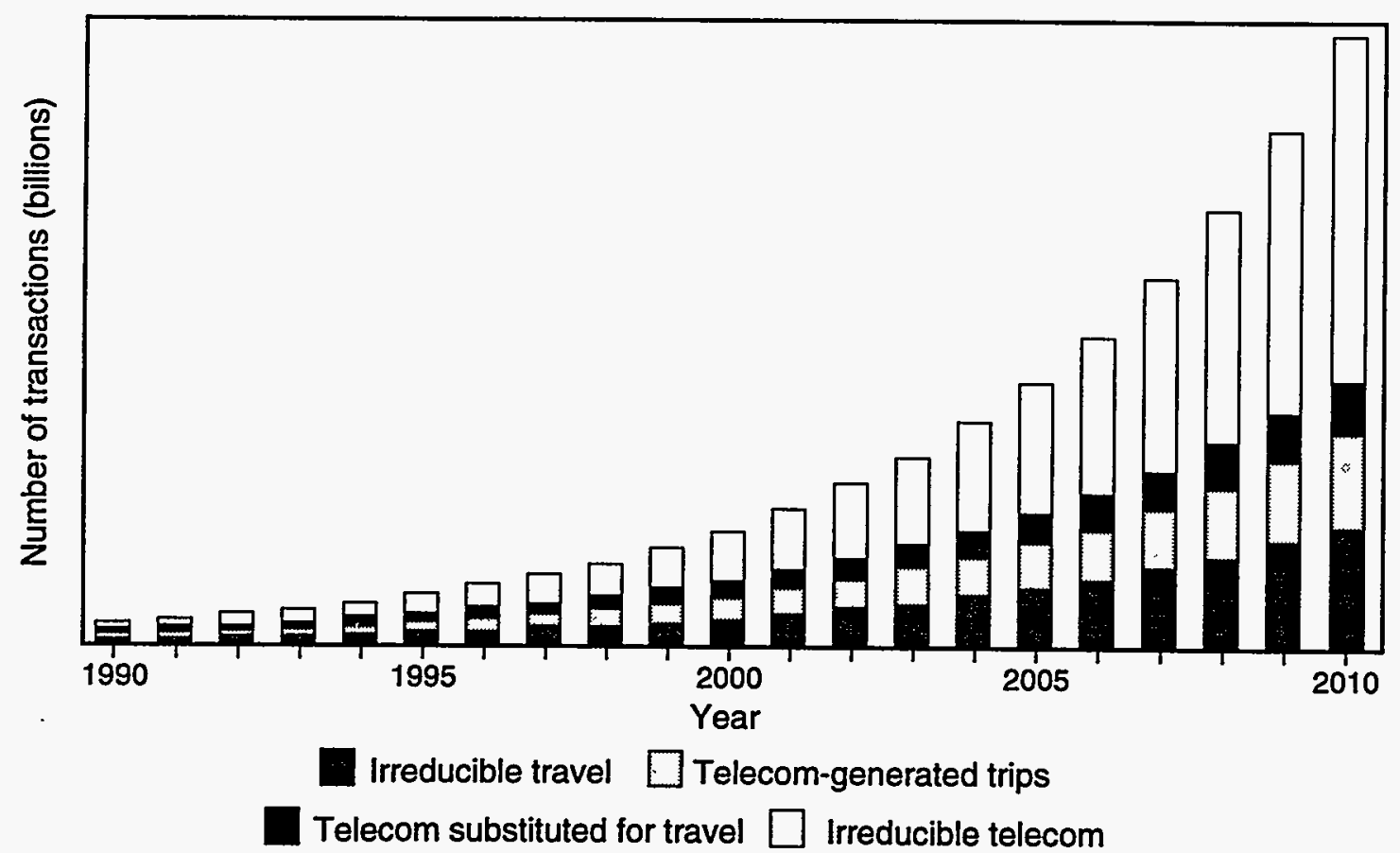

Ex 2-9: Simulation of telecommunications-transportation interactions (net travel stimulation despite substitution). (Source: Global Telematics.) 
The underlying complexity in determining the interplay of substitution and stimulation is shown in the following example:

A person may have several dozen electronic interactions with her bank every month through cash machines and electronic point-of-sale terminals. These same electronic transactions do not, however, replace several dozen trips to the bank, since she may have formerly made only one trip to the bank per pay period. Furthermore, her bank may well have been easily reachable on the drive home from work and thus may not have been a mileage generator. Going further, the most significant impact of the new electronic world she lives in may be the personal time savings from not waiting in line to deposit her check.

Then we must ask, "How are the time savings now used? Is there any new trip-making impact from more ready access to cash and electronic transactions?" Perhaps she is making more frequent trips to the ATM for smaller withdrawals of only the cash she needs and enjoying greater security in carrying smaller amounts of cash.

This study effort did not have access to the necessary data or to the analytical tools that would let the balance of travel substitution and stimulation be quantified. The present analysis does, however, provide enough data to show that telecommunications stimulation of travel is probably a strong counterweight to travel substitution, even though we are not able to prove how strong.

\section{Physical Proximity}

The most plausible argument for growing demand for travel and transportation lies in the simple observation that the closeness of physical presence often provides a better method of interaction than telecommunicationsdependent remote access. The superiority of being "on the scene" applies across many circumstances in the social, entertainment, leisure, and work domains.

For example, telecommuting is not for every job, every employee, every work group, or every company, as detailed in the USDOT Telecommuting Study (1993, p. 57) and in other telecommuting literature. Indeed, the USDOT study forecasts that telecommuters will be only in the range of $5-10 \%$ of the work force in the year 2002 (1993, p. 59, Table 6). Furthermore, telecommuting is almost universally established as a pattern that works best when practiced on some work days but not on all of them. Even half-time telecommuting is at the high end of telecommuting practice, which means that at least the other half of normal commuting is still occurring.

Physical proximity of workers in an office usually yields a high level of casual, serendipitous, spontaneous, nonintrusive communications among office staff. Communications between people who are nearby can be more easily synchronized to times when all parties are mentally ready to focus on the communications. The process of synchronization is much easier in an environment where people can see each other peripherally. Staff located in separate places must be much more intentional in their efforts to communicate. Appointments and interruptions are necessary for communications to take place successfully when people cannot see each other before beginning to communicate.

In office technology, despite the trend toward rapidly growing costeffectiveness in home office electronics, shared equipment in corporate 
commercial office space will always be able to provide powerful, heavy-duty capabilities that are too expensive or too large for most home offices. This is another reason for the importance of central offices.

There is work underway in Xerox Palo Alto's Research Center and other research labs to develop telematic tools that permit closer working collaboration among colleagues who are geographically separated. These include networked computer applications that permit workers to control and easily display on remote screens their willingness to be interrupted by colleagues. The different icons on a computer monitor are the telematic equivalent of leaving one's office door fully open, slightly ajar, closed, or closed and marked "unavailable." Other video communications arrangements have been designed to provide the equivalent of a casual, peripheral glance that offers little more than awareness of the presence of somebody in the remote location, equivalent to seeing somebody down the corridor on the way to lunch. Those researchers who study such environments report, however, that software and video tools for collaboration across multiple geographically separate offices provide a qualitatively different working experience than the face-to-face environment of proximity in a single office (Bly, 1993; Nakamura, 1994). One other conclusion is that remote collaboration through telecommunications is sometimes, but not always, "better than being there" (Hollan, 1992).

We turn now from telework to teleservices. Shopping malls provide customers with a variety of sensate experiences that are hard to duplicate through remote teleshopping: eating experiences, entertainment, changing exhibits, and opportunities to interact face to face with attractive and interesting people. Grocery stores are gradually moving toward the deployment of a variety of telecommunications-based systems, such as talking shelves and video displays on shopping carts (Grover, 1993), designed to motivate impulse buying by consumers. These features are not easily duplicated in a shop-from-home environment.

In health care service delivery, face-to-face interactions will be sought by people who want more than medical diagnoses and treatments from their doctor. These patients may want expressions of caring and concern in personal interactions (Nyberg, 1993, p. 99).

On the personal side, traveling to meet a friend or colleague for an enjoyable meal together is at the moment (and perhaps always) not satisfactorily achieved via telecommunications.

There are some circumstances where using telecommunications to avoid travel is controversial:

- Home schooling of children via TV and computer terminals as a substitute for traveling daily to a classroom, especially when traditional schools are available nearby.

- Running a growing, dynamic business from the residence where one lives for more than an initial start-up period, considered ill-advised by many counselors.

- Compulsive consumer attention to home shopping channels, video gaming and gambling, and ordinary entertainment TV.

- Remote jobs based upon low-paid piecework by docile, isolated, homebased workers, a use attacked by labor unions, other worker advocates, and progressive people generally, no matter what the level of savings. 
There is also a human need for the sensate experience of traveling. Travel satisfies an innate psychological need in some people. People enjoy the pleasure of driving, which is sold by auto companies like beer and soda pop. Travel relieves boredom and provides a changing visual input as scenery passes. A small portion of personal travel is without a functional purpose related to the destination: cruising, wandering aimlessly, looking for excitement, and so on.

In summary, human preference for management by walking around, eyeballing, and touching yields an emphasis on transportation over telecommunications that shows up in the allocation of resources across all of human life, both personal and organizational. Household and organizational budgets in support of travel and proximity (transportation, events, buildings, and other expenditures that bring people together) are much higher than those for telecommunications.

\section{Expansion of Relationships}

Though there are numerous examples of telecommunications providing opportunities to reduce travel, telecommunications also acts in many ways to stimulate the demand for travel.

Telecommunications and travel both involve relationships, as discussed earlier. Maintenance or growth of a relationship of any kind (personal, professional, or business; relationships to people, relationships to activities, and relationships to places) often profits from the direct presence that is the result of travel as well as from the remote interaction made possible by telecommunications. For example,

- If I have a friend, I both travel to see that friend and converse on the phone.

- If I like baseball, I go to see games, and I watch on television when I can't make it to the stadium.

- If I have a customer, I maintain the relationship both in person and with phone calls.

Furthermore, relationships often include the exchange of letters, packages, and other physical objects, which require transportation services.

The existence of cheaper and better voice mail, fax transmission, and e-mail expands the number of people with whom one communicates or increases the number of transactions that require the movement of paper and goods. Higher levels of personal and professional interactions established through telecommunications generate demand for follow-up face-to-face interaction that requires trip-making. Spectacular growth in the use of the worldwide Internet computer network has spurred more international collaboration among scientific researchers in developing countries.

Consider a business that is able to sell its products over a wide geographic area through telemarketing. The development of customers in distant cities entails higher levels of both transportation and telecommunications. Consider a family unit that separates, one spouse and perhaps the children living in one city and the other spouse living in a distant city. This split family likely becomes a big consumer of both telecommunications and transportation services. 
The more people one calls on the phone or exchanges e-mail with, the more people are candidates for face-to-face meetings. This complementary nature of telecommunications and travel is especially true when both sides find the relationship desirable, but it is also true when relationships are one-sided. Consider the activities of the police, the Internal Revenue Service, and bill collectors. They use a mixture of telecommunications and travel: phone calls, letters, and visits.

The $38 \%$ of leisure time that the average American spends watching TV is time not spent traveling, but presumably the advertising on TV causes people to spend some of their non-TV time traveling to stores to buy things. Higher, more effective levels of TV and radio advertising, telemarketing, and direct mail marketing generate new demand for travel to described locations or generate product shipments on trucks to fulfill customer demand. (Direct mail is telecommunications intensive in that " 800 " telephone numbers are often part of the order fulfillment process or the mailing list generation process.)

Many, and perhaps most, uses of facsimile and electronic mail do not represent replacements of overnight express package shipments, postal mail, face-to-face meetings, or even other telecommunications modes but rather are communications that simply never would have been considered prior to the availability of these new electronic tools. The highly competitive overnight delivery industry represented by companies like Federal Express and Airborne Express is growing despite the rapid growth of facsimile and electronic mail as means to transmit documents.

The history of videoconferencing over the past 20 years illustrates that the fastest growing applications are not travel substitutions but rather new interactions that had never been allowed to take place using travel resources. The travel-intensive alternative for carrying out these interactions was too expensive (including being too impractical or in violation of rules or customs) to be allowed. Several studies of videoconferencing as an attempt to substitute for face-to-face meetings revealed that total travel increased (Mokhtarian, 1990; Egido, 1988).

Although videoconferencing vendors reported a surge of interest in using their equipment and services during the Gulf War of 1991 as a replacement for long-distance travel (Burgess, 1991), one empirical study on the subject from Norway found no surge in telecommunications activity during the war and a pattern of postponed trips rather than one of trips replaced (Erdal, 1992).

The reach of telecommunications thus generates the knowledge of locations to visit and the motivating relationships to go there. Furthermore, telecommunications creates the linkages that allow travelers to stay in touch with people, work processes, and events back home, thus making travel more feasible. Voice mail, paging, and other telecommunications techniques make people more accessible and productive on an "as-needed" basis while operating in the distant locations that result from travel. If a professional has access to a document on a portable computer via modem attached to a hotel phone, that capability reduces the requirement to stay near the office.

Even if broadband telecommunications becomes more like "being there," the value of using travel to focus human attention exclusively on face-to-face presence, sensate experience, and physical interaction at meetings, places, and events will rise as a principle of economics. Opportunities for such physical presence are inevitably limited by the time and money limits of using transportation, whereas broadband telecommunications creates a world that 
exponentially enlarges the universe of choices for remote access to information and for interaction. A physical meeting when there are a universe of telecommunications-based alternatives will inevitably have higher value than a video phone call, because the face-to-face meeting illustrates focus on and commitment to a relationship.

In summary, the tendency for telecommunications to substitute for some trips is countered by the propensity of telecommunications to enlarge travel demand. By increasing the total number of relationships that generate travel, the amounts of both transportation and telecommunications are increased.

\section{Geographic Dispersal}

The same telecommunications capabilities that make some trips unnecessary also support and amplify the land use patterns and densities, and the resultant origins, destinations, and activities that cause growing amounts of vehicle travel. These land use patterns can be characterized as a mix of centralization and decentralization yielding, in effect, an archipelago economy. Metropolitan areas of all sizes are the islands, and rural areas are the sea. Transportation and communications between the metropolitan islands are critical to economic functioning. The hotels and meeting rooms of cities serve as places for face-to-face encounters.

The continuing strength of city nodes is a reflection of the clustering patterns that occur as a result of agglomeration economies and the accumulation of critical resource mass. Telecommunications networks organize around city patterns very well, with switching, points of presence, order taking, and other network management functions located where there is access to a work force.

So, population and business activity are growing fastest within metropolitan areas rather than in nonmetropolitan, more rural areas. Within the larger metropolitan areas, however, the forces of the partially regulated market economy are causing a pattern of decentralization and sprawl, known lately as Edge City (Garreau, 1991), to develop. Sprawling suburban patterns of residential, employer, and service locations are understood by transportation analysts to be the nation's major generator of automobile travel. The nonmetropolitan areas growing the fastest are those directly adjoining metropolitan areas, in transformation toward becoming part of the metropolitan region in a future population census. As the metropolitan areas sprawl outward into surrounding rural counties, becoming what Ed Risse (1993) calls the "new urban regions," traffic must travel on typically less developed roadway infrastructure, generating worsening congestion.

Transportation analyst Alan Pisarski (1992) has analyzed the growth of vehicle miles traveled (VMT) during the 1980s and found that it can be statistically traced to the following five factors measured by the Nationwide Personal Transportation Survey (NPTS) and the U.S. Census: population growth, growth in the number of daily trips per household, longer average trip lengths, lower automobile occupancy loads, and falling public transit use. The relative weights of these five factors are shown in Exhibit 2-10. All five are quite prominent, ranging in relative contribution to VMT growth from $13 \%$ for population growth, to $36 \%$ for the longer average trip lengths. 


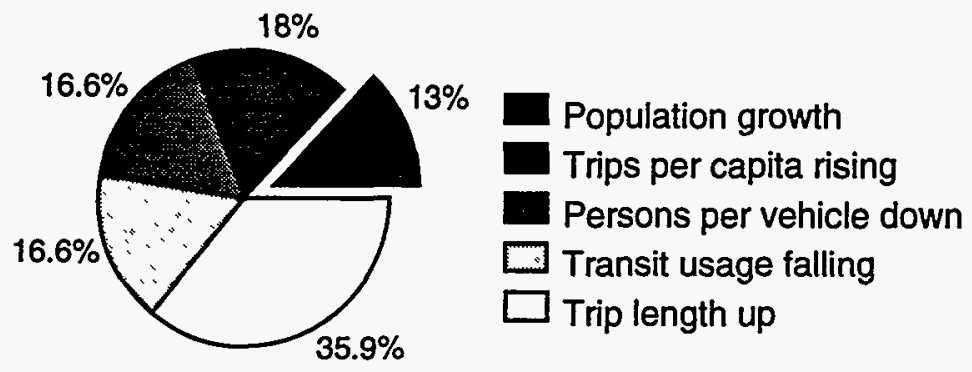

Ex 2-10: Causes of travel (VMT) increase, 1983-1990. (Data source: Pisarski, 1992.)

Each of these five VMT growth factors is strongly linked to the continuing expansion of the suburbs as the dominant place for Americans to live and work. Population growth is now occurring mostly in suburban parts of the U.S., as seen in Exhibit 2-11. The suburbs are now home to $46 \%$ of the population. Most employment and retail growth is taking place in the suburbs as well. Of the new office space constructed since $1970,80 \%$ is outside central business districts (FHWA, 1992).

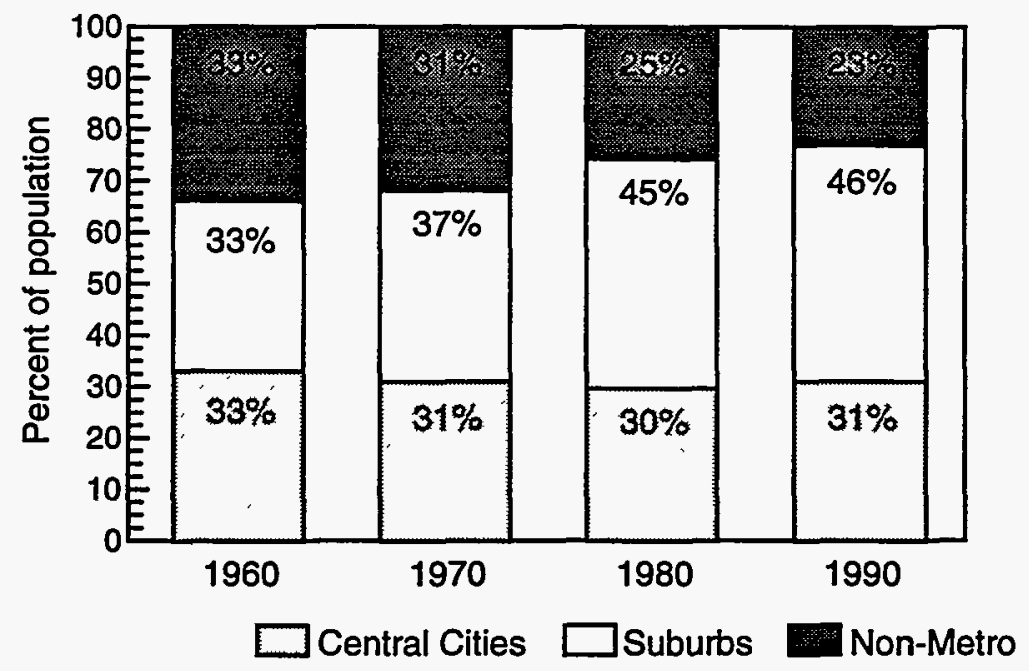

Ex 2-11: Growing suburbanization. (Data source: Census Bureau.)

The lower densities and dispersed destinations of the suburbs lead to more trips and longer trips. The inability of the public transportation industry to offer services that gain significant market share in suburb-to-suburb commuting and the dispersion of destinations lead to the dominance of single-occupant automobile use as the best way to make on-demand, rapid, door-to-door movement.

The ongoing deployment and use of telecommunications has been a cause of suburbanization in the United States. Causation here means that including the history of the deployment and use of telecommunications in a history of U.S. suburbs provides a better explanation of how and why they have evolved than excluding the development of telecommunications. Analysts would also assign inexpensive real estate on the metropolitan periphery and increasingly affordable 
access to automobiles as causations. Telecommunications, automobiles, and inexpensive real estate are each necessary but not sufficient conditions for the development of the sprawling suburbs that have arisen since World War II.

In analyzing the role of telecommunications and land use, some would hold that telecommunications is a neutral facilitating technology that could just as well have supported more centralized, higher density patterns as it did the suburban land use patterns that in fact have come to dominate the U.S. scene. Perhaps, but what is striking is in fact how the Edge City pattern found from coast to coast is now universally shaping metropolitan areas that began at such different times in the history of the country and with such different economic and lifestyle bases.

The first mass telecommunications medium, the telephone, rose to prominence when a significant portion of the population still lived in rural areas but when the center cities of the early 20th century were growing as well. Central city downtowns were facilitated in their growth by the deployment of technologies that served to put large numbers of working people into close proximity: mass transit systems, skyscrapers, and elevators. The automobile and telephone were widely adopted, after the first stages of deployment of these technologies of closeness, to make remoteness work better, including facilitation of taller skyscrapers and making a major improvement in the quality of rural life. The multiple Edge City office complexes and industrial parks of the suburbs are a product of technologies that limit and control mass proximity by providing only limited and controlled access: automobiles on freeways and multifunctional, computerized telecommunications. Newer forms of telecommunications (for example, cellular phones, voice mail, alphanumeric paging, and wireless e-mail) make remoteness and mobility work even better (Pratt, 1993).

As USDOT noted in its telecommuting study, telecommunications and information technology "have made possible a high degree of geographic decentralization of work, characterized by an almost continual flow of telephone conversations, faxes, and overnight express packages on a national and international scale. Customers, colleagues, and suppliers are increasingly likely to be physically distant, linked by modern telecommunications and other services" (USDOT, 1993, p. 9).

The role of telecommunications as one cause of the development of the suburbs is conventional wisdom among analysts of suburbs (Fishman, 1990; Garreau, 1991; Downs, 1992). Suburbs began as new residential zones, followed initially by shopping and other services and later by manufacturing and office employment locations, including many relocations from downtown and centercity locations. Simultaneously with the rise of the suburbs since World War II, telecommunications has become increasingly necessary for basic business functioning. All production of goods and services is becoming increasingly telecommunications intensive, as described earlier.

There are several underlying reasons why telecommunications has been a stronger support technology for the suburbs than for the central cities or for the rural areas that are more distant from metropolitan areas.

First, the growing capability of telecommunications allows businesses and other organizations to locate operations more flexibly, where managers want them to be located. Where managers want to be, more and more, is suburbia. The lower density settlement patterns that characterize suburbia have natural 
strengths in the modern economy, including how they resonate with telecommunications-based growth opportunities.

Inexpensive space in the suburbs is a critical requirement for the newer, smaller firms that grow up as strong users of new telecommunications technologies. Larger, more flexible space available in suburbs allows for rapid changes in configuration and tenant commitment that are necessary for survival in the wired, high-speed, chaotic new economy.

A greater choice of newly constructed buildings allows for provision of new inside wiring for telecommunications. Clearer, more nearly interference-free, less restricted, and more abundant roof space gives line-of-sight access to satellites and distant microwave towers. Radio frequency characteristics in lower density areas are less problematic than those found in busy downtowns.

Larger floor space options and more room for parking allow customer access from a wide geographic area. Thus, national chain stores can capitalize on the economies of scale that arise from telecommunications-intensive systems.

Better public schools for employees' children are typically found in suburbs, compared to central city schools. Suburban schools generally have more computers and are doing better at using them in the curriculum. Suburbs provide better access to more educated and skilled job applicants, including those having a stronger facility in using telecommunications and computers. Telecommunications makes having back offices and branch offices in locations closer to suburban workers possible because of telecommunications connections to traditional center city headquarters.

Finally, movement to outlying suburbs is sometimes made in search of better access to suppliers in order to receive frequent just-in-time shipments, as described later in this chapter. National and export-oriented businesses seek better access to airports, typically located on city outskirts. Air travel is a complementary means of getting to the distant markets that are opened up through telecommunications.

Robert Reich, in The Work of Nations (1991), writes of the clustering instincts of symbolic analysts, the $20 \%$ of the U.S. work force that solve, identify, and broker problems by manipulating symbols. Reich associates these professional people-managers, designers, engineers, scientists, lawyers, and consultantsvery closely with the computer and telecommunications tools with which they work. "Symbolic analysts can work almost anywhere there exist a phone, fax, modem, and airport" (pp. 294-95). They choose, however, to cluster in suburbs located near universities, research parks, or corporate headquarters as a way of seceding into communities of like-minded people with similar incomes and values (pp. 271-272).

Some transportation planners have lately taken to predicting that more successful metropolitan-area transportation services than those seen to date are going to require policies that begin to shape land use into a series of relatively high-density residential clusters, employment clusters, and service clusters. These clusters would have to be arranged in a pattern of geographic proximity ready to be served by new public transportation modes that substitute for the single-occupant automobile. Advocates of such land use changes may regard telecommunications as a neutral tool available for use by governments legislating new land use and zoning regulations that fit this less transportation-intensive vision. For example, government policy could stimulate the development of 
telework centers within walking distance of residential neighborhoods. Telecommunications technology would permit these centers to exist.

While these kinds of spatial rearrangements could in theory be established as a goal in the public interest, our reading of present government policy and market forces is that telecommunications, like the automobile, has become a relentless force shaping the suburban-dominated social, economic, land use, and transportation patterns we see actually emerging almost universally across America already. Consequently, major changes in the momentum of these patterns, even at the suburban edges of growth, are not going to be easy to achieve without significant modifications to the current mix of residential choices made available to consumers as well as changes in the cost of doing business. A policy framework of providing consumer and business management choice is likely to continue as a necessity, with limits on the level of compulsion that is feasible, not to mention desirable. A first step in using policy tools to change living and working patterns requires understanding how telecommunications and market forces now shape these patterns.

To summarize this section, the evolving deployment and growing use of telecommunications are important facilitating causes of the suburbanized metropolitan land use patterns and the resulting mobility demands that have emerged nationwide.

\section{Economic Restructuring}

Telecommunications usage has caused growth and structural change in the economy, which in turn have led to growth in the use of transportation.

We explained in an earlier section of this report that travel savings are not the usual motivation for the implementation of teleprocesses but that travel saving could sometimes be a result. In this section, we focus on the economy as a whole and show how teleprocesses act to increase the use of transportation in the economy through restructuring that requires more movement of people and goods. These effects are related to but distinct from the geographic dispersion effects described in the previous section.

There are two underlying economic mechanisms: qualitative and quantitative. Qualitatively, telephenomena drive economic restructuring. Quantitatively, telephenomena drive economic growth. Both the qualitative effect of restructuring and the quantitative effect of growth stimulate higher levels of trip making.

The growing dependence of American business on telephenomena is shown by Morgan Stanley calculations that information technology capital as a share of total industry capital across the combined manufacturing and service sectors has grown from $4 \%$ in 1960 to $14 \%$ in 1991 (Roach, 1993).

Examination of national economic data by DRI/McGraw-Hill and Parker Telecommunications has demonstrated that telecommunications investment causes economic growth (Cronin, 1991) and productivity improvement (Cronin, 1993). The authors of the latter study calculated that, over the period 1963-91, the portion of total economy-wide productivity gains attributable to advances in telecommunications averaged $25 \%$.

The economic growth stimulated by telecommunications investment causes more use of transportation as the production and delivery of goods and services 
increases. For example, the vehicle miles traveled by single-unit trucks with more than four tires rose $4.1 \%$ annually in the period 1982-89 (Davis, 1992, p. 3-40). Economic growth in turn causes further growth in telecommunications investment, and the cycle continues (Cronin, 1991).

Productivity improvement leads in the long run to personal income growth. To the degree that a telecommuter, for example, consistently gets more work done in the same number of working hours, the employee and the organization perform better and incomes increase. Higher household incomes lead to more consumption of transportation, as seen in Exhibit 2-12. This graphic shows household spending for transportation and all telecommunications, including computer hardware and television. Spending is much higher for transportation; at the same time, elasticity of demand as personal income rises is higher for transportation than for information technology.

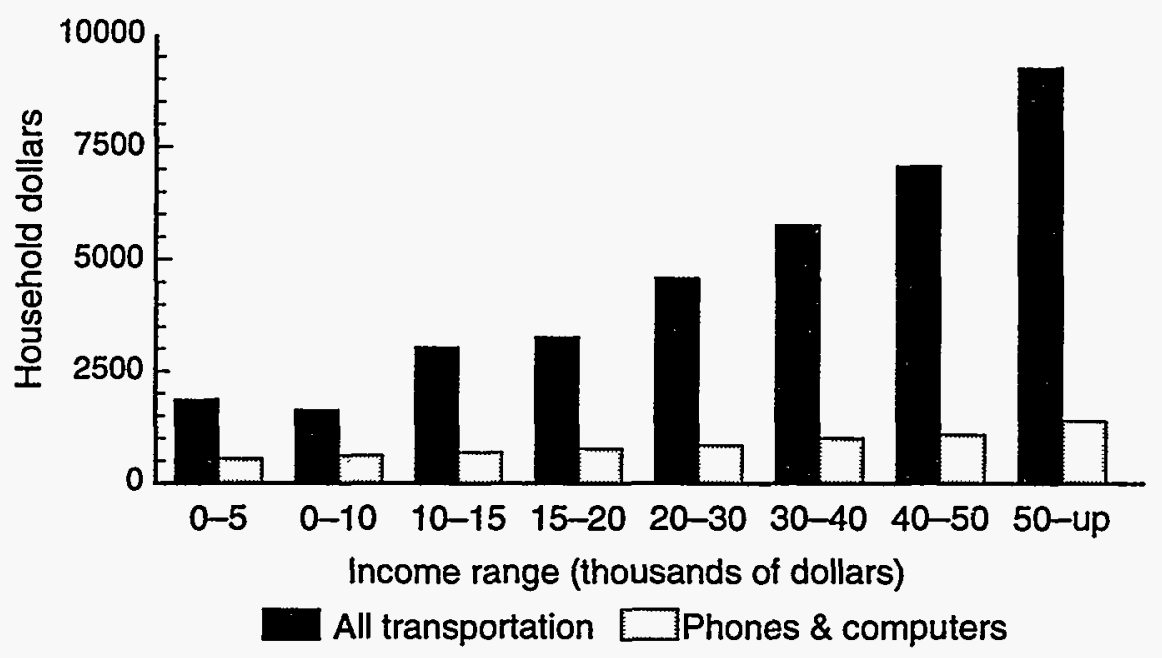

Ex 2-12: Transportation and telecom consumer expenditures grow with income. (Data source: Bureau of Labor Statistics.)

Telecommunications and teleprocesses also create structural changes in the economy that lead to more use of transportation. The most important of these are a more rapid pace of activity and increased pressure for improved performance.

Companies tend to move faster in the face of competition coming from all directions. The time it takes to bring a product to market is critically important to the product's life-cycle profitability. Telecommunications-based service processes can start sooner and be completed faster, which is valued by customers.

Telecommunications (including e-mail, voicemail, portable computers, and cellular phones) establishes a faster rhythm. As noted by Alvin Toffler (1990), because of telecommunications and computers, the most modern, competitive societies are moving faster than the rest. He writes, "In fast economies... [the] pace is determined by the speed of transactions, the time needed to take decisions (especially about investment), the speed with which new ideas are created in laboratories, the rate at which they are brought to market, the velocity of capital flows, and above all the speed with which data, information, and knowledge pulse through the economic system" (Toffler, 1990, p. 397). 
One manifestation of a faster economic pace is the change seen in manufacturing. This sector is being restructured in response to technological innovation, competition, and rapidly shifting consumer demand. The new manufacturing models are information intensive and depend on more predictable flows of supply inputs and product outputs. These changes hold major implications for transportation and energy policy makers.

In the new manufacturing model, mass production of standardized products is giving way to shorter production cycles of customized products at higher levels of quality. In the new manufacturing model, productivity gains result from the introduction of information technology that supports every aspect of the production process, from product design to timely product delivery. More workers are information specialists involved in pre- and postproduction functions. Fewer actual shop floor workers are needed. They too are information workers, as increasingly their job is to monitor computer-guided machinery.

In manufacturing today, the timing of production inputs and outputs is increasingly critical. Time-sensitive operations are called "just-in-time" (IIT). In JIT manufacturing, customer orders, rather than market demand forecasts, determine production schedules, which in turn dictate supply schedules. Parts flow to production facilities and products to customers on a just-in-time schedule. Inventory management in JIT manufacturing substitutes electronic supply ordering for parts on a warehouse shelf. Suppliers may produce and deliver parts as they are needed in response to automatic messages from the manufacturer's production information system. For example:

"Four or five times a day, employees at Dana Corporation, a $\$ 5$ billion automotive-parts supplier based in Toledo, Ohio, dial into an IBM mainframe at Ford Motor Company in Dearborn, Michigan. Their mission: find out whether they need to ship more automotive parts to Ford. Dana employees-schedulers and material managers-call up a menu listing the parts they regularly supply to Ford and start checking. Is Ford experiencing any parts shortages?" (Alter, 1993).

Just-in-time manufacturing has an important effect on transportation demand. Since JIT requires a continuous flow of inbound supplies to support a continuous flow of products out, the transportation patterns it produces are fundamentally different. Rather than large, infrequent delivery of parts by tractor trailer or rail car, parts are more likely to arrive frequently by small trucks and vans. Product shipments will also decrease in size and increase in frequency. At the same time, this dynamic tends to cause suppliers to locate facilities closer to their customers.

A more rapid pace of activity leads to increased pressure on people to use time more efficiently. Saving time is sought in all activities, including more single occupant vehicle use and overnight package delivery, both of which consume more energy than slower modes. Jumping into one's car and driving solo to the office or to an off-site meeting usually takes less time than waiting for the bus or coordinating a shared ride with a co-worker.

At the same time, workers are under pressure to do their usual job plus the job of a laid-off co-worker. Employer expectations for greater productivity, fewer errors, and speedy outcomes are higher. This seems to be translating into longer working hours. Juliet Schor (1992) writes, in The Overworked American, about the increasing number of hours spent on earning and spending and the decline in time spent around the home. She estimates that the average employed person 
worked 163 hours more in 1987 than in 1969, or the equivalent of one month more per year. Workers are spending more hours per week and more weeks per year on the job-sometimes on two or more jobs.

More time is also spent in job searches and in waiting for a call to work as the economy shifts to a worker-on-demand model. U.S. firms are placing increasing reliance on contract employees. Every day, 1.5 million temporary employees report to work, mainly doing work that used to be done by regular, full-time employees. The largest private employer in North America is the temporary help company Manpower, Inc., with 560,000 workers. Manpower Chairman Mitchell Fromstein says that "The U.S. is going from just-in-time manufacturing to just-in-time employment" (Castro, 1993).

As families spend more time working, less time is available for family and personal activities, including normal household work such as preparing meals and washing clothes. Travel data indicate that busy families compensate for the lack of home time and human energy by reducing their household labor and purchasing outside services. This is reflected in the rapid growth of trips that fit the category of "other family and personal business." Both average annual vehicle trips and vehicle miles traveled for this purpose more than doubled from 1969 to 1990 (Pisarski, 1992).

Commonplace consumer services delivery to homes in new ways via telecommunications offers some potential for working families to save time in the responsibilities of everyday living and to eliminate some trips as well. Renewing driver and pet licenses, interacting with the bank or an insurance broker, attending an evening training seminar, participating in job interviews, locating a new house or apartment, and even selecting groceries for delivery could potentially emerge as common uses of an interactive, broadband National Information Infrastructure reaching into millions of homes (Hadden, 1993). Whether the expansion of knowledge, choices, and relationships from such a telecommunications capability expands travel demand for purposes not served by network use is unclear.

\section{Telecommunications as a Force for Improving Transport}

Telecommunications also has a stimulative effect on travel by making the transportation system work better than it might otherwise. People and organizations use telecommunications to make transportation and travel safer, faster, more reliable, and more productive.

One way this happens is that increasingly better and less expensive wireless telecommunications, such as cellular telephone service, lets people stay accessible and productive while in motion. Cellular telephone growth is very strong, as shown in Exhibit 2-13.

Furthermore, in the information age, transportation is being redefined. With greater use of information technology, raw transportation value decreases, but the other attributes of transportation-speed, timeliness, accountability, predictability, flexibility, and responsiveness-become more important. Information technology applied in the sectors that transportation serves is the force that creates the demand for these attributes. Information technology applied to transportation itself is what can provide these capabilities. Officials can now apply to. transportation the same information substitution principles that are emerging in other sectors. 


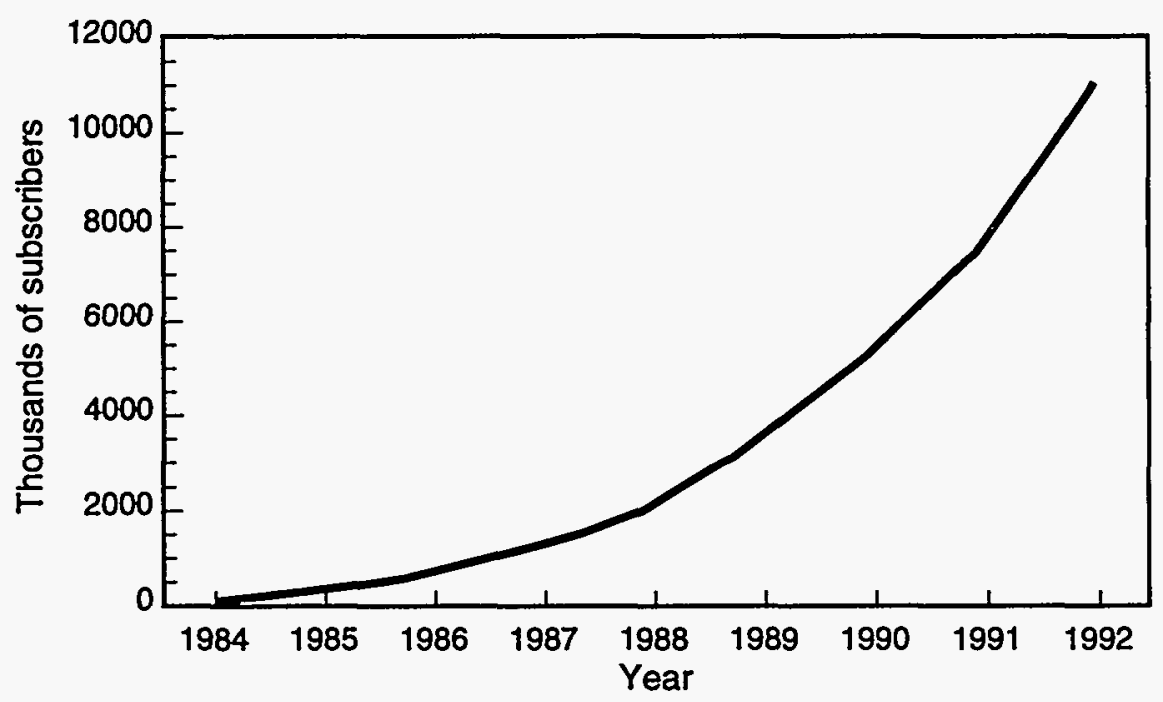

Ex 2-13: Cellular phone use is soaring. (Data source: Cellular Telephone Industry Association.)

The dominant automobile-based portion of the transportation system is moving toward higher levels of integration with telecommunications, such as microprocessors networked together inside every auto and multiple telecommunications systems serving travelers [such as AM/FM radio receivers, cellular phones, Advanced Traveler Information Systems (ATISs), and satellite Global Positioning Systems (GPSs) for navigation]. Overnight package delivery is completely telecommunications intertwined, every package, vehicle, and pickup or delivery location being tracked by powerful real-time telecommunications systems.

Intelligent vehicle highway systems (IVHS) research and development programs are an effort by business and government to apply telecommunications toward making rubber-tired vehicle travel work better, especially by increasing the capacity and maximum flow rates on existing roads. The IVHS concept offers the potential to reduce vehicle travel times or at least make travel time more predictable. Initial IVHS systems are providing drivers with information about traffic conditions and alternatives on a real-time basis to permit a greater measure of route deviation to avoid congestion. Intelligent vehicle highway systems could also be designed to improve the performance of buses, carpools, and other high-occupancy vehicles by giving them an information access advantage on the road that supplements the advantage offered by diamondmarked lanes (Niles and Toliver, 1992).

\section{Conclusion}

Our reading of the evidence presented in this chapter is that the net effect of telecommunications and of all other travel motivations across the economy and society as a whole is to increase simultaneously the usage of telecommunications and transportation. There are just as many ways that telecommunications serves to increase trip making as there are ways that telecommunications saves trips. Whether telecommunications is serving as a net reducer of travel demand is 
unclear pending future results from a sophisticated, computer-based analysis of travel and telecommunications data from an entire nation or large region. This is discussed later as a recommendation. 


\section{Chapter 3}

\section{POLICY ANALYSIS}

Telecommunications and vehicle transportation are two important modes of interaction. Surface transportation delivered 3.2 trillion domestic passenger miles to the U.S. economy in 1989. The public switched telephone network delivered 2.5 trillion minutes of telecommunications connections. These two systems deliver transactional and relationship value to the American people at similar order-of-magnitude volumes if personal time is used as a common denominator for transportation volume and telecommunications volume. (3.2 trillion passenger miles at $30 \mathrm{mph}$ equals 6.4 trillion passenger minutes. 2.5 trillion minutes in phone conversations between two people equals 5 trillion user minutes.)

Transportation and telecommunications will both continue to be key inputs to U.S. economic performance and quality of life, and both modes need continuing government attention to the design and implementation of public policies. Public policies for telecommunications and transportation need to overlap and be coordinated in light of how telecommunications and transportation interact. This chapter describes how government and civic leadership can respond to the interplay of the two modes.

\section{Telecommunications Infrastructure Policy}

Some public policy analysts have argued that government regulatory changes aimed at accelerating the deployment of switched broadband telecommunications to residential premises, small businesses, and community service facilities such as schools and libraries would boost the use of telecommuting and other travel-substituting applications of telecommunications (Boghani, 1991, p. 61). Broadband means the capacity to carry at least one million bits of information per second.

The argument for explicitly modifying public policy to speed up deployment of broadband for travel substitution derives from a two-stage chain of logic: First, higher bandwidth telecommunications provides a step-up in communications capability. Second, a wide-spread improvement in communications capabilities throughout communities would accelerate trip substitution.

The first point is certainly true. Examples of telecommunications applications that work better as bandwidth increases are transmission of large document files, high-resolution images, and video segments; dial-in remote access to the internal computer network of a business; and videoconferencing.

On the second point, some particular uses of telecommunications that substitute for travel will undoubtedly be realized as higher bandwidth capabilities deploy more widely into residential neighborhoods. A CAD/CAM terminal operator would be able to link to the company mainframe from home 
while recovering from an accident. A doctor would be able to receive a digitized medical image at home and not have to drive in to the hospital on her longplanned day at home writing a research paper. Some supervisors would have a better feeling of control by seeing a video picture of the workers from a telecommuting location and thus might let telecommuting occur more often with more people.

But some caveats are in order. First and foremost, not all trip substitution requires new high-bandwidth infrastructure. Telecommuting is now growing by more than $10 \%$ annually using traditional infrastructure that works better because of new network attachments (like faster modems) and new telecommunications services (like ISDN) that squeeze out more bandwidth from the traditional copper wires that attach to all houses with telephone service. Many telecommunications applications that support telecommuting, such as voice mail, fax, and electronic mail, work well with today's services and customer premises equipment. These applications that are possible with today's low-bandwidth infrastructure provide for a growth in user experience and a thirst for efficiency in remote access that will increase user demand for the highbandwidth applications of the future.

For the moment, and perhaps for the foreseeable future, low bandwidth is preferable in many telecommuting and teleservice situations. A video teleconference requires that one make an extra effort to make oneself presentable; a phone call does not. A lack of access to a company's future video-capable email gateway may let a telecommuter gain a higher level of concentration on the immediate task at hand. As another example, successful persuasion activity often works better with incomplete and even distorted information to the prospective "buyer." More information provided by high bandwidth or other means is not obviously better. New and small firms operating in humble facilities succeed in the early stages only by distorting information to prospective customers about their level of resources.

The preference for low bandwidth noted here does not mean that on-call, readily available, optional access to broadband services would not be helpful to the support of trip substitution in the context of a particular organization and its employees and customers. The point, rather, is that lack of high bandwidth is not likely to be an obstacle to getting started on travel elimination. Further, the decision to upgrade to higher bandwidth applications can be analyzed as an incremental improvement over existing communications patterns.

In addition, the newer high-bandwidth applications such as two-way video communications do not automatically lead to trip substitution. For example, a detailed evaluation of a long-term continuous video connection (called a "media space") between two Xerox laboratories located in different cities concluded: "Mediated communication systems such as the media space are frequently compared to face-to-face interaction. It is important to reiterate that we did not try to replace face-to-face communication nor do we believe that mediated communication can replicate the face-to-face experience" (Bly, 1993).

A recent Delphi forecast panel of information technology experts estimated notably lower success probabilities for utilization levels of telecommunications applications that significantly substitute for travel than it estimated for the prospects for new hardware and software tools that would make such services technologically feasible (Halal, 1993). For example, the panel judged that broadband public networks would be deployed by the year 2007 with a probability of $84 \%$ and that much more powerful parallel processing computers 
would be available on networks by the year 2003 with a probability of $71 \%$. The same group judged that electronic meetings replacing the majority of business travel had a probability of $40 \%$ of occurring by the year 2006 and that telecommuting by half of all workers would manifest with a probability of $52 \%$ by the year 2009. In these and other forecasts by the panel, the striking point is the relative optimism of the technology development forecasts in contrast to the relative pessimism of the technology utilization forecasts.

Furthermore, as the use of teleprocesses expands, the value of using travel will tend to increase. The opportunity to focus human attention exclusively on face-to-face presence, sensate experience, and physical interaction at meetings, places, and events will be a "scarce good" and thus more valuable, as a principle of economic supply and demand. Lunch with the boss, a teacher, or a good customer will always be worth more than a videoconference with that person. This dynamic means that travel demand is not likely to abate.

Could widespread broadband deployment offer new, unforeseen services that in some manner provide people with a compelling reason to travel less frequently? The evidence to date on the compelling things that people do now, such as eating, sleeping, having various kinds of fun, and engaging in addictive behaviors, is that people invariably like to do them in a variety of different locations. Tens of thousands of drunk driving accidents every year illustrate that people like to enjoy social contact and mobility even when the circumstances increase the probability that injuries and death may occur.

Most importantly, having a better telecommunications infrastructure available sooner will not automatically alter the dynamics that make telecommunications a travel generator, as described earlier: new relationships and transactions over a wider area, economic growth, suburbanization, transportation improvement, and just-in-time logistics. Simply accelerating the deployment of broadband interactive telecommunications connections into more end-user locations is unlikely to transform the economy toward lower transportation intensity, given the trip-increasing dynamics of telecommunications discussed in the previous chapter. Travel-generation dynamics, such as wealth generation and transportation improvement, are just as likely to be stimulated by more widespread broadband telecommunications as are the more familiar trip-saving dynamics.

Without targeting of investments based upon a more thorough understanding of the relationship between telecommunications and transportation on the part of decision makers in both the telecommunications and transportation sectors, public policy that succeeds in accelerating the deployment of more capable telecommunications infrastructure (such as residential broadband) risks stimulating social and economic forces that increase transportation consumption. Market-driven geographic phasing of new deployment of residential broadband is likely to exacerbate present trends. Early deployment to higher income areas in the suburbs would probably make traffic congestion worse, given the income elasticity of transportation expenditures shown in Exhibit 2-13. The point here is that public policy has to focus on the issue of transportation substitution and do something explicitly different to transportation, such as raising the cost of travel, if changes from present trends are to have any chance at all of happening. 


\section{Cost of Transportation}

One important factor in the continuing strength of surface travel demand in the face of telecommunications alternatives is that the cost of driving that is paid directly by users is actually declining. This is partly because of the increasing energy efficiency of automobiles and partly because of a reduction in the real cost of fuel since 1980. From 1978 to 1991, transportation outlays decreased from $20.2 \%$ to $16.9 \%$ of the gross national product, as shown in Exhibit 3-1.

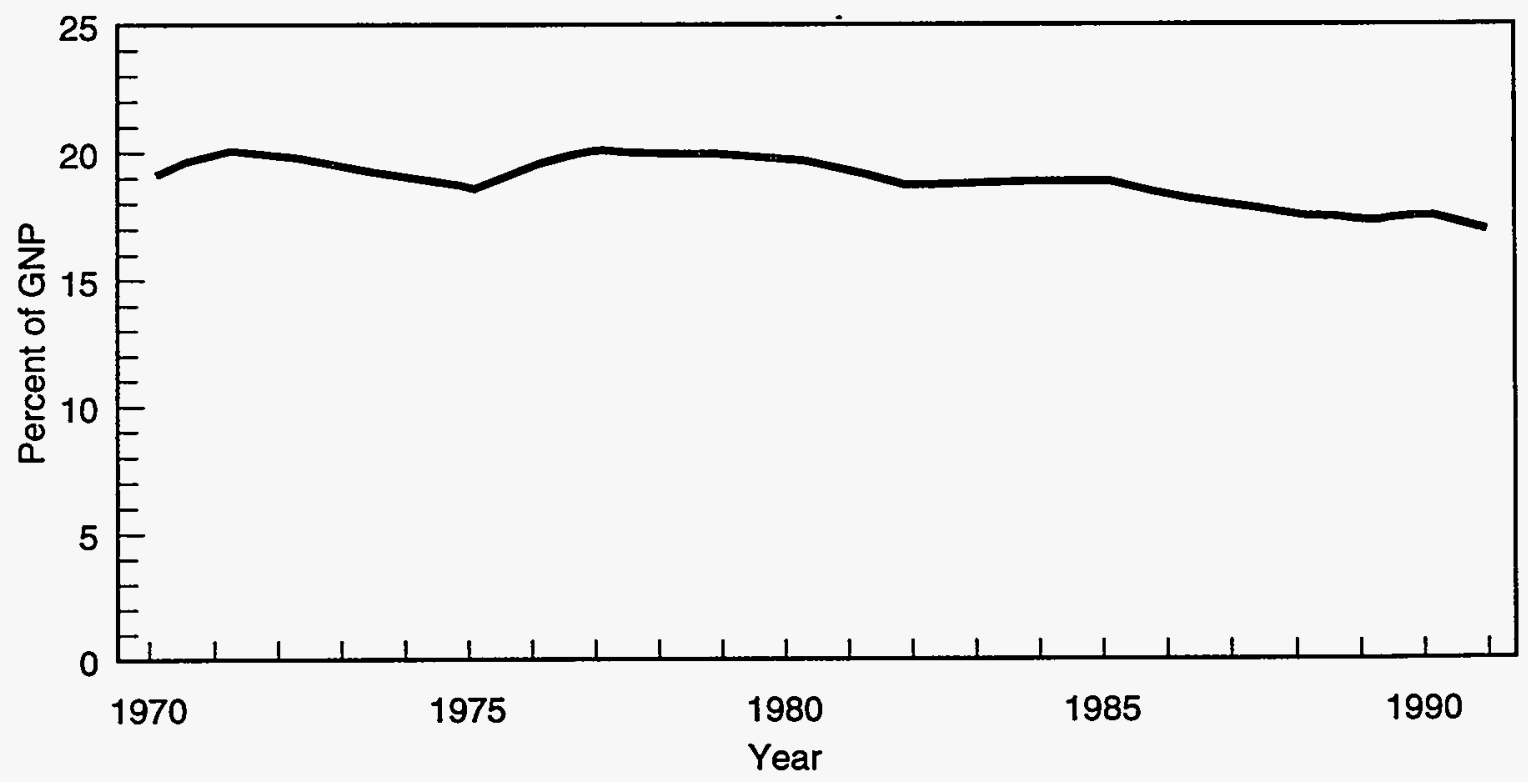

Ex 3-1: Transportation's share of the gross national product is falling. (Data source: Eno Foundation.)

The increasing energy efficiency of travel, with a consequential reduction in this portion of travel costs, is one reason why transportation continues to be attractive as an economic input. In comparing consumer expenditures for transportation and telecommunications in Exhibit 3-2, two observations stand out. First, transportation spending is much higher than telecommunications spending, which also includes home computer purchases. Second, the share of transportation spending is actually falling.

Transportation seems less expensive than it really is, because a substantial portion of the costs are indirect and not felt by vehicle drivers and owners. Costs of automotive transportation are not fully covered by the "user fees" of fuel taxes, vehicle taxes, and tolls and require "subsidies" from local property taxes, general funds, and other indirect revenue sources. These costs include expenditures for roadway construction and maintenance, highway services, and parking. In 1991, about $40 \%$ of the $\$ 78$ billion spent by federal, state and local government on highway capital and operating costs came from sources other than highway user fees (FHWA, 1991, p. 42).

Costs of parking are also mostly paid indirectly. An estimated $90 \%$ of all commuters park at no cost in employer-supplied parking. Much of the retail and other commercial business parking outside central business districts is also free. 


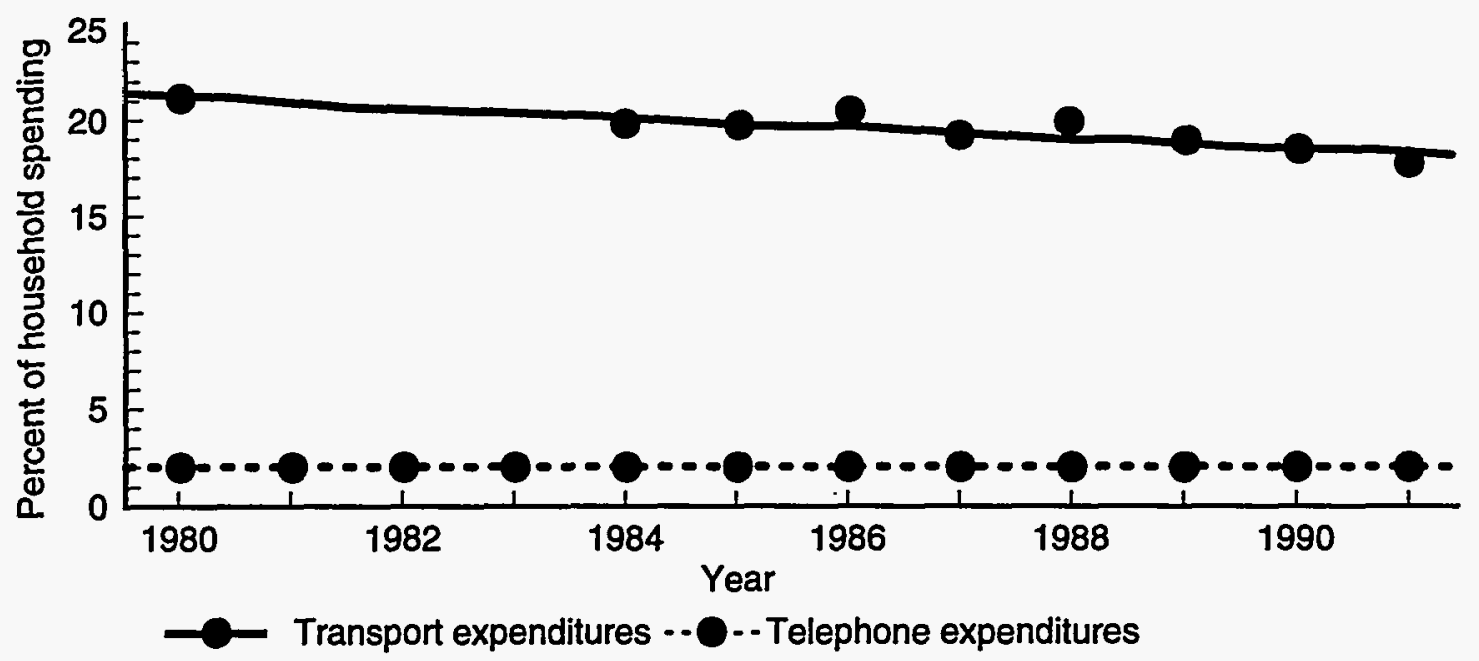

Ex 3-2: Consumer expenditures: transportation share falling; telephone share constant. (Data source: Bureau of Labor Statistics.)

Parking, of course, involves significant costs: land, development, maintenance, and administration. The average annual cost of an off-street parking space has been estimated as $\$ 1000$ (Shoup, 1990).

Riders of public transit also do not feel direct costs of transportation, since most transit systems, to meet operating costs, rely heavily on state and local tax sources or fund transfers to supplement fare box revenues. In 1991, state and local assistance accounted for more than $52 \%$ of transit operating costs (APTA, 1992).

This socializing of the cost of surface mobility means that transportation users experience a lower cost than would otherwise be borne. This then becomes one of the many economic forces that determine when and how much people drive and whether they make the effort to carry passengers. Even though telecommuting provides an alternative to commuting, the fact that driving is becoming less expensive in terms of direct out-of-pocket costs paid by drivers reduces the incentive for commuters to try telecommuting.

As long as transportation remains as inexpensive and functional as it is, the potential for telecommunications to displace surface transportation is limited. Coping with transportation disruptions caused by disasters and events is the exception to this conclusion. Unless public policies or other causes raise the perceived, directly-felt cost of travel, there is unlikely to be a slackening in the per-capita demand for travel, even as telecommunications applications diffuse more widely and more opportunities to avoid travel emerge. This conclusion comes straight from utility experience. When electricity is inexpensive, or does not increase in price at times when supplies are low, people use more of it. In many urban areas, in peak-demand periods, transportation is underpriced for users, and demand exceeds capacity. When prices are too low, demand for a desirable good rises to meet the supply. In the case of driving, congestion is the only cost to drivers that limits the "supply" and functionality of transportation.

Some drivers perceive rising traffic congestion as a growing cost of driving. There is much objective evidence that traffic congestion is becoming worse 
(Downs, 1992); however, the proportion of drivers who actually experience congestion on a regular basis has not been measured. Of drivers who do experience it, the evidence is lacking that a major proportion perceive congestion as a large enough cost to motivate behavior changes.

\section{How to Increase Telecommunications Substitution for Travel}

Public policy could be focused on preparing society for using telecommunications as an alternative to travel during inevitable future periods when transportation capability degrades because of disasters (such as the January, 1994 Los Angeles earthquake), demand surges (such as Atlanta will see in the 1996 Olympic Games), and underfunding of infrastructure maintenance.

As transportation or proximity itself becomes relatively more expensive or even impossible, telecommunications becomes more attractive as a substitute for transportation. Telecommunications works better than travel where costly, timeconsuming, arduous, or dangerous trips can be avoided and the function of the trip can still be mostly achieved.

Telecommunications offers opportunities for people to choose new methods of meeting transaction and relationship needs besides making a trip. Traveling 20 miles on Los Angeles freeways in the 3:00 to 6:00 p.m. period to attend a halfhour meeting may be less useful than attempting to achieve the same meeting purpose through teleconferencing. Meeting someone for lunch is best, but a phone call will do if the bridge is blocked. Ordering by phone is better if the store one usually goes to is out of product because the delivery truck is stuck in traffic. Experience in using a telecommunications alternative to travel can lead to repeat use and, eventually, new habits.

General, widespread substitution of telecommunications for travel is not a reasonable government policy objective. There are many good reasons to travel. Other policy objectives such as economic flexibility and competitiveness can often be in conflict with travel reduction. Furthermore, there are also powerful vested economic interests at work to preserve and enhance the value of travel. The automobile, public transit, airline, hotel, restaurant, tourism, retail shopping, professional sports, and real estate industries come to mind.

Government policy can, however, focus on telecommunications as a means for society to gain the flexibility to cope with and work around travel disruptions such as energy supply shocks and natural disasters. An example of the latter was the 1989 Loma Prieta earthquake in the San Francisco Bay area, when use of telecommunications for telecommuting and other purposes jumped up and stayed high until the bridges were repaired (Pratt, 1991). Although the track record of telecommunications companies in providing survivable, sufficient capacity following hurricanes, snowstorms, and earthquakes is apparently admirable, there is reason for governments to maintain oversight as the critical dependence of society on telecommunications continues to rise and the level of economic regulation goes down.

Another, related government policy focus can be on providing options to avoid what might be called bad travel-a trip in congested traffic, bad weather, an air pollution emergency, or other circumstances where a citizen simply prefers not to travel. This focus follows easily from a policy emphasis on mitigating disruptions. 
Once telecommunications-based alternatives to travel are in place for sudden disruptions and for indisputably bad travel, they are then also available for use as the price of transportation rises for any reason and as the capability of transportation to deliver mobility and closeness gradually degrades because of resource limitations. As people learn to make their telecommunications-based alternatives work, telecommunications becomes a force for letting the economy restructure away from making trips that people do not want or need to make or for which there are attractive alternatives.

Telecommunications can contribute to improving the transportation patterns of the United States if two necessary conditions are met: (1) more understanding about telecommunications-transportation interactions is developed and disseminated to professional and political leadership, and (2) that knowledge is joined with politically acceptable public transportation policymaking aimed at specific transportation outcomes. These two conditions for effectiveness would be met by incorporating telecommunications technology into an integrated resource planning (IRP) methodology that is focused on transportation improvement. Integrated resource planning is discussed below, following some background on transportation planning.

\section{Existing Transportation Planning Approaches}

The Intermodal Surface Transportation Efficiency Act (ISTEA) and the Clean Air Act Amendments of 1990 (CAAA) require a fundamentally new and comprehensive level of transportation planning at state and regional levels. Planning must link transportation to land use and must consider intermodality and management of congestion. States must develop and implement management systems for congestion, public transportation, and intermodal connections. Metropolitan area transportation plans must conform with state implementation plans for meeting federal air quality standards.

Conformity means that transportation plans and programs within a metropolitan area must provide for the expeditious implementation of transportation control measures specified in state plans. These control measures must be directed toward reducing emissions of air pollutants from transportation sources by improving traffic flow, reducing congestion, or reducing vehicle use. In areas where air quality is not a serious issue, planning usually responds instead to growing roadway congestion and proposals to increase transportation system capacity.

The requirements of ISTEA and CAAA and new flexible federal funding have stimulated states and metropolitan areas to identify new ways to control and manage the demand for transportation and reduce the need for ever more transportation capacity while, at the same time, achieving both the clean air and the mobility that Americans desire.

Telecommuting has begun to be identified in state and metropolitan area plans as one of a broad set of transportation control measures to be encouraged through government policy and private action. Previous telecommuting studies in Washington State and California suggest steps that states can take to expand the adoption of telecommuting in the public and private sectors. Other telecommunications applications are candidates for measures specified in air quality and transportation plans. These applications may include real-time transit information systems, computer ride-matching services, and other IVHS techniques. 
Several states and local governments have adopted commute trip reduction laws. Rather than imposing specific transportation demand management (TDM) measures on employers, these laws usually allow employers to plan their own program and select measures appropriate to their situation.

Although not explicitly stated in federal law or rule, the goal of ISTEA to utilize the existing transportation system more efficiently implies that planning should be concerned comprehensively about the costs and benefits of all transportation plans, programs, projects, and measures that reduce congestion and improve air quality

In a March, 1993 national forum in Washington, DC sponsored by the Energy Foundation and the International Institute for Energy Conservation, participants remarked that, although recent federal legislation (ISTEA, CAAA) has pushed for the integration of transportation options, analysis and policy have not responded. Though ISTEA provides new opportunities for planning, funded for the first time with federal money, it leaves much up to states and citizens. The forum concluded that a collaborative approach is needed to develop an integrated resource planning strategy for transportation.

\section{Integrated Resource Planning}

Officials now have an opportunity to design transportation planning and policies in response to the changing character of travel demand as shaped by teleprocesses. Integrated resource planning (IRP) techniques developed for energy planning offer a promising path for including a wide range of telecommunications issues in transportation planning.

Integrated resource planning is a policy planning and analysis technique to find the right balance between transportation supply and transportation demand management. It would consider a wide range of transportation supply and demand management measures, including telecommunications applications. It also can incorporate data and assumptions about the overall impact of telecommunications on travel demand.

Integrated resource planning refers to a process for developing a public resource acquisition strategy that evaluates a range of supply and demand side options, taking into account such factors as cost, performance, uncertainty, reliability, availability, and environmental externalities. It has been used extensively in electrical power planning, and it has been applied to water resource allocation. A variation is its use to plan strategies for solid waste management that involve complex choices between source reduction, reuse and recycling, and disposal options.

Integrated or least-cost planning has, over the last decade, become the standard methodology for electrical power planning in multi-state regions and in both public and private utility service areas. Public utility commissions have directed electric utilities to base their resource acquisition decisions on least-cost methodology. Municipal electric utilities have, through action of governing boards and local governments, created least-cost planning frameworks to meet new customer demand. In some cases, IRP has been extended to the question of appropriate fuel choice. Tradeoffs between electricity and natural gas as end-use energy sources have been analyzed by using least-cost models.

Transportation planners and policy makers have begun to explore the opportunities offered by IRP and least-cost planning. A number of states have 
already developed energy strategies that include transportation energy reduction programs or call for comprehensive transportation energy planning. Washington State's energy strategy suggests that least-cost planning methods, developed out of experience in the electrical energy sector, could be applied to transportation. Legislation in California requires a biennial forecast of transportation energy use based on "least environmental and economic cost."

Comparisons of the application of demand-side management in the utility sector to its potential in the transportation sector point up many similarities but also significant differences involving technology and regulatory and institutional issues (Steiner, 1992; Hillsman, 1993). Nevertheless, recent work by Nelson and Shakow (1994) suggests that IRP is the next logical step in the progressive improvement of transportation planning and resource allocation at the federal, state, and local levels. The IRP method could be the planning framework for metropolitan planning organizations (MPOs) and states as they implement the planning requirements and congestion management system requirements of ISTEA.

An IRP framework, as described by Nelson and Shakow, steps beyond transportation demand management (TDM), which is often approached as a supplement to supply-side investments. In these situations, transportation demand measures are often viewed as producing supplemental benefits beyond the congestion relief gained by expanded roadway or transit capacity. Demandside measures are not considered as alternatives that may, in fact, deliver more transportation benefit for less cost than additional capacity, such as new lanes of highway or a rail transit system. Integrated resource planning embraces a comprehensive set of measures, each assessed objectively for cost effectiveness and ordered by rank. These measures reach across institutional boundaries for funding and implementation.

New governmental arrangements will be necessary to coordinate elements that may range far beyond those found in traditional transportation plans: from local transit capacity improvements to state assistance for low-income housing near transit stations; from employer-provided transportation allowances to local and state tax subsidies to encourage ride sharing and transit use; from land use policies calculated to capture tax revenues for local governments to regional taxsharing mechanisms. Congestion itself can be evaluated as a demand management measure, having benefits as well as costs measured in time loss, environmental quality, and so on. Latent travel demand would be balanced against any action to increase system capacity.

Integrated resource planning would allow for the inclusion of two distinct influences of telecommunications capabilities on transportation. First, advanced telecommunications is an increasingly important, far-reaching influence upon the urban transportation dilemma; it shapes the direction and pace of modern economies, including land use patterns and mobility demands. Second, as described earlier, telecommunications is the underlying technology base for a number of new transportation system approaches, many coming under the label Intelligent Vehicle Highway Systems (IVHS). Direct applications of telecommunications and computers are likely to revolutionize transportation in the same way that these technologies have revolutionized manufacturing.

Plans developed with IRP would address freight movement as well as passenger travel and would weigh the economic costs and benefits of solutions that ignore one mode at the expense of the other. Plans would also take into 
account the impact that restructuring the economy to a just-in-time model has on traffic demand.

There are lessons to be learned from recent developments in manufacturing. Just-in-time manufacturers place a much higher value on transportation predictability than on the transportation and energy efficiency of the delivery mode. Even congestion delays, if they are predictable, can be tolerated. Unpredictable delays can have serious consequences, and manufacturers and their suppliers establish strategies to reduce the uncertainty of delivery and avoid production shut-downs.

An important implication of JIT for government transportation planners is the potential for increased traffic congestion. Depending on plant and supplier location, and on the frequency and timing of delivery, having a larger number of small, partly loaded delivery vehicles may contribute to congestion. A second implication is perhaps more serious. As information management continues to increase in effectiveness and decline in cost, the productivity improvement it has fostered will expand beyond manufacturing into the services sector. This development can be expected to have a similar and even greater impact on transportation demand.

Just as the new manufacturing model may exacerbate the urban transportation problem, it may also provide transportation planners with opportunities to manage transportation systems better. That is possible.because companies adopting JIT tend to reduce the number of their transportation vendors in order to develop relationships that produce more reliable yet flexible delivery and shipment schedules. These relationships can lead to practical models for transportation system utilization that are more information based. If transportation planners design a dynamic, comprehensive model of the transportation system, encompassing freight and passenger transport, they may find that manufacturers are willing to contribute important data that will help manage the transportation system. Manufacturers and their vendors may also be more responsive to incentives to use transportation capacity at times and in ways that contribute to its overall efficiency.

\section{Telecommunications Applications Beyond Telecommuting}

The agenda of public issues relative to the relationship between telecommunications and transportation extends beyond telecommuting and travel effects to other kinds of impacts. Current government, business, and citizen attention to the development of the National Information Infrastructure is very broad in scope, extending to issues of equity, health care, public education, and government effectiveness, all of which will be considered next.

In fact, the issues can become mixed together in developing workable solutions to real-world problems. An example of such a problem is the lack of jobs and other economic opportunities in inner-city neighborhoods. The problem is often posed as one of transportation for disadvantaged individuals between their homes in the city and the plethora of job opportunities in the suburbs. This issue is the subject of much research (Kasarda, 1993). In fact, pure transportation solutions have not worked very well (Lemov, 1993). An alternative opportunity is to try teleservice delivery of training and other employment support services into inner-city neighborhoods. Delivery points could be located near telecommuting centers offering jobs. 
Viewed from the perspective of services provided by telecommunications and transportation, disadvantaged people are those who are unable without social services to move from a pattern that includes both closeness to undesirable conditions and remoteness from desirable conditions. This situation could be improved through the socially planned and funded deployment of telecommunications and transportation. Telecommunications applications could be designed and implemented that are an effective, relatively low-cost channel for providing disadvantaged people with access in their homes and communities to education, training, health services, and social services; to jobs and other economic opportunities; and to information about services and opportunities.

\section{Health Care Sector}

The U.S. health care industry could achieve higher quality care, and better access in rural areas and to low-income populations, while reducing the country's total cost of health care as a percent of gross domestic product.

The future health system must depend to a great extent on the electronic delivery and management of health care services and medical practices, utilizing networked information infrastructure technology and applications. New telecommunications applications already beginning to be used will contribute significantly to efficiency and improved care when more widely deployed. Care will be more cost effective when based on electronic access to personal medical records, extensive and current best medical practice information, and consultations delivered by teleconference to the most appropriate location, which might be remote from the health care professional.

Care givers' access through telecommunications to timely and accurate information ensures that the combination of appropriate care and appropriate location is achieved. The model of information flows shown in Exhibit 3-3 illustrates how the health care system, like other service delivery systems, can work better when comprehensively reengineered around the National Information Infrastructure.

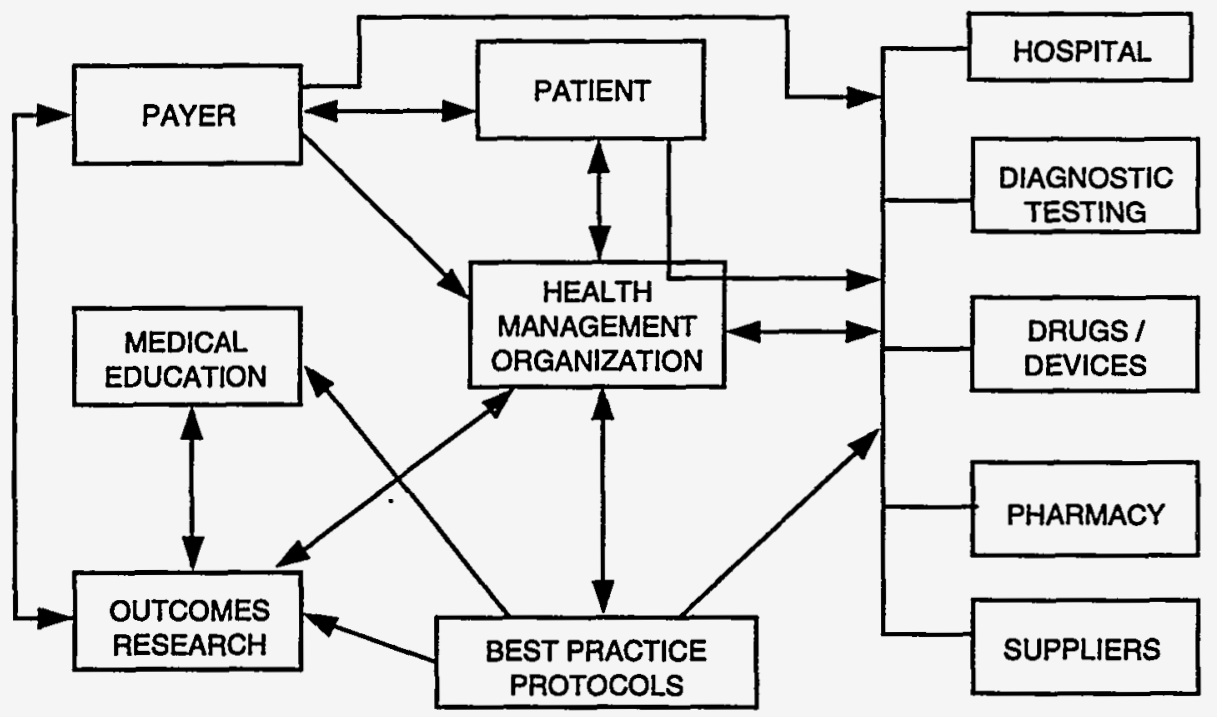

Ex 3-3: Macro-model of tele-health information flows. (\$1993 Research \& Planning, Inc.) 
The information system shown in Exhibit 3-3 can be designed to let the overall performance of the medical system be measured and reported to patients and care givers. Preventive care can be included as part of services where that improves performance. The system can be designed to let patients rely more on self-help information to diagnose and treat nonthreatening conditions. Standards of care can be managed to be more consistent from one community to the next, from urban area to rural area, and across the income spectrum.

A confidential electronic medical record-keeping system allows health care providers access to comprehensive family and patient health histories as part of the routine process of diagnosis and prescribing treatment. It will replace the cumbersome and far less complete manual record system, enable faster and more accurate diagnosis, and allow appropriate care at an appropriate location. More complete and timely information can help eliminate mistakes and the need for costly multiple medical tests that are ordered because knowledge of a patient's medical history is incomplete.

A physician, who faces the daunting task of staying current with medical knowledge that grows explosively, will use new on-line services that provide access to current medical literature about the problems diagnosed and best practice treatments.

A restructured health system could, over time, reduce health costs by as much as $25 \%$. At current expenditure levels, savings of $\$ 200$ billion per year would be realized. Major savings will result as information management practices merge with structural reforms to remove duplication and fragmentation in computer networks. Up to $40 \%$ of all hospital costs are related to the generation, storage, and transfer of information.

Significant indirect benefits will result from reform as well. Lower health costs will translate to lower labor costs and fewer jobs lost to countries with more efficient health systems. For the same reason, lower health costs will reduce the price of United States goods and services and improve their competitiveness in world markets. Expanded health care access will reduce the social cost of pain, illness, death, and loss in work productivity. Workers and their families will gain a measure of security as employers use fewer part-time and temporary employees to avoid expensive health benefits. Since health care is a major cost of government, more funds will be available for education and other services or for deficit reduction.

A new health delivery system will produce changes in travel patterns. Exhibit 3-4 illustrates how health care system functions might be divided geographically between rural and urban locations. It also shows how some kinds of critical information are available anywhere through remote electronic database access.

Telecommunications can also expand home health care service access through new attachments to home telephone service, providing consultation and monitoring services as needed, especially to the less mobile elderly population, while reducing the number of trips to health centers. In some cases, tele-health will increase travel as a result of the system transforming to provide higher quality, very specialized services around fewer, more competent centers. Examples are national and regional centers of excellence for advanced procedures, such as open-heart surgery. 
National Outcomes

Research Database

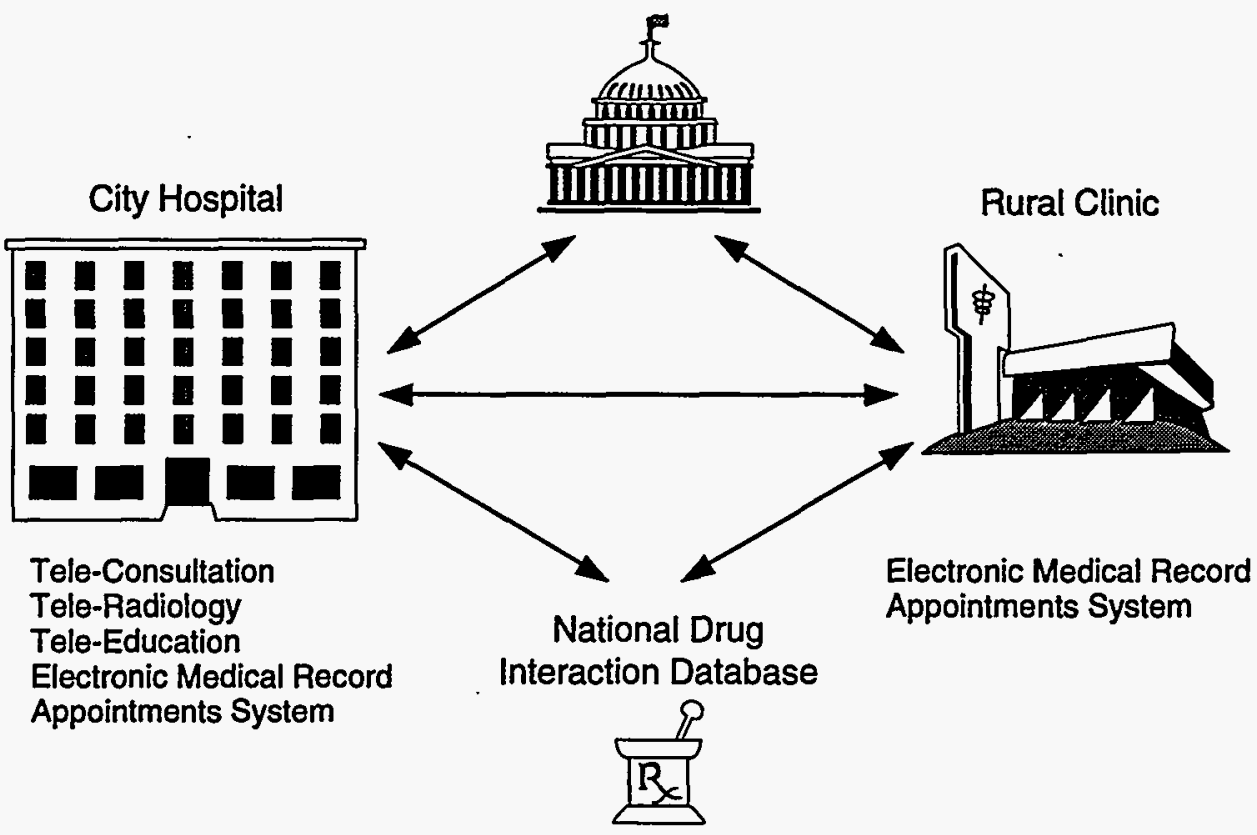

Ex 3-4: Rural tele-health application. (@1993 Research \& Planning, Inc.)

Travel patterns in health care reform are a minor consideration, however, compared to the potential in cost savings and improved care. As Exhibits 3-5 and 3-6 illustrate, medical trips per household appear to be rising again, but they are a small and shrinking component of household travel overall.

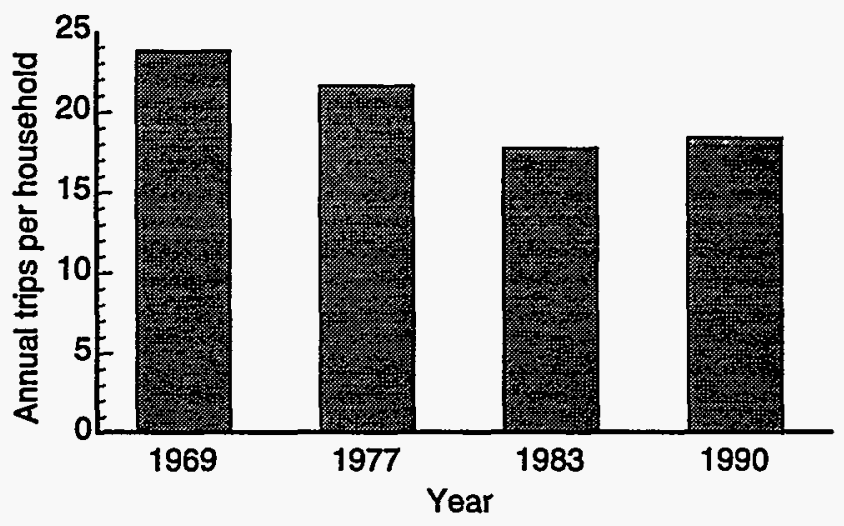

Ex 3-5: Annual medical trips per household are rising again. (Data source: Nationwide Personal Transportation Survey.) 


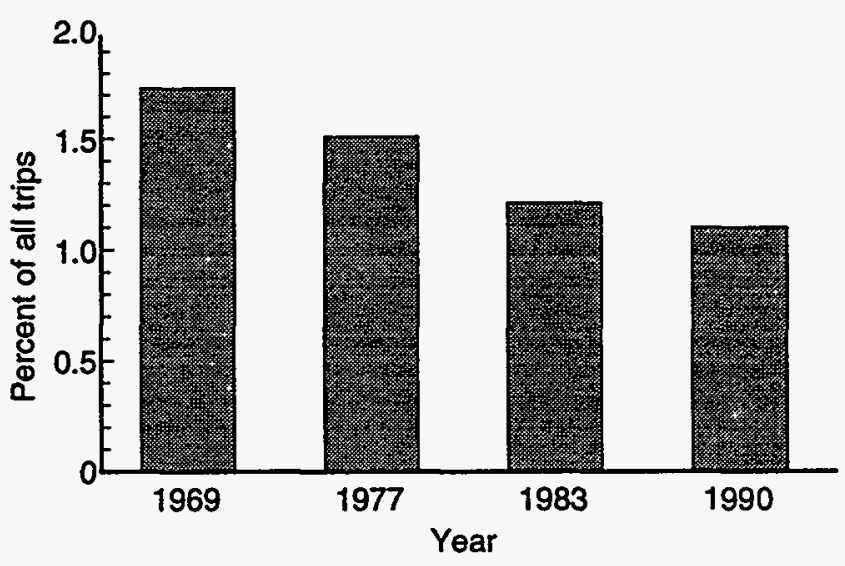

Ex 3-6: Medical trips: falling share of household vehicle trips. (Data source: Nationwide Personal Transportation Survey.)

\section{K-12 Education Sector}

Profound economic and social changes are causing a new reassessment of the form and substance of $\mathrm{K}-12$ education. The expanding National Information Infrastructure is playing a strong, supportive role in that effort. There is a growing recognition that the restructuring of our education system is fundamental to our economic prosperity and personal well being.

In a world where many nations find their competitive advantage in abundant inexpensive human labor, U.S. economic strength lies in the capacity to marshal human intellect more effectively. More citizens must be empowered with skills enabling them to compete with high-wage workers in other technically advanced nations and increasingly with low-wage but high-skill workers in advancing nations.

At the same time, education cannot avoid the social needs of its consumers, our children. Educational performance of schools correlates too closely with the numbers of children from single-parent households or eligible for free meals.

Distance learning, which provides an educational structure for students not in face-to-face contact with a teacher, is an example of the dramatic changes in learning activity resulting from telestructure and teleprocess. Compared to traditional correspondence learning, teleprocessed distance learning allows many different combinations of audio, video, and data exchange and interaction.

As telestructure declines in cost and becomes more ubiquitous, less and less distinction will be made between information technologies that have been separately associated with home, school, and office. This will produce two important consequences: learning will not be constrained to fixed time periods and locations, and transitions from home to school and from school to work environments will be easier.

Telephenomena benefit students and teachers in numerous ways:

- Students everywhere can have equal access to the full range of courses.

- Students and teachers can interact with experts in higher education, business, and the community on specific topics of interest.

- Teachers can have easier access to professional development resources. 
- Complete records of student academic achievements and needs can be easily accessible, even when students change schools.

Advanced telecommunications has a large potential benefit in educational administration as well as in instruction. The exchange of student records between districts and the reporting of student information to state and federal agencies is a large cost item. Several states have implemented, and many more are planning to implement, electronic statewide student record systems.

The current penetration of teleprocesses used to provide distance learning is shown in Exhibit 3-7. The matrix lists the predominant teleprocess formats and the key telestructure components used to support them. A high degree of choice exists in format and component selection.

Though teleprocess is a standard tool used by some educators, there is evidence that it is far from being an integral part of the learning experience.

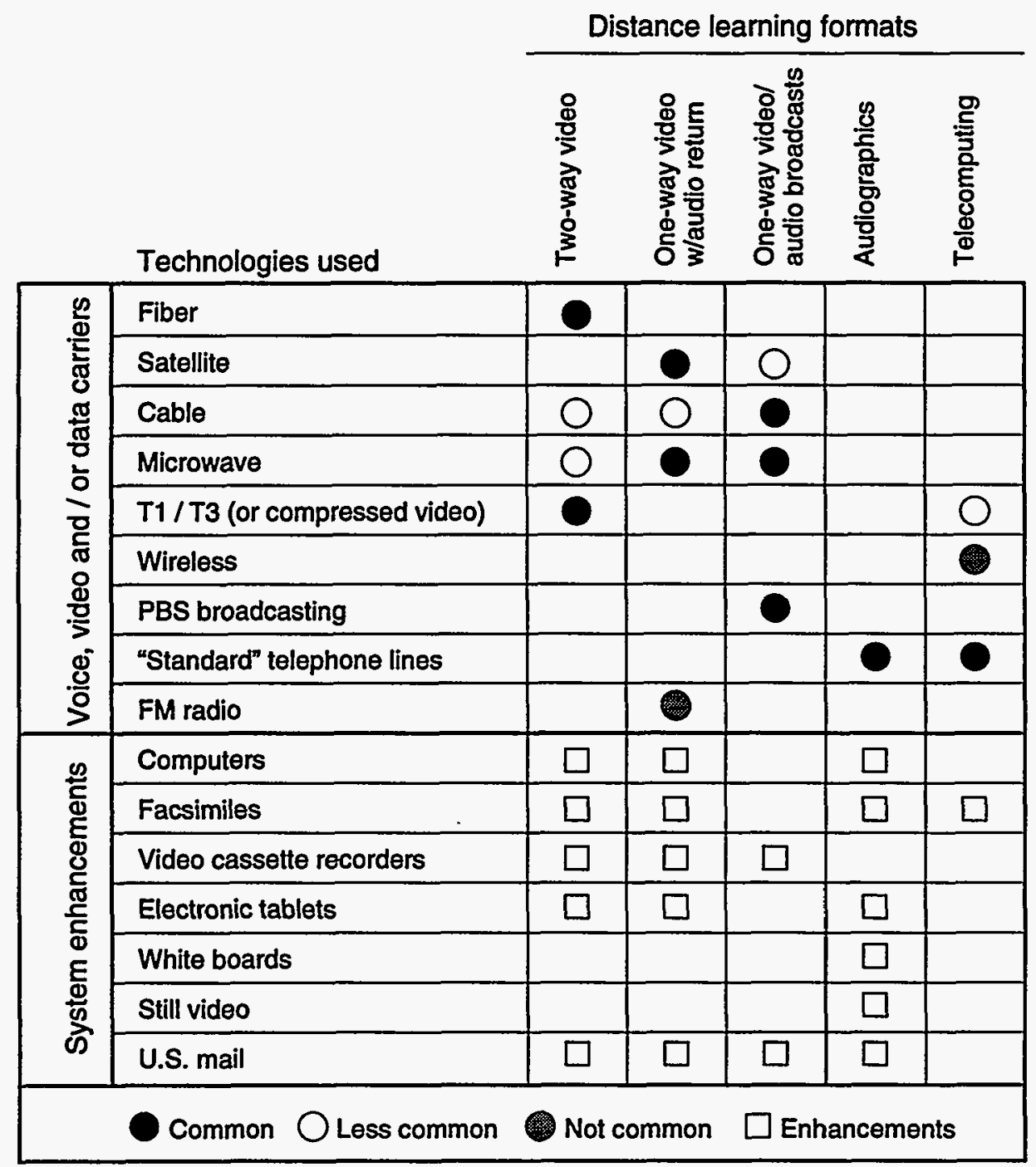

Ex 3-7: Formats and technologies for K-12 educational teleservices. (Source: Dunau Associates.) 
Surveys show that there are serious barriers to the use of teleprocess: lack of hardware, lack of access, insufficient administrative support, lack of time within the school schedule, and lack of professional development opportunities to enable teachers to fully utilize it.

State governments are rapidly increasing their involvement in distance learning systems. By 1991, 46 states had systems in place or were developing strategic plans; however, the rate at which distance learning is made available to administrators, teachers, and students is affected by fragmentation of authority across various state agencies.

The Internet now linking millions of computer users worldwide is the federal government's most significant support to date of telestructure and teleprocess for $\mathrm{K}-12$ and other public services. The National Research and Education Network (NREN), authorized in 1991, builds on the federally funded portion of the Internet. It provides users in government, industry, and education with access to the information resources of libraries, schools, and government research agencies.

The state regulatory environment strongly affects the development of telestructure relating to $\mathrm{K}-12$ education. State public service commissions are debating the fundamental choice between establishing distinct education tariffs at rates below those for business service, to support school use of the public switched network for learning, or else maintaining a strong least-cost service policy for the public as a whole.

The 1990s are likely to see large investments, both public and private, in telestructure and teleprocess that will benefit $\mathrm{K}-12$ education:

- A major federal inter-agency effort is under way, focusing on converting defense technologies to civilian uses. Focus areas include training and instruction, health care, and information infrastructure.

- Congress is considering funding support for multiple forms of instructional technology.

- Matching federal grants will be available to states, school districts, libraries, and other nonprofit entities in support of teleprocess activities.

- Several states are directly funding telestructure and teleprocess for schools and other public institutions.

- Local school districts are using tax levies and bond issues to buy computer and networking technology.

- A nonprofit consortium has proposed a satellite dedicated to educational use.

While these investments are fragmented and uncertain in their collective impact, they reflect educators' beliefs that telestructure and teleprocess will help meet instructional and administrative needs. Even in the face of serious budget problems, a majority of districts in one survey indicated that they plan to increase their teleprocess investments.

There is little focus upon travel savings in the planning for teleprocess that is going on. One interesting observation, noted in Exhibit 3-8, is that the transportation intensity of student services is going up, as shown by the growing per-capita school bus mileage figures. 


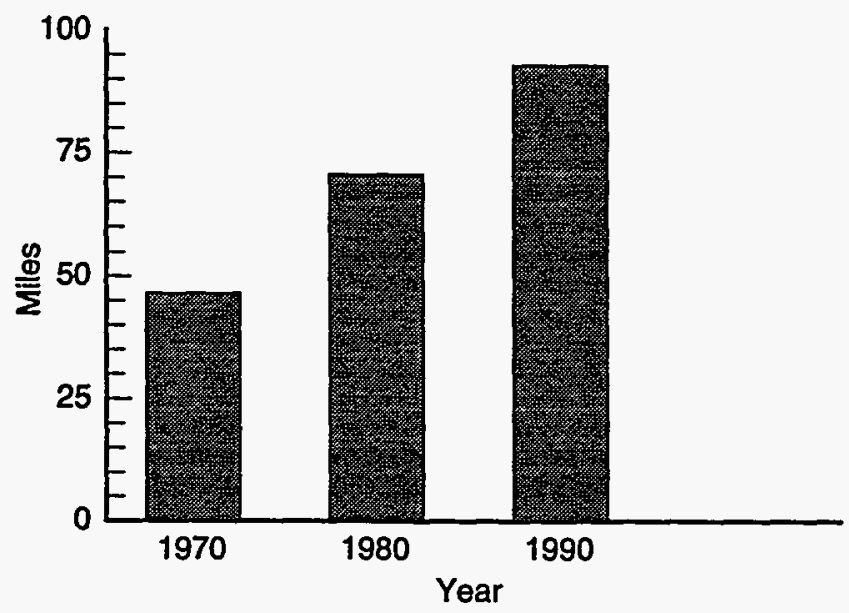

Ex 3-8: Annual school bus miles per K-12 student are rising. (Data sources: Oak Ridge National Laboratory and U.S. Department of Education.)

\section{Government Sector}

Government agencies at all levels are introducing new applications of the NII for a variety of functions, primarily to improve the quality of service to the public, but also to reduce the cost of providing service and to improve agency productivity. There is strong pressure for agencies to make all three of these types of improvements (Osborne and Gaebler, 1992).

Decisions to introduce new telecommunications in government agencies generally have not been prompted by desires to reduce transportation or to promote telecommuting. Unless an agency specifically intends for telecommunications to affect travel, for institutional reasons it is unlikely to examine the transportation impacts of a new technology, so most of the impacts of telecommunications on transportation must be inferred.

Notable examples of the use of telecommunications have been in the area of document handling, to make it easier for agencies to process the paperwork associated with issuing regulations, granting permits, recording transfers of property, improving the use of information to collect taxes or assessments, and processing claims for benefits. Many of these applications of telecommunications allow agencies to deliver services to clients in a matter of minutes rather than hours and by telephone rather than in person.

As in the case of large private organizations, use of telecommunications in this kind of government application allows work to be done with a smaller staff. Some agencies strive to reassign persons displaced by telecommunications, but others may reduce staffing; in the latter case, the reduction in employees could have as large an effect on travel as the travel savings by clients or from telecommuting by the remaining employees.

Another major application of telecommunications is in inspection, monitoring, enforcement, and other fieldwork activities that are essential parts of many agencies' operations. As examples, remote air-quality monitors and utility meters can be queried by phone, databases can be checked from the field, reports can be filed from the field, and surveillance can be maintained via remote video. 
Although some of these applications clearly have the potential to reduce travel by field staff, in most cases telecommunications is introduced to improve staff productivity, and reducing travel just happens to be one way of doing so. The nature of some jobs, such as building inspection and police patrolling, means that the technology will save little if any travel, the real benefits accruing via more rapid processing of forms or via the provision of timely information when a trip back to the agency office would introduce unacceptable delays in staff action. Some introductions of telecommunications, however, may make it possible for agency employees who do not work in the field to telecommute more often once information from field employees is reported, stored, and analyzed in electronic form.

A third area is in the analysis and planning of government operations. Several states have undertaken development of database and analysis systems that allow municipal or county agencies to obtain data rapidly or to perform analyses to improve efficiency. One state now requires local school districts to use a state-supported system to plan school bus routes, and these districts are achieving substantial reductions in bus fuel consumption. Local police agencies have been able to obtain information about crimes, licenses, and vehicle ownership from state databases for years, and efforts are underway to develop improved information systems to coordinate drug enforcement and other activities that involve more than one agency. Again, many of these applications seem unlikely to have much effect on transportation, either to increase it or to decrease it.

The final major area of activity is in information outreach by local governments to their citizens. In many cases, governments rely on information published in newspapers, on mailings, or on contacts initiated by citizens to pass information to citizens. A number of municipalities are experimenting with providing electronic bulletin boards, remote information terminals, or computer information kiosks that citizens can use to find out more about available services or activities, complete applications for licenses, or find out what regulations apply to a proposed activity. Most of these efforts seem unlikely to reduce travel because they often are adding a service that did not previously exist; in some cases, they may increase the amount of travel if citizens learn about a service and decide to use it.

Barriers remain to all of these applications. Many laws, for example, require the signing of documents, the retention of signed documents in vehicles or at construction sites, or the witnessing of document signing; although some agencies have chosen to interpret these requirements loosely, many small legal changes may be needed to allow effective use of telecommunications in some applications.

\section{Conclusion}

A deliberate policy of greater investment in telecommunications by all levels of government and in all sectors of the economy is worthwhile for environmental, social, and economic reasons. Most of these reasons have nothing to do directly with transportation but rather address other national concerns, such as lowering the costs and improving the quality of health care, education, government services, and manufactured goods. Focusing on these beneficial applications rather than on travel demand reduction is a more positive, less controversial focus for government telecommunications policy. 


\section{Chapter 4}

\section{RECOMMENDATIONS}

\section{Research on Telecommunications-Transportation Interactions}

The USDOE and USDOT should support research that quantifies, through statistical analysis of economic data, the impact of telecommunications spending on transportation consumption per unit of economic output. This research should be designed to verify whether the relationship is one of net substitution of telecommunications for transportation or net stimulation. Given the prevalent conventional wisdom that telecommunications is a substitute for travel, and given the Federal government's interest in promoting the National Information Infrastructure while reducing peak-period vehicle trips in many urban areas, this is a critically important determination to make.

The effects of increasing technological maturity and falling prices for greater capability should be incorporated into the research. Also, the relative energy intensity of the production and consumption of telecommunications services should be compared to the energy intensity of the production and consumption of transportation services. Input-output tables of the US economy permit measurement of the total consumption of both telecommunications and transportation.

The research could test whether reduction in energy consumption from the substitution of telecommunications for transportation is more evident in sectors facing a more competitive market structure than in sectors, like government and public education, that are less subject to such forces.

This research should use the same kind of national econometric models used in earlier research that determined that telecommunications spending causes economic growth and productivity improvement (Cronin, 1991). Use of such models provides a basis for estimating the effects of future policy choices, such as changes in the method of paying for transportation services and the effect of higher gasoline taxes. A later focus of this research should include international comparisons.

\section{Integrated Resource Planning Demonstrations}

The USDOE should take action to initiate demonstration projects by state government planning agencies and metropolitan planning organizations that provide a transfer of proven energy planning techniques to the transportation sector. The need is to translate energy planning techniques into an integrated resource planning methodology applicable to metropolitan area surface transportation. The telecommunications applications to be considered in the IRP process should include both the private-sector teleprocesses that influence transportation demand and the government applications of telecommunications that the new transportation IRP could influence directly. Under DOE leadership, 
the overall goal of the IRP demonstration projects could include increasing the energy efficiency of regional economies. The IRP projects should encompass a wide range of actions (including promotion of telecommuting) to manage transportation demand as well as actions to improve the performance of transportation systems. Telecommunications is pertinent to both of these kinds of action.

The USDOE-supported methodology should include consideration of the telecommunications potential for increasing as well as reducing trips and for influencing travelers to choose high-occupancy or single-occupancy vehicular transportation modes. Demand for the transport of goods and services as well as passengers should be analyzed. Passenger transportation should include trips other than commuting trips.

Planning and implementation of transportation are local and state government responsibilities, but the federal government has a role in developing tools, disseminating them, and encouraging their use. The USDOE demonstration projects should include a requirement for reporting results and lessons learned for the use of policy makers in Washington, DC, state capitols, city halls, and county administrations. The goal of this feedback should be to inform the budget authorization and appropriation processes about the fiscal, regulatory, and institutional barriers at the local and state levels that impede implementation of IRP.

\section{Federal Data Collection}

Federal data collection should encompass measurement of economic activity conducted in locations outside of traditional, fixed employment locations reached by the traditional home-to-work commute. These other locations include homes, vehicles, and variable customer locations. Many of the relevant issues are described by Pratt (1987).

Federal data collection also needs to focus on travel behavior outside of commuting, which accounts for a majority of trips, energy consumption, and emissions. Of special interest are the specific trip purposes and destinations included in "other family and personal business," the third largest and the fastest growing trip category identified in the Nationwide Personal Transportation Survey (NPTS).

Federal data collection should be directed toward measurement of NII usage volumes at a level of detail that would aid in understanding transportation impacts. For example, there could be better measurement of telecommunications data and video traffic across both public and private networks. Also, policy development would be aided by measurements of telecommunications usage that impacts transportation directly, such as the volume of cellular telephone calls from automobiles.

The Federal government should also take steps to measure access to and usage of telecommunications services by households, firms, and schools with the objective of collecting data that illuminate whether some groups have become excluded from basic opportunities provided by telecommunications access for earning a living, educational attainment, and civic participation. 


\section{Federal Support of Research and Development}

The Federal government should support policy-focused research on the social and economic consequences (including unintended ones), opportunities, and costs resulting from telecommunications-stimulated flexibility in the use of time and space. Particular transportation issues that are not well understood and that would yield to focused research include

- The determinants and dynamics of patterns of activity, land use, and travel in the new just-in-time economic paradigm.

- Costs and benefits of a range of public policies and private actions available for responding to routine peak-period traffic congestion that results from travel demand exceeding roadway capacity.

- The role of information in travel timing and mode choice.

- The cause and extent of latent travel demand for new trips that manifests when new road capacity is made available.

- A value assessment of personal vehicle travel based on trip purposes, to better inform the expenditure of public resources that make travel possible.

\section{Robustness of Telecommunications}

The Federal Communications Commission and state regulatory authorities should continue to emphasize robust telecommunications capabilities that can continue operations after major natural disasters, accidents, system malfunctions, and acts of sabotage in either telecommunications or transportation systems. Providing an alternative to disruptions in transportation is a compelling government motivation for pursuing the National Information Infrastructure as a transportation substitution.

\section{Telecommunications Access to Service}

Federal, state, and local government agencies should focus on investments in the design, development, and implementation of those teleprocesses that reengineer service delivery to meet all of the following criteria simultaneously: agency cost savings and avoidance, customer and taxpayer satisfaction, service delivery effectiveness and coverage, and reduced travel generation for both customers and employees.

Government teleprocess investments should be the focus of an accompanying research program that develops and disseminates new knowledge about critical success factors such as data security measures, preserving personal privacy, patterns of employee-employer interaction, sufficient bandwidth in the telecommunications infrastructure, and user interfaces for distributed environments.

An important source of funding for teleprocess initiatives would be redirection from budgets that cover the planning, design, development, and construction of government-owned and -supported public works infrastructure and buildings. These existing budgets are now a source of powerful momentum for older, travel-intensive modes of government operation. 
Federal health care program regulations that require office visits as a condition of payment for a physician's services should be reviewed in light of the new tele-health model that suggests that best practice is achieved when appropriate care is provided at the appropriate location. Best health care practice may now require routine use of telecommunications for remote diagnosis, consultation, or monitoring. Legal and administrative restrictions on these practices were put in place prior to the current opportunity for telecommunications-based restructuring of the health care delivery system. New protections can be designed that will provide for more flexibility in the use of telecommunications and at the same time assist the important objective of managing health care costs.

\section{K-12 Public Education}

The US Department of Labor and the US Department of Education should jointly work on public policy changes that would accelerate the financial investments needed in $\mathrm{K}-12$ public education to respond to the trends identified in this report. New investments, which in some cases may require budget redirections within the present funding base, would pay for the new technology, instructional materials, and teacher preparation that allow schools to motivate and enable children to learn skills that better prepare them for a lifetime in an economy that is continually restructuring itself around the National Information Infrastructure.

These skills are outlined in the final report of the U.S. Department of Labor Secretary's Commission on Achieving Necessary Skills (USDOL, 1992). Footnotes in this report suggest annual investments of $\$ 300$ per student for teacher training and development activities and $\$ 1000$ per student, spread over a number of years, for hardware technology. This translates to investments of $\$ 774$ million annually and a total of $\$ 43$ billion in 1993 dollars for the nation's public schools. Additional expenditures will be necessary to keep the technology current.

\section{Conclusion}

Overall, these recommendations call for government leaders to shift their focus on telecommunications and travel beyond telecommuting to the much larger set of teleprocesses that are engendered by the National Information Infrastructure. The NII is changing the patterns of movement and location for both organizations and individuals in many different ways. By responding to the full scope of these changes, public policy can guide the nation toward obtaining more benefits at lower cost from the parallel growth of transportation and telecommunications. 


\section{REFERENCES}

Alter, Allan E. 1993. EDI Release 2.0. CIO (June 15): 63-66.

American Public Transit Association (APTA). 1992. Transit fact book. Washington, DC.

Bar, Francois. 1990. Configuring the telecommunications infrastructure for the computer age: The economics of network control. The Berkeley Roundtable on the International Economy, Working Paper no. 43. Berkeley, CA: Univ. of California, Berkeley.

Bly, Sara A, Steve R. Harrison, and Susan Irwin. 1993. Media spaces: Bringing people together in a video, audio, and computing environment. Communications of the ACM 36 (January): 28-47.

Boghani, Ashok B., Eric W. Kimble, and Ethan E. Spencer. 1991. Can telecommunications help solve America's transportation problem? MA: Arthur D. Little, Inc.

Burgess, John. 1991. War boosts use of video business links. The Washington Post (January 24).

Burgess, John. 1990. When it has to get there overnight, The Washington Post (August 5): 1.

Burgess, Philip M. 1992. Knowledge workers move into America's hinterlands. The Oregonian (August 7): C9.

California State Department of Transportation (CalTrans). 1991. Transportation technology development for California: program and policy review.

Castro, Janice. 1993. Disposable workers. Time (March 29): 43-47.

Cronin, Francis J., Edwin B. Parker, Elisabeth K. Colleran, and Mark A. Gold. 1991. Telecommunications infrastructure and economic growth. Telecommunications Policy (December): 529-35.

Cronin, Francis J., Elisabeth K. Colleran, Paul L. Hebert, and Steven Lewitzky. 1993. The contribution of telecommunications infrastructure investment to aggregate and sectoral productivity. DRI/McGraw-Hill. Draft working paper.

Cronin, Francis J. 1993a. Personal communication.

Davenport, Thomas H. 1993. Process innovation: reengineering work through information technology. Harvard Business School Press.

Davis, Stacy C., and Melissa D. Morris. 1992. Transportation energy data book. 12th ed. Oak Ridge National Laboratory.

Downs, Anthony. 1992. Stuck in traffic. The Brookings Institution.

Egido, Carmen. 1988. Videoconferencing as a technology to support group work: A review of its failure. Communications of the ACM (September): 13-24.

Erdal, Olai Bendik, and Hanne Stine Hallingby. 1992. Business as usual during the Gulf War-The Norwegian case. Draft paper presented at the Annual Meeting of the Transportation Research Board, January. Paper CS031. 
Federal Highway Administration (FHWA). 1992 (December). Edge city and ISTEA. Policy Discussion Series, no. 7.

Federal Highway Administration (FHWA). 1991. Highway statistics. U.S. Department of Transportation. FHWA-PL-82-025.

Fishman, Robert. 1990. America's new city: Megalopolis unbound. The Wilson Quarterly 14 (no. 1).

Fulton, Lew. 1993. Personal communication.

Garreau, Joel. 1991. Edge city: Life on the new frontier. Doubleday.

Gore, Al. 1992. Earth in the balance. Houghton Mifflin.

Gottmann, Jean. 1983. Urban settlements and telecommunications. Ekistics 302, V. 50, (September/October): 411-16.

Grover, Ronald, Laura Zinn, and Irene Recio. 1993. Big Brother is grocery shopping with you. Business Week (March 29): 60.

Hadden, Susan G., and Barbara O'Connor. 1993. Connecting each to all: A telecommunications platform for the information age. Washington, DC: Alliance for Public Technology.

Halal, William E. 1993. The information technology revolution: Computer hardware, software, and services into the 21st century. Technological Forecasting and Social Change 44: 69-86.

Heifetz, Laurel. 1992. Final focus group report: Puget Sound telecommuting demonstration, WSEO \# 92-147. Olympia, WA: Washington State Energy Office.

Hepworth, Mark, and Ken Ducatel. 1992. Transport in the information age: Wheels and wires. London: Belhaven Press.

Hillsman, Edward L. 1993. Transportation DSM: Building on electric utility experience. Unpublished paper.

Hollan, Jim, and Scott Stronetta. 1992. Beyond being there. Human Factors in Computing Systems, CHI '92 Conference Proceedings, pp. 119-25.

Howland, Marie. 1993. Technological change and the spatial restructuring of data entry and processing services. Technological Forecasting and Social Change 43 (no. 2): 185-96.

Hu, Patricia S. 1993. Changes in Americans' journeys-to-work. Presented at the Annual Meeting of the Association of American Geographers, 8 April, Atlanta.

Information Infrastructure Task Force. 1993. The National Information Infrastructure: Agenda for action, Washington, DC: U.S. Department of Commerce.

Kasarda, John D., and Kwok-fai Ting. 1993 (January). The impact of skill mismatches, spatial mismatches, and welfare disincentives on city joblessness and poverty. Lincoln Institute of Land Policy. Working paper.

Keen, Peter G. W. 1988. Competing in time. Ballinger Publishing.

Kitamura, Ryuichi, Konstadinos Goulias, and Ram M. Pendyala. 1990. Telecommuting and travel demand: An impact assessment for State of California Telecommute Pilot Project participants. Research Report UCD-TRG-RR-90-8. Prepared for the State of California Department of Transportation by the Transportation Research Group, Univ. of California, Davis. 
Kunkle, Rick. 1992. Puget Sound telecommuting demonstration: Case studies. WSEO\# 92-146. Olympia, WA: Washington State Energy Office.

Lemov, Penelope. 1993. Where the jobs are. Governing 6 (no. 9): 32-35.

Loken, Stewart C., ed. 1993. Information technology resources assessment. LBL-33700. Prepared for the U.S. Department of Energy Information Resources Management Long-Range Plan, Lawrence Berkeley Laboratory, University of California.

Miller, Tom. 1993. Minor revisions noted in LINK resources study. Telecommuting Review (July): 10.

Mokhtarian, Patricia. 1991. The transportation impacts of telecommuting in two San Diego pilot programs. Report \# UCD-ITS-RR-91-12. Davis, CA: Institute of Transportation Studies, University of California, Davis.

Mokhtarian, Patricia L. 1990. A typology of relationships between telecommunications and transportation. Transportation Research A 24A(no. 3): $231-42$.

Nakamura, Kiyoh, Yuri Masuda, Keijiro Araki, Zengo Furukawa, and Yukio Kiyokane. 1994. Role of multimedia communication in the teleworking and telelearning field. Proceedings of the Pacific Telecommunications Council, Sixteenth Annual Conference, pp. 686-90.

Nelson, Dick, and Don Shakow. 1994. Applying least cost planning to Puget Sound regional transportation. Seattle: Institute for Transportation and the Environment.

Niles, John S., and Paul A. Toliver. 1992. IVHS technology for improving ridesharing. Proceedings of the Second Annual Conference of the Intelligent Vehicle Highway Society of America.

Nyberg, David. 1993. Truth telling and deceiving in ordinary life. The Aspen Institute Quarterly 5 (no. 3): 91-114.

Osborne, David, and Ted Gaebler. 1992. Reinventing government. New York: Penguin Books.

Pisarski, Alan. 1992 (July). Nationwide personal transportation survey: Travel behavior issues in the 90s. Federal Highway Administration.

Pratt, Joanne H. 1993. An interview with Joanne H. Pratt. Family Business Review 6 (no. 4).

Pratt, Joanne H. 1991. Travel behavior impact of telecommuting following the San Francisco earthquake: A case study. Transportation Research Record no. 1305. Transportation Research Board.

Pratt, Joanne H. 1987. Methodological problems in surveying the home-based workforce. Technological Forecasting and Social Change 31: 49-60.

Quaid, Maureen, and Brian Lagerberg. 1992. Puget Sound telecommuting demonstration: Executive summary. WSEO \# 92-138. Olympia, WA: Washington State Energy Office.

Reich, Robert. 1991. The work of nations. Alfred A. Knopf.

Risse, E.M., and Linda T. Risse. 1993. The impact of telecommunications technology including telework and telecommuting on travel demand and travel demand management in the next decade. Unpublished paper prepared 
for a Transportation Research Board Conference, Travel Demand Research and Innovation: Setting a Strategic Agenda for the Future, 15-16 November.

Roach, Stephen S. 1993 (April 16). Making technology work. New York: Morgan Stanley and Co.

Salomon, Ilan. 1990. Telematics and personal travel behaviour with special emphases on telecommuting and teleshopping. In Telematics, transportation, and spatial development, ed. H. M. Soekkha et al. Utrecht, the Netherlands: VSP.

Salomon, Ilan. 1987. Geographical variations in telecommunications systems: The implications for location of activities. Transportation 14: 311-27.

Salomon, Ilan. 1986. Telecommunications and travel relationships: A review. Transportation Research A A (no. 3): 223-38.

Salomon, Ilan. 1985. Telecommunications and travel: Substitution or modified mobility? Journal of Transport Economics and Policy (September): 219-35.

Schor, Juliet B. 1992. The overworked American: The unexpected decline of leisure. Basic Books.

Selvanathan, E.A., and S. Selvanathan. 1994. The demand for transport and communication in the United Kingdom and Australia. Transportation Research $B 28$ (no. 1): 1-9.

Shoup, and Wilson. 1990. Employer-paid parking: The influence of parking prices on travel demand. Proceedings of the Commuter Parking Symposium, sponsored by the Association for Commuter Transportation and the Municipality of Metropolitan Seattle, 6-7 December, Seattle, Washington.

Steiner, Ruth L. 1992. Least-cost planning for transportation? What we can learn about transportation demand management from utility demand-side management. Presented at TRB Annual Meeting, January.

Toffler, Alvin. 1990. Powershift. Bantam Books.

U.S. Department of Energy (USDOE). 1993 (December). Energy, emissions, and social consequences of telecommuting.

U.S. Department of Labor (USDOL). 1992 (April). Learning a living: A blueprint for high performance.

U.S. Department of Transportation (USDOT). 1993. Transportation implications of telecommuting.

U.S. Department of Transportation (USDOT). 1993a. State of the nation's highways, bridges, and transit; Condition and performance. Report of the Secretary to Congress, Washington, DC.

Washington State Department of Information Services. 1993 (October). Savings realized through use of video telecommunications. Washington Interactive Television information sheet.

Williams, Ellen. 1993. Telecommunications as transportation: Pouring the electronic highway. Conference Report. 